In cooperation with the Central Platte Natural Resources District

\title{
Time-Domain Electromagnetic Soundings Collected in Dawson County, Nebraska, 2007-09
}

Data Series 581 
Blank Page 


\section{Time-Domain Electromagnetic Soundings Collected in Dawson County, Nebraska, 2007-09}

By Jason D. Payne and Andrew P. Teeple

In cooperation with the Central Platte Natural Resources District

Data Series 581 


\title{
U.S. Department of the Interior \\ KEN SALAZAR, Secretary \\ U.S. Geological Survey \\ Marcia K. McNutt, Director
}

\section{U.S. Geological Survey, Reston, Virginia: 2011}

\author{
This and other USGS information products are available at http://store.usgs.gov/ \\ U.S. Geological Survey \\ Box 25286, Denver Federal Center \\ Denver, CO 80225 \\ To learn about the USGS and its information products visit http://www.usgs.gov/ \\ 1-888-ASK-USGS
}

\author{
Any use of trade, product, or firm names is for descriptive purposes only and does not imply endorsement by the \\ U.S. Government. \\ Although this report is in the public domain, permission must be secured from the individual copyright owners to \\ reproduce any copyrighted materials contained within this report. \\ Suggested citation: \\ Payne, Jason D., and Teeple, Andrew P., 2011, Time-domain electromagnetic soundings collected in Dawson County, \\ Nebraska, 2007-09: U.S. Geological Survey Data Series 581, 46 p.
}




\section{Contents}

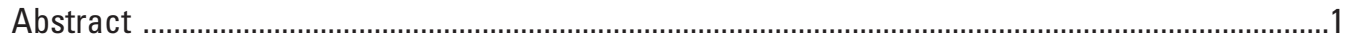

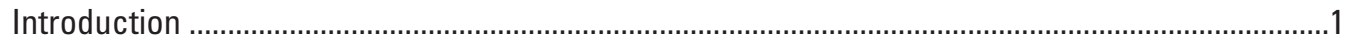

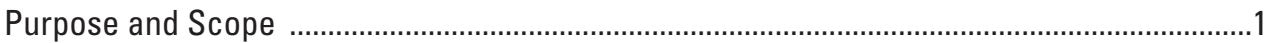

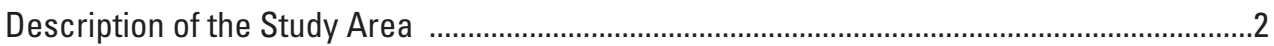

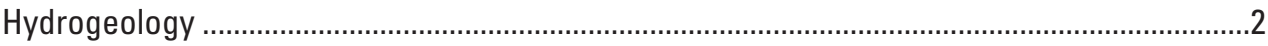

Methods (Time-Domain Electromagnetic Sounding) ...............................................................2

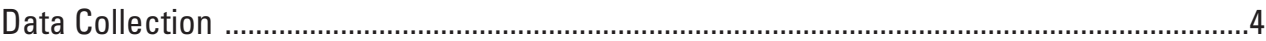

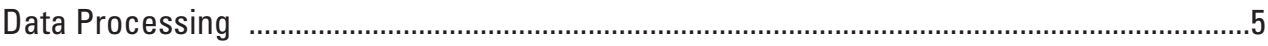

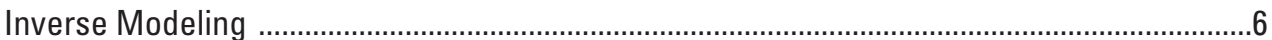

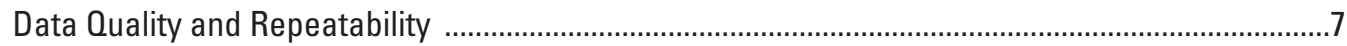

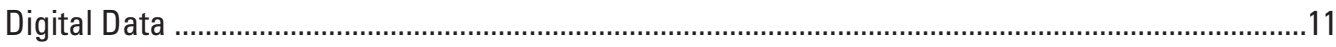

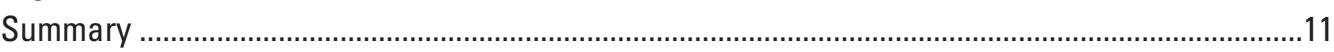

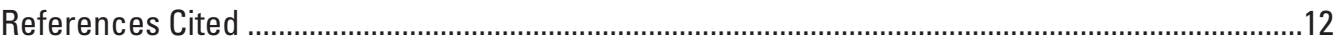

Appendixes

1. Datasets of raw and processed time-domain electromagnetic data .............................15

2. Graphs showing time-domain electromagnetic resistivity from field measurements as a function of time and inverse modeling results .....................................................16

\section{Figures}

1. Map showing time-domain electromagnetic sounding sites in Dawson County, Nebraska, 2007-09

2. Diagram showing $A$, the central loop configuration, and $B$, the coincident loop configuration system used to collect time-domain electromagnetic soundings in Dawson County, Nebraska, 2007-09

3-4. Photographs showing:

3. A, receiver coil (loop) for Geonics Protem-47, and B, receiver coil for Geonics Protem-57

4. Alpha Geoscience TerraTEM time-domain electromagnetic system, which includes transmitter and receiver, current-limiting controller box, and battery pack

5-6. Comparison of time-domain electromagnetic (TDEM) data to borehole resistivity logs measured by Anderson and others, 2009, in a test hole at

5. Site 72A. A, 64-inch normal resistivity borehole geophysical log overlain by simplified layered-earth model with depth constraints obtained from TDEM inversions. $B$, Cumulative conductance plots for the original resistivity log and the simplified layered-earth model. $C$, Direct comparison of TDEM smooth and layered inverse modeling results (models of true resistivity as a function of depth) to borehole geophysical and lithologic logs collected by Anderson and others, 2009

6. Site 71. A,64-inch normal resistivity borehole geophysical log overlain by simplified layered-earth model with depth constraints obtained from TDEM inversions. $B$, Cumulative conductance plots for both the original resistivity log and the simplified layered-earth model. $C$, Direct comparison of TDEM smooth and layered inverse modeling results (models of true resistivity as a function of depth) to borehole geophysical and lithologic logs collected by Anderson and others, 2009 


\section{Tables}

1. Location of time-domain electromagnetic soundings, Dawson County, Nebraska, 2007-09

2. Root mean square (RMS) error between measured and calculated apparent resistivity for soundings, Dawson County, Nebraska

\section{Conversion Factors, Datums, and Water-Quality Units}

\section{SI to Inch/Pound}

\begin{tabular}{lcc}
\hline Multiply & By & To obtain \\
\hline Length & foot $(\mathrm{ft})$ \\
\hline & 3.281 & \\
\hline square meter $\left(\mathrm{m}^{2}\right)$ & Area & square foot $\left(\mathrm{ft}^{2}\right)$ \\
\hline
\end{tabular}

\section{Datums}

Temperature in degrees Celsius $\left({ }^{\circ} \mathrm{C}\right)$ may be converted to degrees Fahrenheit $\left({ }^{\circ} \mathrm{F}\right)$ as follows:

$$
{ }^{\circ} \mathrm{F}=\left(1.8 \times{ }^{\circ} \mathrm{C}\right)+32
$$

Temperature in degrees Fahrenheit $\left({ }^{\circ} \mathrm{F}\right)$ may be converted to degrees Celsius $\left({ }^{\circ} \mathrm{C}\right)$ as follows:

$$
{ }^{\circ} \mathrm{C}=\left({ }^{\circ} \mathrm{F}-32\right) / 1.8
$$

Vertical coordinate information is referenced to the North American Vertical Datum of 1988 (NAVD 88).

Horizontal coordinate information is referenced to the North American Datum of 1983 (NAD 83).

Altitude, as used in this report, refers to distance above the vertical datum.

*Transmissivity: The standard unit for transmissivity is cubic foot per day per square foot times foot of aquifer thickness [(ft $\left.\left.\mathrm{ft}^{3} / \mathrm{d}\right) / \mathrm{ft}^{2}\right] \mathrm{ft}$. In this report, the mathematically reduced form, foot squared per day $\left(\mathrm{ft}^{2} / \mathrm{d}\right)$, is used for convenience.

Specific conductance is given in microsiemens per centimeter at 25 degrees Celsius $(\mu \mathrm{S} / \mathrm{cm}$ at $\left.25^{\circ} \mathrm{C}\right)$.

Concentrations of chemical constituents in water are given either in milligrams per liter (mg/L) or micrograms per liter $(\mu \mathrm{g} / \mathrm{L})$.

NOTE TO USGS USERS: Use of hectare (ha) as an alternative name for square hectometer $\left(\mathrm{hm}^{2}\right)$ is restricted to the measurement of small land or water areas. Use of liter (L) as a special name for cubic decimeter $\left(\mathrm{dm}^{3}\right)$ is restricted to the measurement of liquids and gases. No prefix other than milli should be used with liter. Metric ton (t) as a name for megagram (Mg) should be restricted to commercial usage, and no prefixes should be used with it. 


\title{
Time-Domain Electromagnetic Soundings Collected in Dawson County, Nebraska, 2007-09
}

\author{
By Jason D. Payne and Andrew P. Teeple
}

\begin{abstract}
Between April 2007 and November 2009, the U.S. Geological Survey, in cooperation with the Central Platte Natural Resources District, collected time-domain electromagnetic (TDEM) soundings at 14 locations in Dawson County, Nebraska. The TDEM soundings provide information pertaining to the hydrogeology at each of 23 sites at the 14 locations; 30 TDEM surface geophysical soundings were collected at the 14 locations to develop smooth and layeredearth resistivity models of the subsurface at each site. The soundings yield estimates of subsurface electrical resistivity; variations in subsurface electrical resistivity can be correlated with hydrogeologic and stratigraphic units. Results from each sounding were used to calculate resistivity to depths of approximately 90-130 meters (depending on loop size) below the land surface. Geonics Protem 47 and 57 systems, as well as the Alpha Geoscience TerraTEM, were used to collect the TDEM soundings (voltage data from which resistivity is calculated). For each sounding, voltage data were averaged and evaluated statistically before inversion (inverse modeling). Inverse modeling is the process of creating an estimate of the true distribution of subsurface resistivity from the measured apparent resistivity obtained from TDEM soundings. Smooth and layered-earth models were generated for each sounding. A smooth model is a vertical delineation of calculated apparent resistivity that represents a non-unique estimate of the true resistivity. Ridge regression (Interpex Limited, 1996) was used by the inversion software in a series of iterations to create a smooth model consisting of 24-30 layers for each sounding site. Layered-earth models were then generated based on results of smooth modeling. The layered-earth models are simplified (generally 1 to 6 layers) to represent geologic units with depth. Throughout the area, the layered-earth models range from 2 to 4 layers, depending on observed inflections in the raw data and smooth model inversions. The TDEM data collected were considered good results on the basis of root mean square errors calculated after inversion modeling, comparisons with borehole geophysical logging, and repeatability.
\end{abstract}

\section{Introduction}

Time-domain electromagnetic (TDEM) sounding can be used to identify variations in the electrical resistivity of the subsurface, which can be linked to changes (depth wise) in the physical and chemical properties of soil, rock, and pore fluids. The resistivity of soils and rocks are controlled by mineralogy, clay content, water content, salinity, and porosity. Changes in the resistivity of soils and rocks, either vertically or horizontally, produce variations in the electromagnetic signature measured by geophysical tools. These changes can be related to variations in the chemical and physical properties of the subsurface geology, to the level that differences in lithology or rock type can be identified (U.S. Army Corps of Engineers, 1995). However, to efficiently distinguish the differences in lithology, the geologic characteristic to be defined must have properties considerably different from background conditions (American Society for Testing and Materials, 1999). Typically, clay and shale are less resistive than sand and gravel, which in some cases provide contrasts that can be noticeable with TDEM methods (U.S. Army Corps of Engineers, 1995). TDEM sounding (Fitterman and Labson, 2005) is one of a number of surface-geophysical methods used to characterize subsurface geologic and hydrogeologic properties.

The U.S. Geological Survey (USGS) began a multiyear geophysical study in cooperation with the Central Platte Natural Resources District in 2007. As part of this study, the USGS collected TDEM soundings at selected sites in Dawson County, Nebr., between April 2007 and November 2009. TDEM sounding can be used to detect variations in electrical resistivity of the subsurface that can be related to changes in the physical and chemical properties of soil, rock, and pore fluids. The TDEM soundings documented in this report are part of a larger study to characterize the hydrostratigraphy of the area.

\section{Purpose and Scope}

This report describes the techniques and findings of TDEM profiling between April 2007 and November 2009 in 
Dawson County, Nebr. The report documents the acquisition and processing of TDEM soundings made at land surface at 23 different sites representing 14 locations. The report briefly describes TDEM theory and its application to characterize properties of the subsurface. The resulting models of subsurface resistivity are discussed in terms of data quality and repeatability. The data at three of the sites, including gamma and 16- and 64-inch normal-resistivity borehole geophysical logs, are plotted with geophysical data previously collected at each respective site and published in another USGS report (Anderson and others, 2009). The methods of data acquisition and processing, inverse modeling, and data quality and reliability are explained. The data for each site are described as one-dimensional (1D) inverse modeling results to visualize the electrical stratigraphy of the area.

\section{Description of the Study Area}

The study area is part of the broad floodplain of the Platte River in Dawson County, Nebr. All the sites where TDEM soundings were made (with the exception of the Shelton site) are north of the Platte River in Dawson County, between the cities of Gothenburg, Nebr., to the west and Overton, Nebr., to the east (fig. 1). The majority of the land use is agricultural but also includes rangeland, urban, light industrial, and infrastructure. Meteorological records from Gothenburg, Nebr., for 1961 through 1990 indicate the mean annual temperature is 50.95 degrees Fahrenheit $\left({ }^{\circ} \mathrm{F}\right)$, with a mean maximum of $89.6{ }^{\circ} \mathrm{F}$ in July, a mean minimum of $14^{\circ} \mathrm{F}$ in January, and mean annual precipitation of 22.2 inches (The Weather Network, 2010).

\section{Hydrogeology}

The study area overlies the High Plains aquifer, which consists of hydraulically connected deposits of Tertiary and Quaternary age. The Tertiary deposits include the upper part of the White River Group and the Ogallala Formation, whereas the Quaternary deposits include alluvium and eolian sands (Pettijohn and Chen, 1983; Gutentag and others, 1984). The upper White River Group forms the basal unit of the High Plains aquifer and consists primarily of siltstone with some sandstone beds. Zones of higher permeability in the upper White River are typically associated with densely spaced fractures and bedding-plane partings (Barrash and Morin, 1987). The High Plains aquifer is underlain by confining units composed of the Cretaceous-age Pierre Shale and Tertiaryage claystone and siltstone of the lower part of the White River Group. The Ogallala Formation, which overlies the White River Group, forms the principal unit in the High Plains aquifer and is made up of unconsolidated gravel, sand, silt, and clay with some zones of caliche. Laterally extensive alluvial deposits of gravel, sand, and silt blanket the Ogallala. Locally the alluvium is overlain by eolian deposits of dune sand and loess. The most permeable zones in the Ogallala and alluvium are associated with the coarse-grained sands and gravels (Schultz and Stout, 1955).

\section{Methods (Time-Domain Electromagnetic Sounding)}

Preliminary sites were selected for the collection of TDEM soundings that were conducive to additional studies of the subsurface. TDEM sounding locations were chosen from the list of preliminary sites on the basis of site access and the amount of electromagnetic interference. Soundings made at sites in or near cities have a higher likelihood of electromagnetic interference, but because of difficulties with obtaining access to enough sites in the rural areas of Dawson County, soundings were also collected at the airports near Cozad, Nebr., and Lexington, Nebr., as well as in open space in the city of Lexington. Thirty TDEM surface geophysical soundings were collected at each of 23 sites representing 14 different locations (fig. 1; table 1) to develop smooth and layeredearth resistivity models for each location. Sites at the same location are given the same site number followed by a letter (for example, sites 58A and 58B are at the same location). Data from each sounding at each site was used to calculate apparent resistivity to depths of approximately 90-130 m (by using 40-m or 80-m loops, respectively) below the land surface.

Time-domain electromagnetic measurements were made by transmitting an alternating current into square loops of insulated wire deployed on the land surface. Each sounding also has a receiver coil or loop that is discussed later. The transmitter loop current consists of equal periods of time-on and time-off base frequencies (that ranged in this application from 285 to 3 hertz [Hz]), which produce an electromagnetic field near the loop of wire. Termination of the current flow is not instantaneous but occurs over a few microseconds, known as the ramp time, during which the magnetic field is time-variant. The time-variant nature of the induced electromagnetic field creates a secondary electromagnetic field in the ground underneath the loop in accordance with Faraday's Law (Halliday and Resnick, 1974). This resultant field instantly begins to decay, generating additional eddy currents that spread downward and outward into the subsurface like a succession of smoke rings (North Carolina Division of Water Resources, 2006) (figs. 2a and 2b). These eddy currents then produce a magnetic field of their own that is recorded as voltage measurements throughout the time-off period by a receiver positioned in the center of (fig. 2a) or coincident with (fig. 2b) the transmitter loop. Depth of exploration depends on the time interval after shutoff of the current, because at later times, the receiver is measuring eddy currents from increasingly greater depths. The voltage magnitude received from the eddy currents at specific times and depths is determined by the overall conductivity of subsurface rock units and fluids (Stewart and Gay, 1986). From these voltage measurements, apparent resistivity values can be calculated. 


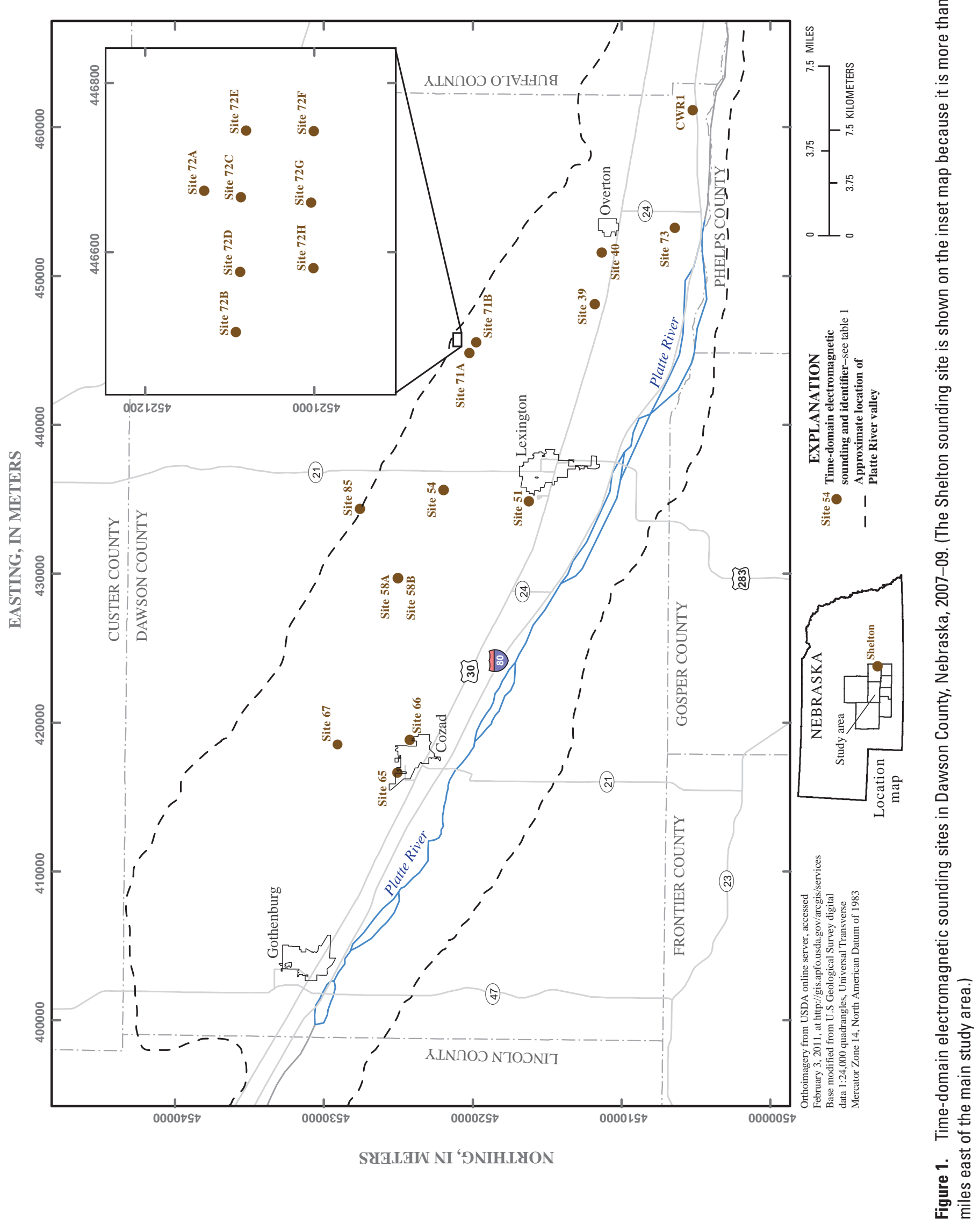



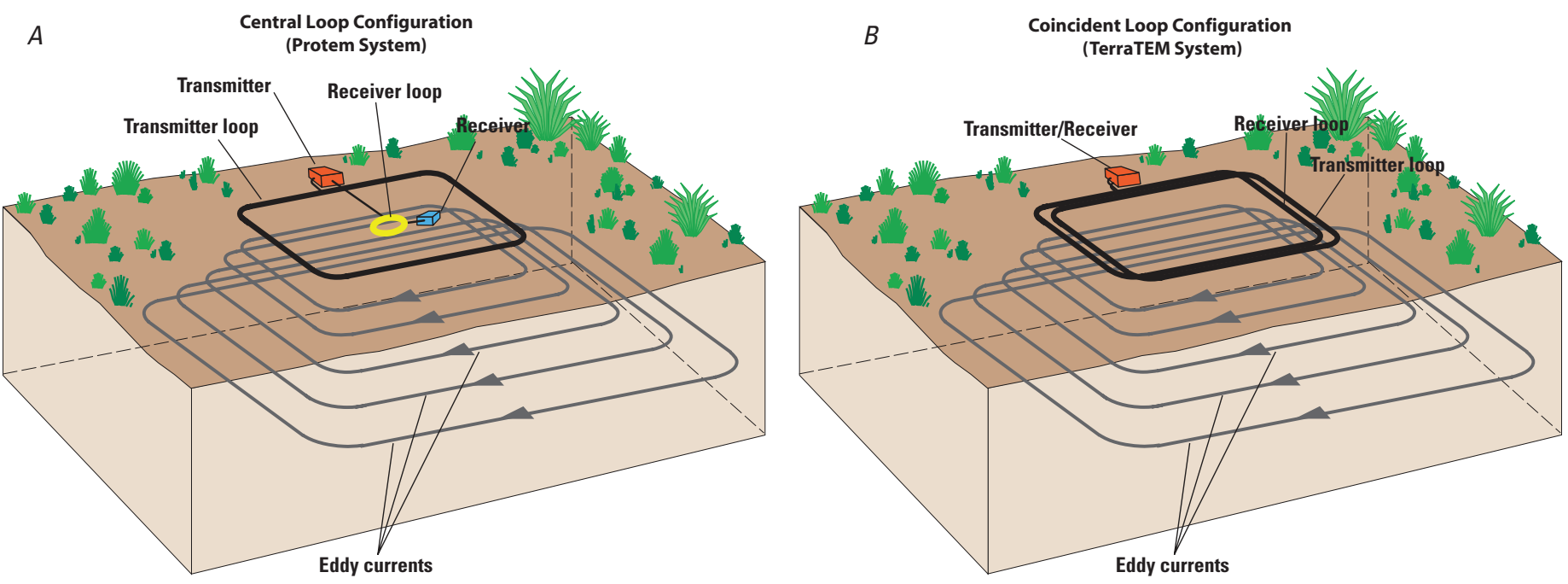

Figure 2. Diagram showing $A$, the central loop configuration, and $B$, the coincident loop configuration system used to collect timedomain electromagnetic soundings in Dawson County, Nebraska, 2007-09.

\section{Data Collection}

Different types of insulated wire loops (antennas) were used to transmit and receive the data. Transmitter (Tx) loop, or antenna, selection is important because of relatively large depths to the basement (lower confining unit) of the High Plains aquifer in the study area. After the currents are applied at the land surface by using square-shaped Tx loops of two sizes, ( 40 by $40 \mathrm{~m}$, and 80 by $80 \mathrm{~m}$ ), voltages are measured from which apparent resistivity values are calculated. The apparent resistivity values were examined for data quality at depth. A larger Tx loop size increases the depth of exploration but at the same time increases resistance of the loop wire, which therefore decreases the current. For example, while using the Protem 57 system, an 80-m Tx loop transmits a current between 15 and 18 amperes (A) because of the added resistance of the wire, whereas a 40-m Tx loop transmits a current between 18 and $22 \mathrm{~A}$ (these values were documented while collecting the field data). Reducing the current in the loop decreases the electromagnetic field strength, and this can lead to a decrease in data reliability from relatively deep zones. Using the 80-m Tx loop (with the reduced current) will in most cases produce a larger magnetic field than the 40-m loop because the magnetic moment (strength of the magnetic field generated) is strongly dependent on the area of the loop (Halliday, 1974). For most of the selected sites, the 40-m Tx loop was sufficient, but some sites were reanalyzed by using the 80-m Tx loop if the Pierre Shale or part of the White River Group was not observed while using the 40-m loop.

The Geonics Protem 47 (fig. 3a) and 57 (fig. 3b) systems, hereinafter referred to as Protem 47 and 57, respectively, were used in 2007 to collect TDEM soundings at each site (Geonics Limited, 2006a, 2006b). The Protem 47 and 57 use a multiturn receiver $(\mathrm{Rx})$ coil to measure electromagnetic fields in the center of the transmitter loop (fig. 2). The Protem $47 \mathrm{Rx}$ coil has an effective area of 31.4 square meters $\left(\mathrm{m}^{2}\right)$ (Geonics Limited, 2006a), whereas the Protem 57 Rx coil has an effective area of $100 \mathrm{~m}^{2}$ (Geonics Limited, 2006b). The effective area of the receiver relates to how sensitive the Rx coil is; the $100-\mathrm{m}^{2} \mathrm{Rx}$ coil is able to measure smaller voltages than that of the $31.4-\mathrm{m}^{2}$ coil. The Protem 47 transmitter produced a current of 2.75-3.0 A, and the Protem 57 transmitter produced currents of 15-22 A, depending on the size of the Tx loop used. The Protem 47 and 57 each have preset frequencies or repetition rates (frequencies at which the system transmits and receives voltages). The Protem 47 uses repetition rates of 285 $\mathrm{Hz}$ (ultra-high), $75 \mathrm{~Hz}$ (very high), and $30 \mathrm{~Hz}$ (high) (Geonics Limited, 2006a). The Protem 57 uses lower repetition rates of $30 \mathrm{~Hz}$ (high), $7.5 \mathrm{~Hz}$ (medium), and $3 \mathrm{~Hz}$ (low) (Geonics Limited, 2006b). The 30-Hz (high) frequency is collected by using each system to check the reliability of the data. At each sounding an integration time of 15 seconds (s) was used to measure 20 different data sets (the compilation of these data sets is referred to as a stack). The integration time is the length of time the system transmits and receives continuously (every few milliseconds) to determine one voltage value. The mean value of all the soundings collected over the integration time is stored. The values stored in the stack are averaged to ensure data quality and repeatability, and averaging is done prior to the inversion step, which is explained in the inverse modeling section of this report. The $15 \mathrm{~s}$ integration time was selected after comparison with data collected while using $10 \mathrm{~s}$ integration times. The longer integration time increased late-time data quality (late time is the length of time after the electrical current is shut off). Longer integration time increases data quality at depth, but the increase in data quality resulting from a longer integration time is less than the increase in data quality resulting from a larger magnetic moment, which results from 
Table 1. Location of time-domain electromagnetic soundings, Dawson County, Nebraska, 2007-09.

[RTK, Real-time kinematic; NAD 83, North American Datum 1983; UTM, Universal Transverse Mercator; NAVD 88, North American Vertical Datum 1988]

\begin{tabular}{|c|c|c|c|c|c|}
\hline \multirow[b]{2}{*}{$\begin{array}{c}\text { Site } \\
\text { identifier }\end{array}$} & \multirow[b]{2}{*}{$\begin{array}{c}\text { Loop } \\
\text { size } \\
\text { (meters) }\end{array}$} & \multirow{2}{*}{$\begin{array}{l}\text { Data } \\
\text { col- } \\
\text { lection } \\
\text { year(s) }\end{array}$} & \multicolumn{3}{|c|}{$\begin{array}{l}\text { RTK-derived coordinates in meters } \\
\text { (rounded to nearest } 0.1 \text { meter) }\end{array}$} \\
\hline & & & $\begin{array}{c}\text { Easting } \\
\text { (NAD } 83 \\
\text { UTM zone } \\
14 \text { north) }\end{array}$ & $\begin{array}{l}\text { Northing } \\
\text { (NAD } 83 \\
\text { UTM zone } \\
14 \text { north) }\end{array}$ & $\begin{array}{c}\text { Elevation } \\
\text { (NAVD } \\
88)\end{array}$ \\
\hline CWR11 & 40 & 2009 & $462,873.0$ & $4,504,101.0$ & 673.9 \\
\hline Shelton & 40 & 2009 & $519,858.0$ & $4,511,460.5$ & 597.0 \\
\hline Site 39 & 40 & 2007 & $449,096.7$ & $4,511,049.0$ & 713.9 \\
\hline Site 40 & 40 & 2007 & $452,764.3$ & $4,510,569.0$ & 708.1 \\
\hline Site 51 & 40,80 & 2007 & $435,128.5$ & $4,515,692.0$ & 732.4 \\
\hline Site 54 & 40,80 & 2007 & $435,840.8$ & $4,521,818.5$ & 739.7 \\
\hline Site $58 \mathrm{~A}$ & 40 & $\begin{array}{l}2007 \\
2008\end{array}$ & $429,577.1$ & $4,525,248.0$ & 732.4 \\
\hline Site 58B & 80 & 2007 & $429,577.1$ & $4,525,248.0$ & 730.4 \\
\hline Site 65 & 40 & 2007 & $415,742.2$ & $4,525,124.5$ & 761.3 \\
\hline Site 66 & 40 & 2007 & $418,072.3$ & $4,524,247.0$ & 759.9 \\
\hline Site 67 & 40,80 & 2007 & $417,786.8$ & $4,529,259.5$ & 772.1 \\
\hline Site $71 \mathrm{~A}$ & 40 & 2008 & $445,609.2$ & $4,519,984.5$ & 710.3 \\
\hline & 40 & $\begin{array}{l}2007, \\
2008\end{array}$ & & & 9.9 \\
\hline & 40 & $\begin{array}{l}2007, \\
2008\end{array}$ & & & \\
\hline Site $72 B$ & 40 & 2008 & $446,504.6$ & $4,521,092.0$ & 737.1 \\
\hline Site $72 C$ & 40 & 2008 & $446,664.2$ & $4,521,086.0$ & 736.8 \\
\hline Site 72D & 40 & 2008 & $446,575.6$ & $4,521,087.0$ & 737.2 \\
\hline Site $72 \mathrm{E}$ & 40 & 2008 & $446,742.7$ & $4,521,080.0$ & 736.5 \\
\hline Site $72 \mathrm{~F}$ & 40 & 2008 & $446,741.9$ & $4,521,000.0$ & 735.3 \\
\hline Site $72 G$ & 40 & 2008 & $446,658.0$ & $4,521,003.0$ & 735.5 \\
\hline Site $72 \mathrm{H}$ & 40 & 2008 & $446,580.5$ & $4,521,000.5$ & 736.1 \\
\hline Site 73 & 40 & 2007 & $454,515.1$ & $4,505,358.0$ & 704.0 \\
\hline Site 85 & 40,80 & 2007 & $434,508.3$ & $4,527,773.5$ & 758.9 \\
\hline
\end{tabular}

${ }^{1}$ Cottonwood Ranch Site Number 1.

the larger loop size (Payne, 2007). For each Protem sounding, a Trimble 5800 dual frequency kinematic global positioning system (GPS) (Trimble, 2007) unit was set up to obtain the precise location and elevation at the center of the loop.

Soundings that were judged by the authors to have the lowest environmental noise (background electromagnetic interference) were collected again by using the Alpha Geoscience TerraTEM system (Alpha Geoscience, 2010) (fig. 4) in 2007-09 for quality control and to verify measurement repeatability. The TerraTEM uses a single-turn coincident Rx coil to measure the electromagnetic fields (fig. 2b).
The effective area of the coincident receiver depends on the size of the antenna (loop); the 80-m loop has an effective area of $6,400-\mathrm{m}^{2}$, and the 40-m loop has an effective area of $1,600 \mathrm{~m}^{2}$. The TerraTEM transmitter produced currents of 8-10 A depending on the size of the transmitter loop. The preset repetition rate for the TerraTEM system is $10 \mathrm{~Hz}$. Instead of a preset integration time, the TerraTEM system collects hundreds or thousands of soundings (stacks) that are later averaged to increase the data quality and repeatability. In this study the soundings were collected with 1,000 to 2,000 stacks per record, depending on the environmental noise in the area, and 10-20 records were collected for each sounding. The Trimble 5800 GPS system used for the Protem soundings was also used for the TerraTEM soundings.

After initial testing was done at each of the 23 sites, three sites were chosen (sites 58, 71, and 72) for additional data collection, including borehole geophysical data collection. Selected borehole geophysical data and gamma logs (Anderson and others, 2009), collected from test holes collocated with the TDEM sites, are included with TDEM soundings in figures 5 and 6 for comparison purposes. The geophysical log data are used to help assess the quality of the TDEM soundings, and the gamma logs were used by Anderson and others, 2009, to help identify formations in the stratigraphic column. TDEM soundings were collected multiple times at sites 58A, 58B, 71, and $72 \mathrm{~A}-\mathrm{H}$. At sites $72 \mathrm{~A}-\mathrm{H}, 8$ TDEM soundings were collected in 2008 in a grid pattern to examine heterogeneity in the area. At site 58A, multiple soundings were collected.

\section{Data Processing}

For each sounding collected with the Protem system, the voltages measured from the eddy currents were averaged and evaluated statistically by using preprocessing scripts (Joe Vrabel, U.S. Geological Survey, written commun., 2010). These scripts use the raw field data (voltage data) and calculate the uncertainty of each time gate (discrete voltages measured at increasingly later times after shutoff of the current) independently. After calculating the standard deviation of the voltage, the user can specify limits to trim the data set (that is, remove extreme outliers prior to inverse modeling). For this study, the Protem data were initially filtered by using a trimmed mean and removing the upper and lower 5 percent of the data. This is done to remove potentially erroneous data points that would affect the average of the 20 duty cycles. Outliers were evaluated by the program and any data that was more than 10 percent above or below other data points were removed. The averages of each time gate are then saved as a processed data file (appendix 1) that can be used in the inversion software (Interpex, 1996). The inversion of data is described in the inverse modeling section.

The TerraTEM data was processed by using similar scripts (Joe Vrabel, U.S. Geological Survey, written commun., 2010) developed by the USGS. These scripts use the raw field data (voltage data) and calculate the uncertainty of each time 

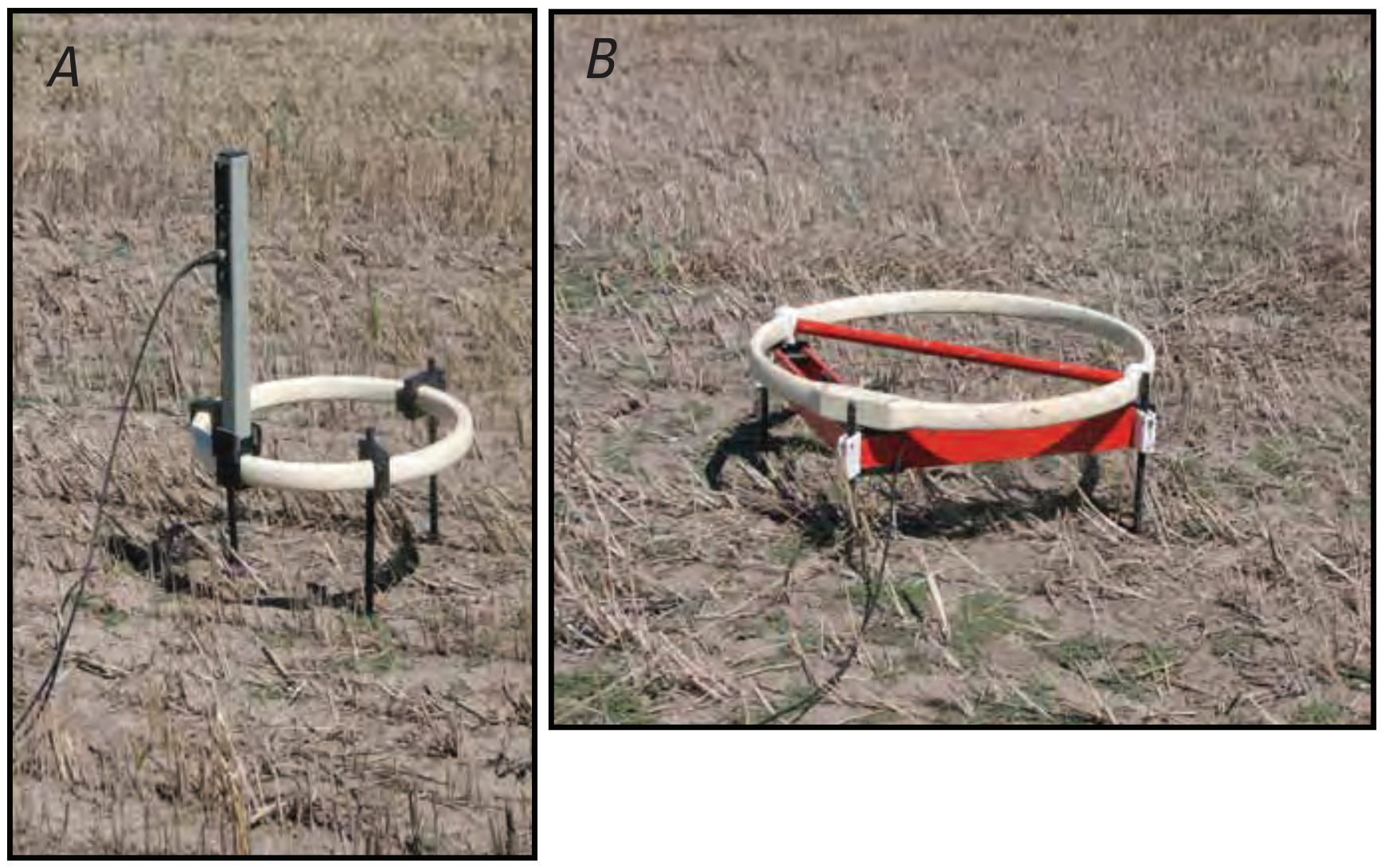

Figure 3. Photographs showing $A$, receiver coil (loop) for Geonics Protem-47, and $B$, receiver coil for Geonics Protem-57.

gate independently. Similar to Protem processing software, the user can specify limits to trim the data set. The same trimmed mean and outlier removal options were used. The processed TerraTEM data files are listed along with the processed Protem data files in appendix 1.

\section{Inverse Modeling}

Apparent resistivity, as calculated from field measurements of voltage, is the resistivity of an equivalent electrically homogeneous and isotropic subsurface (Grant and West, 1965). Inverse modeling is the process of creating an estimate of the true distribution of subsurface resistivity (derived from the actual heterogeneous, anisotropic rocks) from the measured apparent resistivity obtained from TDEM soundings (modeled as homogeneous, isotropic rocks). The IX1D program, developed by Interpex Limited (1996), was used for inverse modeling. Measured apparent resistivity data as a function of time are presented in appendix 2. For each sounding, apparent resistivity values are calculated from the raw voltage values measured. When plotted in time these apparent resistivity values yield a decay curve representing the subsurface electrical stratigraphy. Data points that deviated appreciably (in the judgment of the authors) from the decay curve (and therefore represented suspect data) were deleted before inverse modeling. Appendix 2 includes the decay curve for each sounding as well as the inverse modeling results calculated from the curve.

A smooth model, consisting of 24 or 30 layers and using initial author-specified model settings of a minimum depth of $1 \mathrm{~m}$, a maximum depth of $135 \mathrm{~m}$, and an initial starting resistivity that differed for each sounding, was used to approximate the measured resistivity points. The initial starting resistivity was calculated by doing a single iteration inversion (using IX1D) of a 1-layer (commonly referred to as a half-space) model to best fit the data. The resistivity of the 1-layer model then was used as a starting point for the smooth (24- or 30-layer) model. This starting resistivity would represent the mean resistivity over the entire depth of the sounding. A smooth model is a vertical delineation of calculated apparent resistivity that represents a non-unique estimate of the true resistivity. Ridge regression (Interpex Limited, 1996) was used by the inversion software in a series of iterations to create a smooth model for each sounding site. Iterations were continued until the root mean square error (RMS) between measured and calculated apparent resistivity changed less than 0.1 percent between iterations by using the equation, 


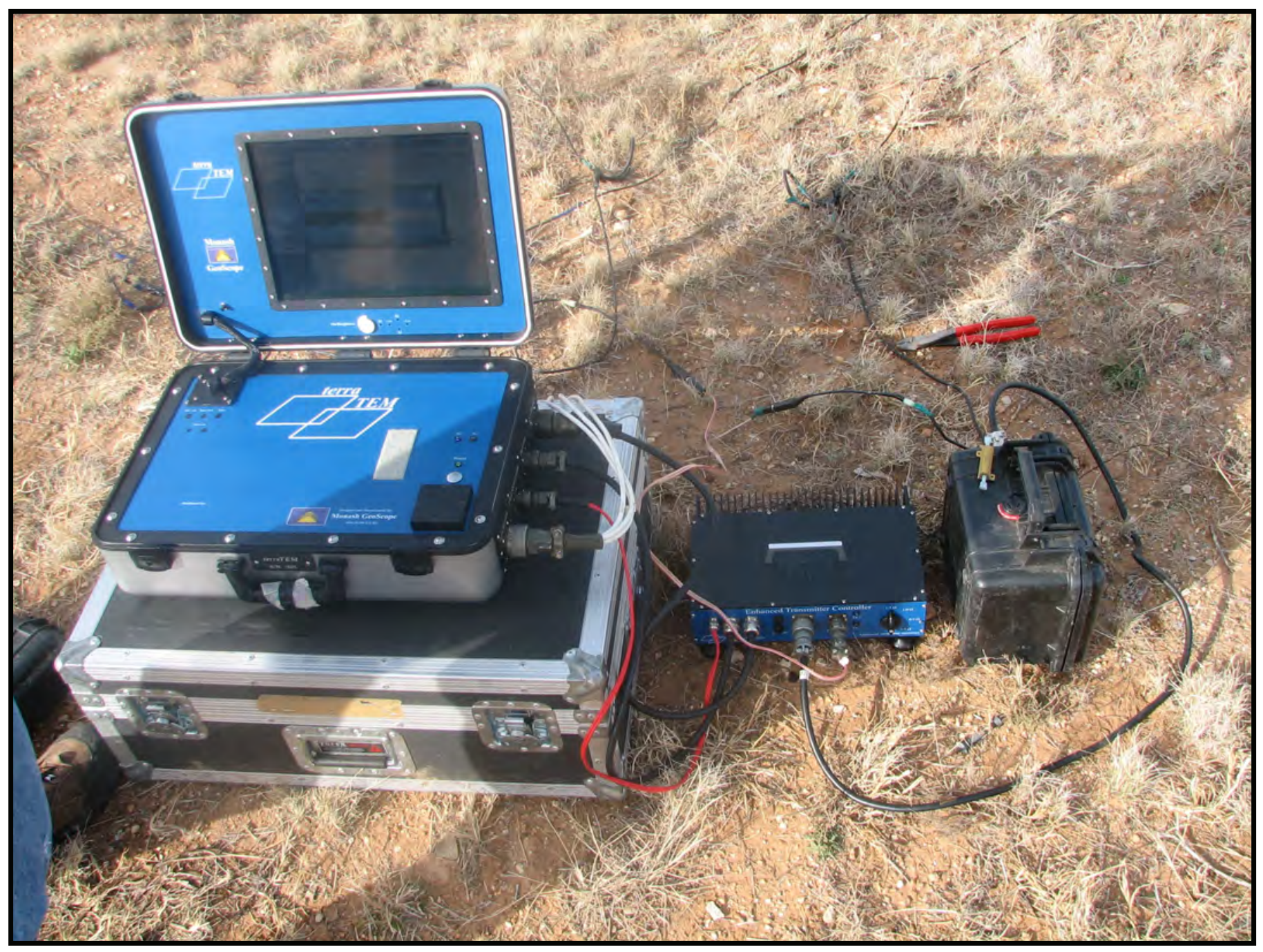

Figure 4. Alpha Geoscience TerraTEM time-domain electromagnetic system, which includes transmitter and receiver, current-limiting controller box, and battery pack.

$$
\text { RMS }=\left[\frac{1}{n} \sum_{i=1}^{n}\left(h_{m}-h_{s}\right)^{2}\right]^{0.5}
$$

Where

$R M S$ is the root mean square error [L],

$n$ is the number of calibration points,

$h_{m}$ is the measured apparent resistivity at point $\mathrm{i}[\mathrm{L}]$,

$h_{s}^{m}$ is the calculated apparent resistivity at point $\mathrm{i}[\mathrm{L}]$

To better represent the electrical stratigraphy of each sounding, layered-earth models were then generated. The layered-earth models are simplified to represent geologic units with depth. Throughout the area, the layered-earth models range from 2 to 4 layers, depending on observed inflections in the apparent resistivity decay curve and smooth model inversions. Graphs of the smooth and layered-earth models for each sounding site are in appendix 2 . The graphs show the raw apparent resistivity data and the inversion results. The smooth (green line, 24- or 30-layer depth profile), layered-earth (red line, 1- to 4-layer depth profile) and error or bounds of layered equivalent models (grey shaded area around depth profiles) are shown in the plots. RMS errors between measured and calculated apparent resistivity for the soundings range from 0.10 to 3.13 percent for the smooth models and 0.10 to 2.87 percent for the layered-earth models (table 2).

\section{Data Quality and Repeatability}

The TDEM data collected throughout the area show good results and are high quality based on RMS error after inversion, comparisons with borehole geophysical logging, and 

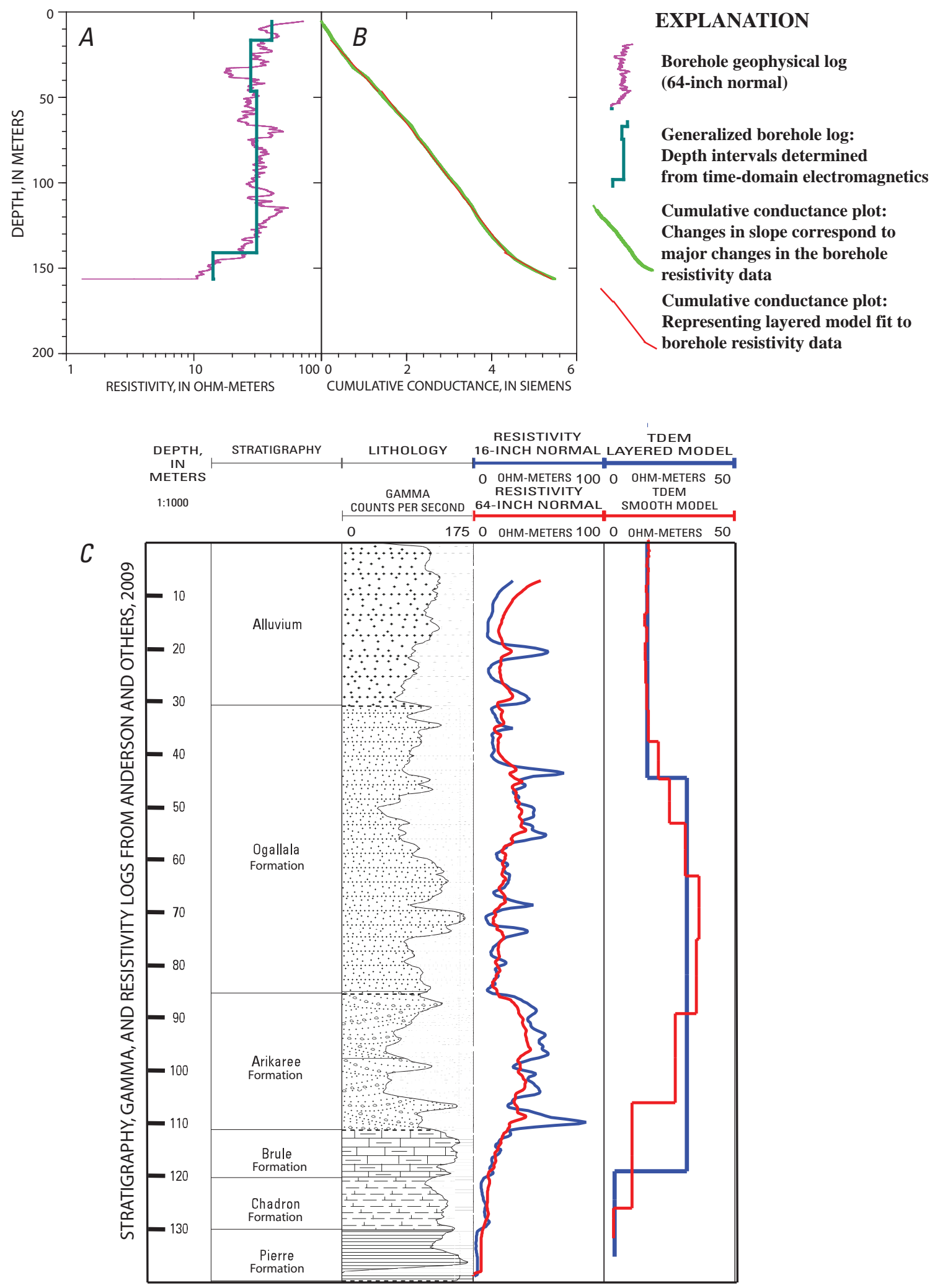

Figure 5. Comparison of time-domain electromagnetic (TDEM) data to borehole resistivity logs measured by Anderson and others, 2009, in a test hole at site 72A. $A, 64$-inch normal resistivity borehole geophysical log overlain by simplified layered-earth model with depth constraints obtained from TDEM inversions. $B$, Cumulative conductance plots for the original resistivity log and the simplified layered-earth model. $C$, Direct comparison of TDEM smooth and layered inverse modeling results (models of true resistivity as a function of depth) to borehole geophysical and lithologic logs collected by Anderson and others, 2009. 

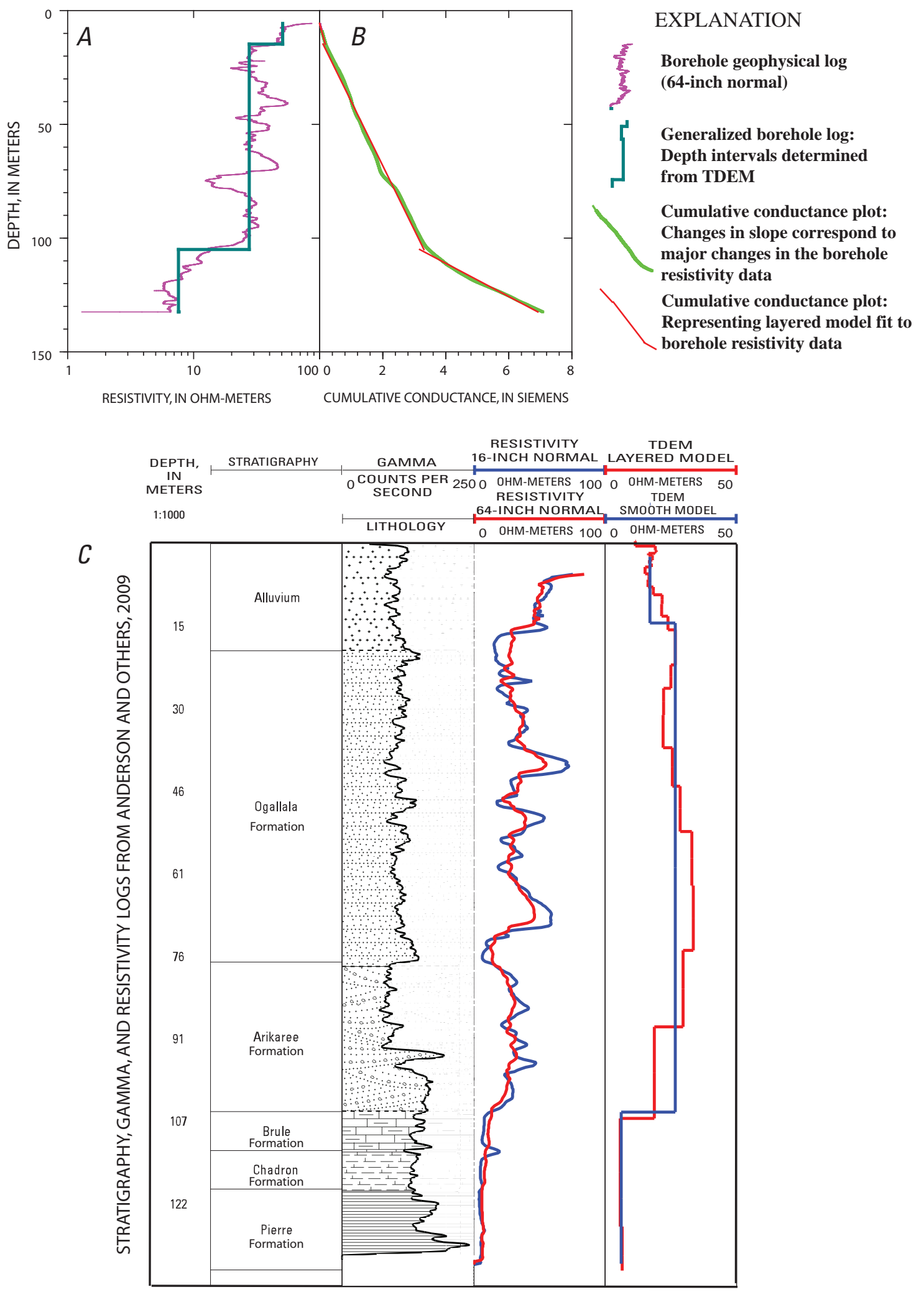

Figure 6. Comparison of time-domain electromagnetic (TDEM) data to borehole resistivity logs measured by Anderson and others, 2009, in a test hole at site 71. $A, 64$-inch normal resistivity borehole geophysical log overlain by simplified layered-earth model with depth constraints obtained from TDEM inversions. $B$, Cumulative conductance plots for both the original resistivity log and the simplified layered-earth model. $C$, Direct comparison of TDEM smooth and layered inverse modeling results (models of true resistivity as a function of depth) to borehole geophysical and lithologic logs collected by Anderson and others, 2009. 
Table 2. Root mean square (RMS) error between measured and calculated apparent resistivity for soundings, Dawson County, Nebraska.

[RMS, root-mean square]

\begin{tabular}{|c|c|c|c|c|}
\hline $\begin{array}{c}\text { Site } \\
\text { identifier }\end{array}$ & $\begin{array}{c}\text { Loop size } \\
\text { (meters) }\end{array}$ & $\begin{array}{c}\text { Data } \\
\text { collection } \\
\text { year }\end{array}$ & $\begin{array}{c}\text { Smooth } \\
\text { model } \\
\text { RMS error } \\
\text { (percent) }\end{array}$ & $\begin{array}{l}\text { Layered- } \\
\text { earth } \\
\text { model } \\
\text { RMS error } \\
\text { (percent) }\end{array}$ \\
\hline CWR11 & 40 & 2009 & 1.61 & 1.57 \\
\hline Shelton & 40 & 2009 & 1.90 & 1.24 \\
\hline Site 39 & 40 & 2007 & .98 & .82 \\
\hline Site 40 & 40 & 2007 & 2.70 & 1.95 \\
\hline Site 51 & 40 & 2007 & 1.14 & 1.39 \\
\hline Site 51 & 80 & 2007 & 1.19 & 1.82 \\
\hline Site 54 & 40 & 2007 & .66 & .77 \\
\hline Site 54 & 80 & 2007 & .76 & .94 \\
\hline Site $58 \mathrm{~A}$ & 40 & 2007 & .10 & 1.10 \\
\hline Site $58 \mathrm{~A}$ & 80 & 2007 & 1.42 & 1.49 \\
\hline Site 58B & 40 & 2008 & .54 & .61 \\
\hline Site 65 & 40 & 2007 & .69 & .86 \\
\hline Site 66 & 40 & 2007 & .73 & .90 \\
\hline Site 67 & 40 & 2007 & .67 & .59 \\
\hline Site 67 & 80 & 2007 & .82 & .10 \\
\hline Site $71 B$ & 40 & 2007 & 1.66 & 1.88 \\
\hline Site 71B & 80 & 2008 & .88 & .84 \\
\hline Site 71A & 40 & 2008 & .94 & .85 \\
\hline Site $72 \mathrm{~A}$ & 40 & 2007 & 1.10 & 1.65 \\
\hline Site $72 \mathrm{~A}$ & 40 & 2008 & .85 & .79 \\
\hline Site 72B & 40 & 2008 & 2.13 & 1.10 \\
\hline Site $72 C$ & 40 & 2008 & 3.13 & 2.87 \\
\hline Site 72D & 40 & 2008 & 1.93 & 1.86 \\
\hline Site $72 E$ & 40 & 2008 & 1.92 & 1.80 \\
\hline Site $72 F$ & 40 & 2008 & 1.93 & 1.76 \\
\hline Site $72 \mathrm{G}$ & 40 & 2008 & 2.47 & 2.21 \\
\hline Site $72 \mathrm{H}$ & 40 & 2008 & 2.24 & 1.92 \\
\hline Site 73 & 40 & 2007 & 1.80 & 1.61 \\
\hline Site 85 & 40 & 2007 & .53 & .47 \\
\hline Site 85 & 80 & 2007 & .56 & .42 \\
\hline
\end{tabular}

${ }^{1}$ Cottonwood Ranch Site Number 1

repeatability. The RMS errors for all soundings were less than 4 percent, with many less than 1 percent (table 2). On the basis of previous study results, RMS errors of 10 percent or less are generally considered acceptable, and RMS errors of 5 percent are generally considered good (Payne, 2007).

Quality assurance of the data was done by comparing the TDEM data with borehole geophysical data collected by Anderson and others, 2009, in a separate phase of the study.
Most of the soundings in the area show a moderately resistive layer (approximately $30 \mathrm{ohm}-\mathrm{m}$ ) within the upper 100 $\mathrm{m}$ (Ogallala Formation) and a conductive layer (less than 10 ohm-m) at the lower confining unit of the High Plains aquifer (lower White River Group or Pierre Shale). The TDEM inversion results compare well with borehole geophysical data collected by Anderson and others, 2009, at sites 72 and 71. At sites 72A and 71 (figs. 5 and 6, respectively), the TDEM results show similar resistivity structures when compared to the 64- and 16-inch normal resistivity borehole geophysical logs collected. A change in resistivity can be seen at depth in both the TDEM inversion and the borehole logs. In each figure, section A represents the 64-inch normal borehole geophysical log (Keys, 1997) overlain by a simplified layered-earth model calculated by using IX1D (Interpex, 2010). The simplified model is similar to the layered-earth inversion results for the TDEM soundings. This was done to visually show how well the layered-earth model calculated from the TDEM data compares with the borehole resistivity data collected by Anderson and others, 2009. The simplified model was created by constraining the depth of each layer to equal the depths observed in the TDEM layered-earth model inversions at each site. The IX1D program was used to alter the resistivity values by averaging the borehole data throughout the extent of each layer. Figures $5 \mathrm{~b}$ and $6 \mathrm{~b}$ each show the cumulative conductance of the borehole data (green) calculated by using IX1D plotted against depth. The red line represents the layered-earth approximation of the borehole $\log$. Inflections in the graphed cumulative conductance data represent different layers (based on resistivity changes) in the borehole data (Interpex, 2008). Small inflections are observed in the borehole data that do not appear in the simplified model. Because the borehole log does not start at the surface, some discrepancies between the simplified borehole log and TDEM inversion results are evident.

Data quality was verified by making multiple duplicate measurements at the same locations. TDEM data was collected multiple times at sites 58 and 72 to determine if the electrical stratigraphy results were consistent between 2007 and 2009. Site 58, at which voltages have been collected and resistivity modeled multiple times with 40- and 80-meter configurations, shows consistent results. Appendixes 2.10 and 2.11 show data collected at site 58A with 40- and 80-meter transmitter loops, and appendix 2.12 shows data collected at site 58B with 80-meter transmitter loops. Although the apparent resistivity decay curves do not match, the inversion results are similar.

Data collection at site $72 \mathrm{~A}$ was repeated several times during the period 2007-09. Appendix 2 shows two soundings collected at site $72 \mathrm{~A}$, one with the Geonics Protem system in 2007, and one with the Alpha Geoscience TerraTEM system in 2008. The apparent resistivity decay curves look different because of the sampling time intervals, loop configurations, and other system-specific settings, but again the inversion results are similar. Soundings were collected in a grid pattern near site $72 \mathrm{~A}$ to determine the electrical heterogeneity of the area. Multiple soundings (sites $72 \mathrm{~A}-\mathrm{H}$ ) were collected in a 
grid pattern at a spacing that approximated the 40-m loop size around the location of site $72 \mathrm{~A}$. The inversion results from each sounding are shown in appendix 2 .

\section{Digital Data}

Digital data in appendix 1 include (1) raw (unprocessed) voltage data, (2) voltage data that has been filtered and averaged, and (3) the resistivity values calculated from inverted voltages. TDEM sounding data is contained under the attached directory RAW_TDEM. The .red files are the raw data downloaded directly from the Protem 47 and 57. The associated Microsoft Excel spreadsheet (Protem Record Numbers.xls) contains all the pertinent information needed to process the raw .red files. The .usf files are the raw data downloaded directly from the TerraTEM. These .red and .usf files can only be read with time-domain processing software. The directory (Processed_TDEM) includes the data after the first phase of processing. The .dat files are the processed (filtered) data from the Protem and TerraTEM systems. The .csv files contain all the pertinent information to be input into an inversion program to calculate resistivity values. The processed data has been filtered to remove outliers that deviate more than 10 percent from other data points and a trimmed mean has been applied removing the upper and lower 5 percent of the data. The directory (INVERSION_TDEM) contains the final inversion results that can be read by using the IX1D program (Interpex, 2010).

\section{Summary}

The U.S. Geological Survey (USGS) began a multiyear geophysical study in cooperation with the Central Platte Natural Resources District in 2007. As part of this study, the USGS collected time-domain electromagnetic (TDEM) soundings (voltage data from which apparent resistivity is calculated) at selected sites in Dawson County, Nebr., between April 2007 and November 2009. TDEM soundings were made at 23 different sites representing 14 locations. The TDEM soundings documented in this report are part of a larger study to characterize the hydrostratigraphy of the area.

TDEM measurements were made by transmitting an alternating current into square loops of insulated wire deployed on the land surface. Geonics Protem 47 and 57 systems, as well as the Alpha Geoscience TerraTEM, were used to collect the TDEM soundings from 40- or 80-meter, square-shaped loops of wire that transmit and measure voltage to depths of approximately 90-130 meters (depending on loop size) below the land surface; transmitting alternating currents and measuring the resulting voltages at a location is referred to as a sounding. For each sounding collected with the Protem system, the measured voltages were averaged and evaluated statistically by using preprocessing scripts. These scripts use the raw field data (voltage data) and calculate the uncertainty of each time gate (discrete voltages measured at increasingly later times after shutoff of the current) independently. The averages of each time gate are presented in this report; these are the processed data that are used with inversion software. Apparent resistivity, as calculated from field measurements of voltage, is the resistivity of an equivalent electrically homogeneous and isotropic subsurface. Inverse modeling estimates the true distribution of subsurface resistivity (derived from the actual heterogeneous, anisotropic rocks) from the measured apparent resistivity obtained from TDEM soundings (modeled as homogeneous, isotropic rocks). The IX1D program, developed by Interpex Limited, was used for inverse modeling. Measured apparent resistivity data are depicted as a function of time. When plotted as a function of time, apparent resistivity values yield a decay curve representing the subsurface electrical stratigraphy.

A smooth model, consisting of 24 or 30 layers using initial author-specified settings of a minimum depth of $1 \mathrm{~m}$, a maximum depth of $135 \mathrm{~m}$, and an initial starting resistivity (which differed for each sounding), was used to approximate the measured resistivity points. The initial starting resistivity was calculated by doing a single iteration inversion (using IX1D) of a one-layer (commonly referred to as a half-space) model to best fit the data. The resistivity of the 1-layer model then was used as a starting point for the smooth (24- or 30-layer) model. This starting resistivity would represent the mean resistivity over the entire depth of the sounding. A smooth model is a vertical delineation of calculated apparent resistivity that represents a (non-unique) estimate of the true resistivity. Ridge regression was used by the inversion software in a series of iterations to create a smooth model for each sounding site. Iterations were continued until the root mean square (RMS) error between measured and calculated apparent resistivity changed less than 0.1 percent between iterations. Layered-earth models are simplified to represent geologic units with depth. Throughout the area, the layered-earth models range from 2 to 4 layers depending on observed inflections in the apparent resistivity decay curve and smooth model inversions. Graphs of the smooth and layered-earth models for each sounding site are presented. The graphs show the raw apparent resistivity data and the inversion results. The smooth layered-earth and error or bounds of layered equivalent models (grey shaded area around depth profiles) are also shown. RMS errors between measured and calculated apparent resistivity for the soundings range from 0.10 to 3.13 percent for the smooth models and 0.10 to 2.87 percent for the layered-earth models. On the basis of previous study results, root mean square errors of 10 percent or less are generally considered acceptable, and root mean square errors of 5 percent or less are considered good. Quality assurance of the data was done by comparing the TDEM data with borehole geophysical data collected in a separate phase of the study. At sites 72 and 71, the TDEM results show similar resistivity structures when compared to the 64- and 16-inch, normal resistivity borehole geophysical logs collected. Data quality was verified by 
making multiple duplicate measurements at the same locations. TDEM data were collected multiple times at sites 58 and 72 to determine if the electrical stratigraphy was consistent between 2007 and 2009. At site 58, voltages were collected and resistivity modeled multiple times with 40- and 80-meter configurations, and the results of time-domain soundings determined by inversion were consistent. Two soundings were collected at site 72, one with the Geonics Protem system in 2007, and one with the Alpha Geoscience TerraTEM system in 2008. The apparent resistivity decay curves look different because of the sampling time intervals, loop configurations, and other system-specific settings, but again the inversion results are similar. Soundings were collected in a grid pattern near site 72 to determine the electrical heterogeneity of the area. Multiple soundings (sites $72 \mathrm{~A}-\mathrm{H}$ ) were collected in a grid pattern at a spacing that approximated the 40-m loop size around the location of site $72 \mathrm{~A}$.

\section{References Cited}

Alpha Geoscience, 2010, TerraTEM: accessed December 2010 at http://www.alpha-geo.com/terratem.html.

Anderson, J.A., Morin, R.H., Cannia, J.C., and Williams, J.H., 2009, Geophysical log analysis of selected test holes and wells in the High Plains aquifer, Central Platte River Basin, Nebraska: U.S. Geological Survey Scientific Investigations Report 2009-5033, 16 p.

American Society for Testing and Materials, 1999, Standard guide for selecting surface geophysical methods: ASTM International Standard D6429.

Barrash, Warren, and Morin, R.H., 1987, Hydrostratigraphy and distribution of secondary permeability in the Brule Formation, Cheyenne County, Nebraska: Geological Society of America Bulletin, v. 99, p. 445-462.

Fitterman, D.V., and Labson, V.F., 2005, Electromagnetic induction methods for environmental problems, in Butler, D.K., ed., Near-surface geophysics-Part 1, Concepts and fundamentals: Investigations in Geophysics, no. 13: Tulsa, Okla., Society of Exploration Geophysics, p. 295-349.

Geonics Limited, 2006a, Protem 47D operating manual for 20/30 gate model: Ontario, Geonics Limited, 80 p.

Geonics Limited, 2006b, Protem 57-MK2 D (C) operating manual for 20/30 gate model: Ontario, Geonics Limited, $58 \mathrm{p}$.

Grant, F.S., and West, G.F., 1965, Electrical conduction and electromagnetic induction methods, pt. 3 of Interpretation theory in applied geophysics: New York, McGraw-Hill, p. 384-572.
Gutentag, E.D., Heimes, F.J., Krothe, N.C., Luckey, R.R., and Weeks, J.B., 1984, Geohydrology of the High Plains aquifer in parts of Colorado, Kansas, Nebraska, New Mexico, Oklahoma, South Dakota, Texas, and Wyoming: U.S. Geological Survey Professional Paper 1400-B, 63 p.

Halliday, David, and Resnick, Robert, 1974, Fundamentals of Physics: New York, Wiley, 827 p.

Interpex Limited, 1996, TEMIX XL user's manual, version 4: Golden, Colo., Interpex Limited.

Interpex, 2010, Software Tutorials: accessed December 2010 at http://interpex.com/TutorialIndex.htm.

Keys, W.S., 1997, A practical guide to borehole geophysics in environmental investigations: Boca Raton, Fla., CRCLewis, $176 \mathrm{p}$.

North Carolina Division of Water Resources, 2006, Time domain electromagnetic geophysics: accessed July 31, 2006, at http://www.ncwater.org/Education_and_ Technical_Assistance/Ground_Water/TDEM/.

Payne, J.D., Kress, W.H., Shah, S.D., Stefanov, J.E., Smith, B.A., and Hunt, B.B., 2007, Geophysical delineation of the freshwater/saline-water transition zone in the Barton Springs segment of the Edwards aquifer, Travis and Hays Counties, Texas, September 2006: U.S. Geological Survey Scientific Investigations Report 2007-5244, 21 p., 6 appendixes.

Pettijohn, R.A., and Chen, H.H., 1983, Geohydrology of the High Plains aquifer system in Nebraska: U.S. Geological Survey Open-File Report 82-502, 3 sheets, scale 1:750,000.

Schultz, C.B., and Stout, T.M., 1955, Classification of Oligocene sediments in Nebraska: University of Nebraska State Museum Bulletin, v. 4, no. 2, p. 17-52.

Stewart, M.T., and Gay, M.C., 1986, Evaluation of transient electromagnetic soundings for deep detection of conductive fluids: Ground Water, v. 24, p. 351-356.

The Weather Network, 2010, Lexington, Nebraska, weather statistics, 1961 to 1990: The Weather Network Web site,

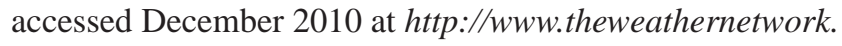
com/statistics/C02257/.

Trimble, 2007, Trimble 5800: accessed May 24, 2007, at http://www.trimble.com/5800.shtml.

U.S. Army Corps of Engineers, 1995, Geophysical exploration for engineering and environmental investigations: Engineering Manual 1110-1-1802, chap. 4, 57 p. 
Appendixes 1-2 
Blank Page 


\section{Appendix 1. Datasets of raw and processed time-domain electromagnetic data.}

\section{Data files:}

Raw_TDEM_-Includes all .red files downloaded from the Protem 47 and 57 systems, as well as all .usf files downloaded from the TerraTEM system. The Raw_TDEM folder also includes an Excel file that illustrates which record numbers (for the .red and .usf files) were used for each sounding.

Processed_TDEM_-Includes all the .dat (data files), and .csv (heading files) created after preprocessing (outliers removed in the data). Each of these files can be imported into the Interpex IX1D inversion software.

Inversion_TDEM_-Includes the .IXP file that can be read into the Interpex IX1D inversion software. The file includes all final inversion figures of each sounding. 
Appendix 2. Graphs showing time-domain electromagnetic resistivity from field measurements as a function of time and inverse modeling results (smooth and layered-earth models).

List of abbreviations used in appendix 2.

OHM Unit of measure of electrical resistance (International System)

OHM-Meters Unit by which resistivity is measured; it is derived from the following equation:

$$
\mathrm{R}=\mathrm{rA} / \mathrm{L}
$$

where

$\mathrm{R}=$ Resistivity in Ohm-meters;

$\mathrm{r}=$ resistance measured in Ohms;

$\mathrm{A}=$ cross sectional area in meters squared; and

$\mathrm{L}=$ length of the resistor in meters.

UTM Universal Transverse Mercator

NAVD 88 North American Vertical Datum of 1988

RMS Root Mean Square error 


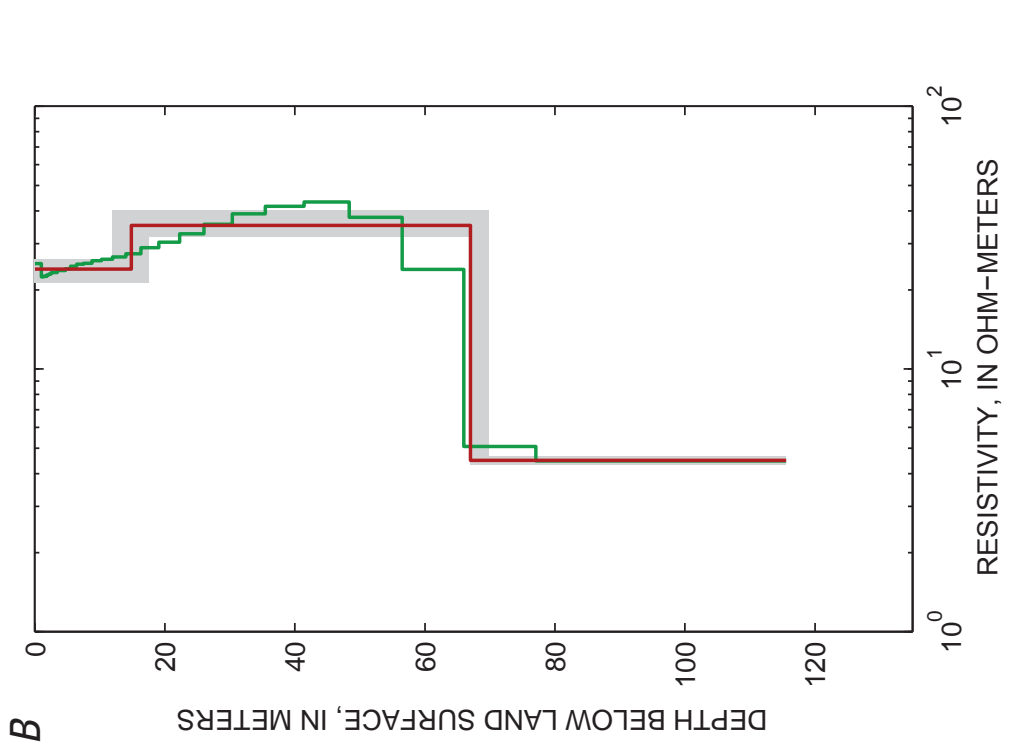

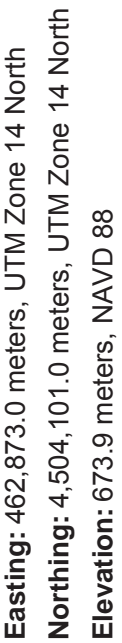
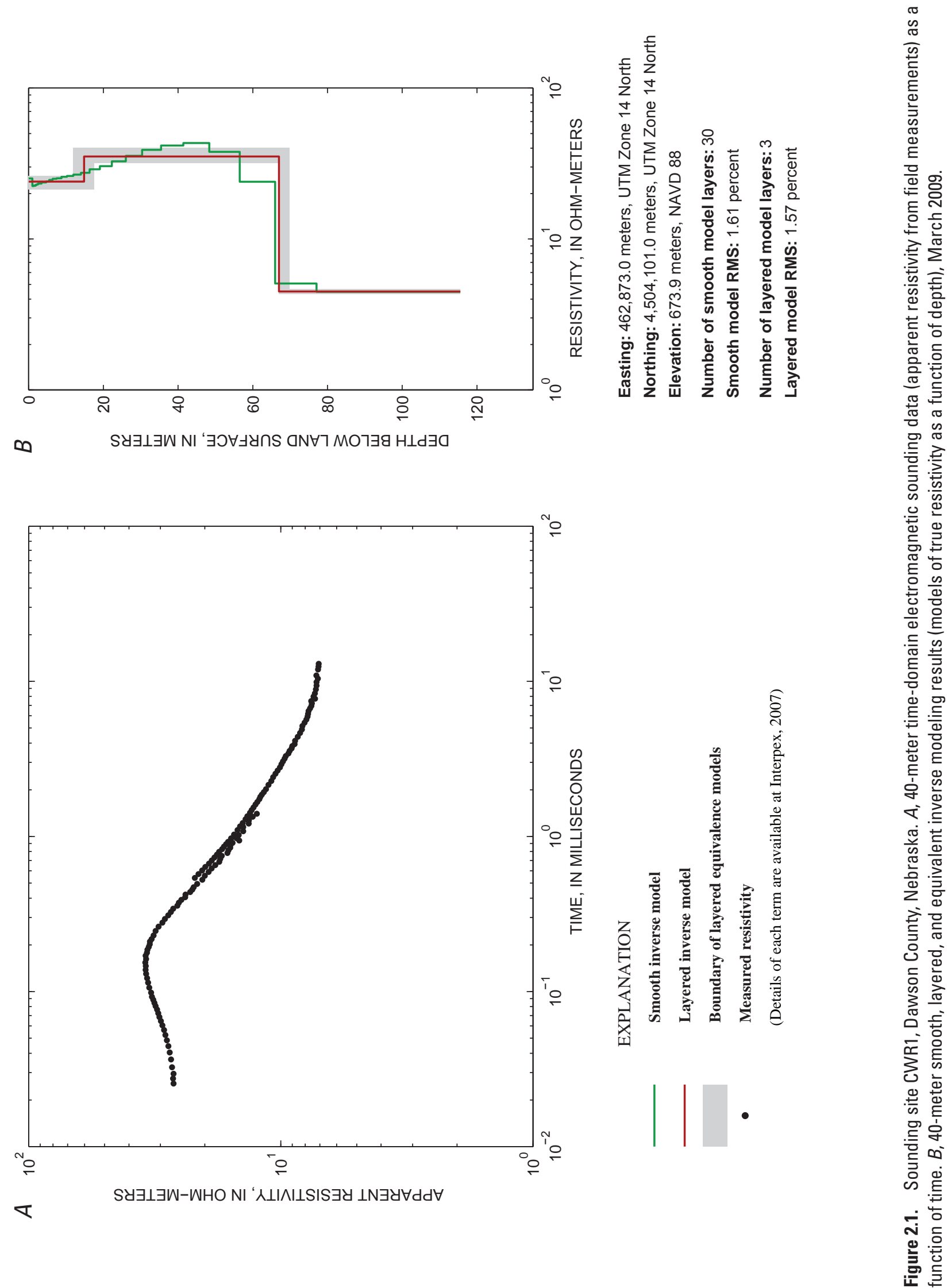

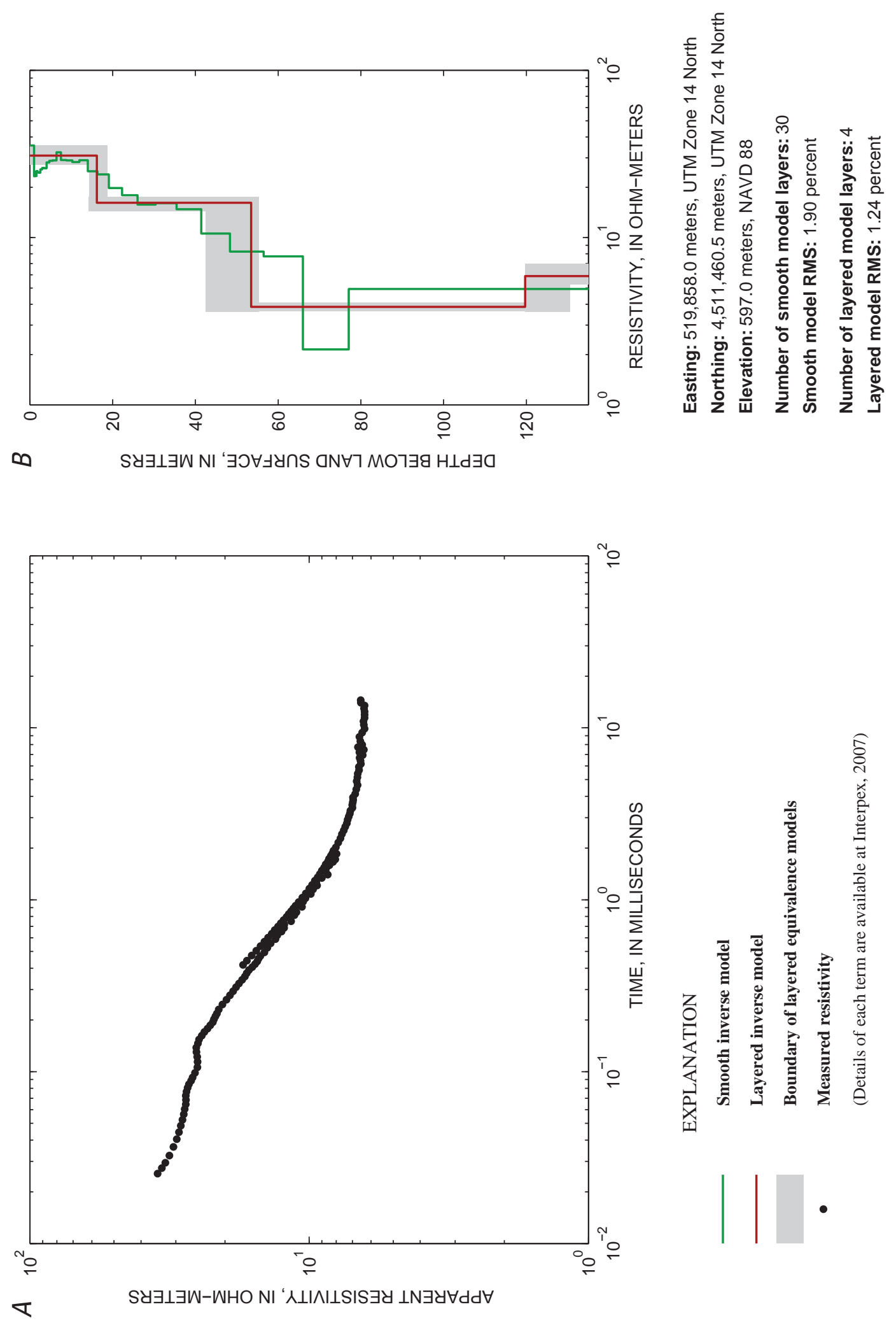

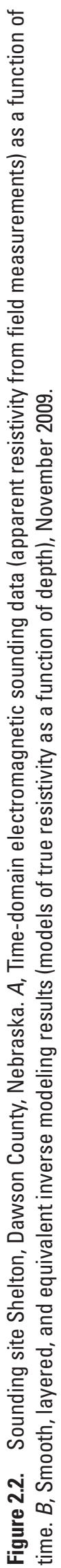



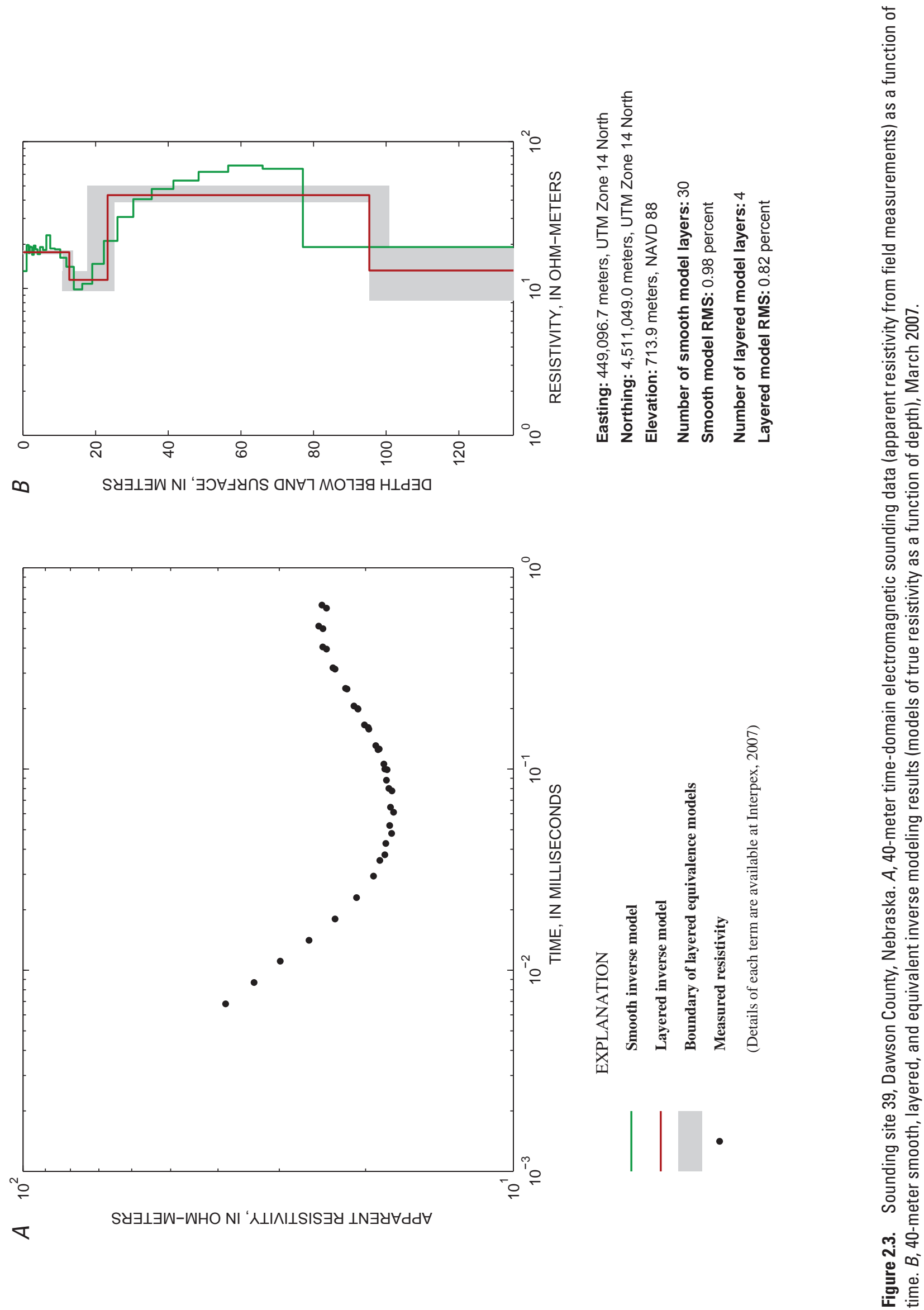

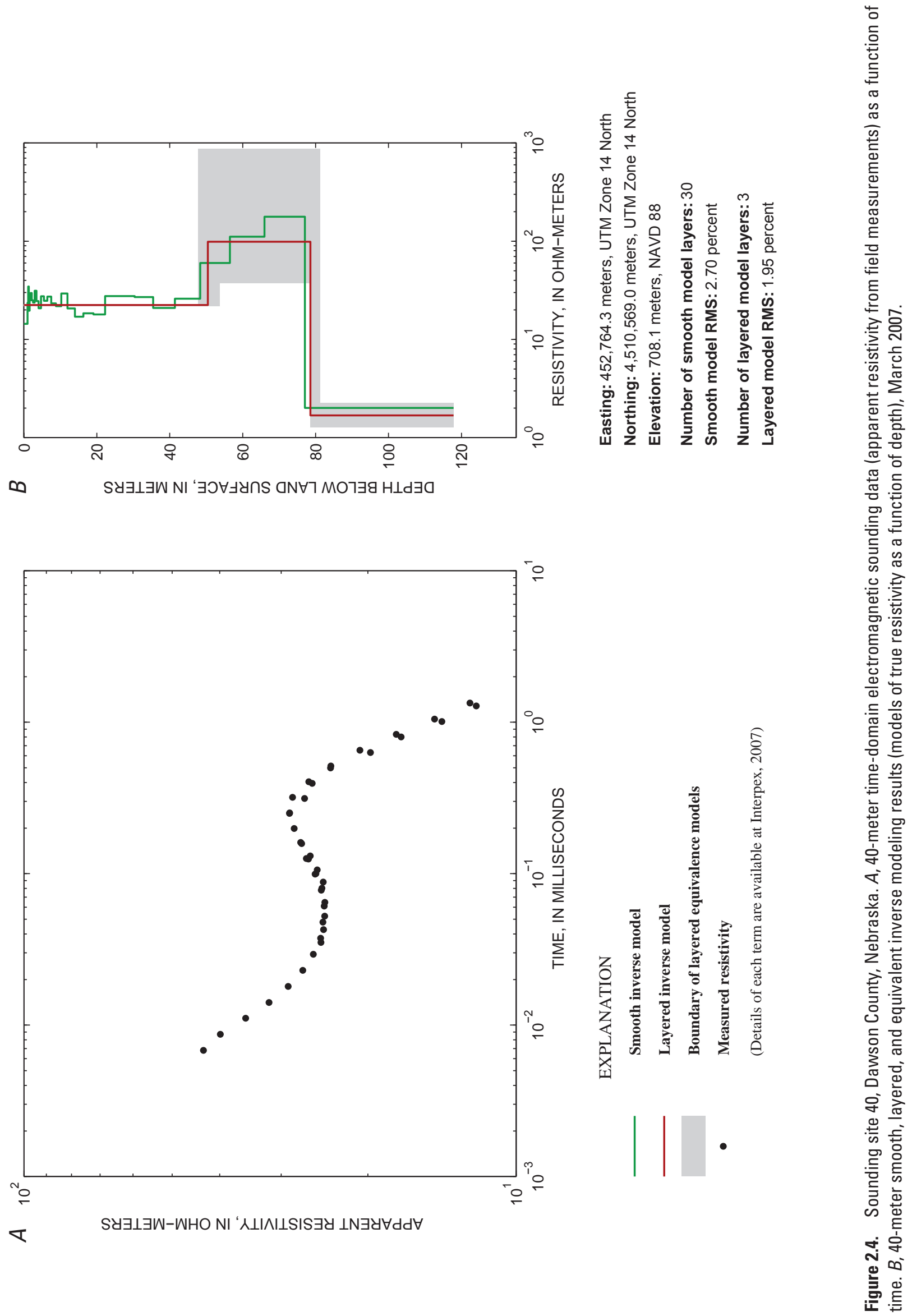

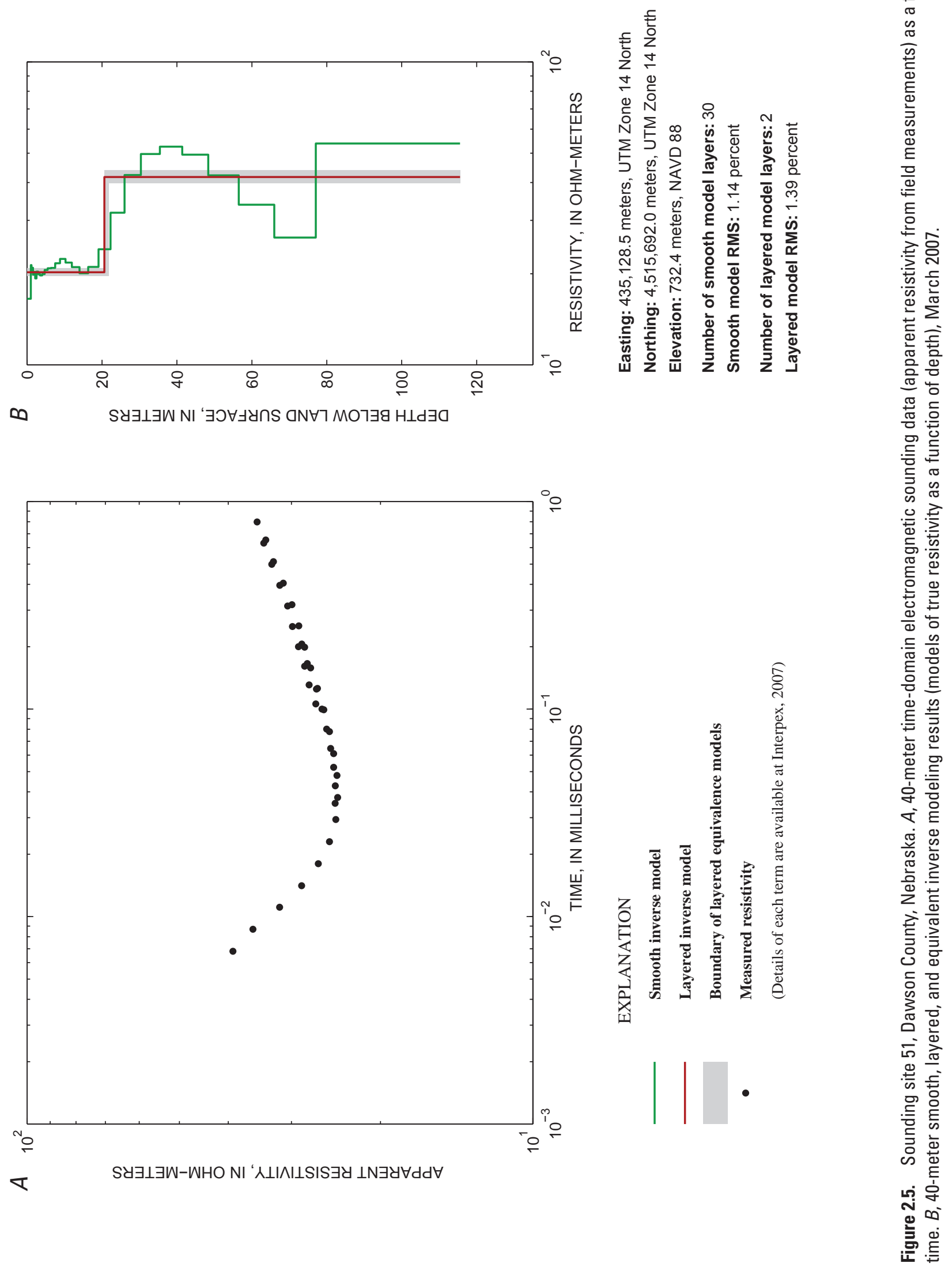

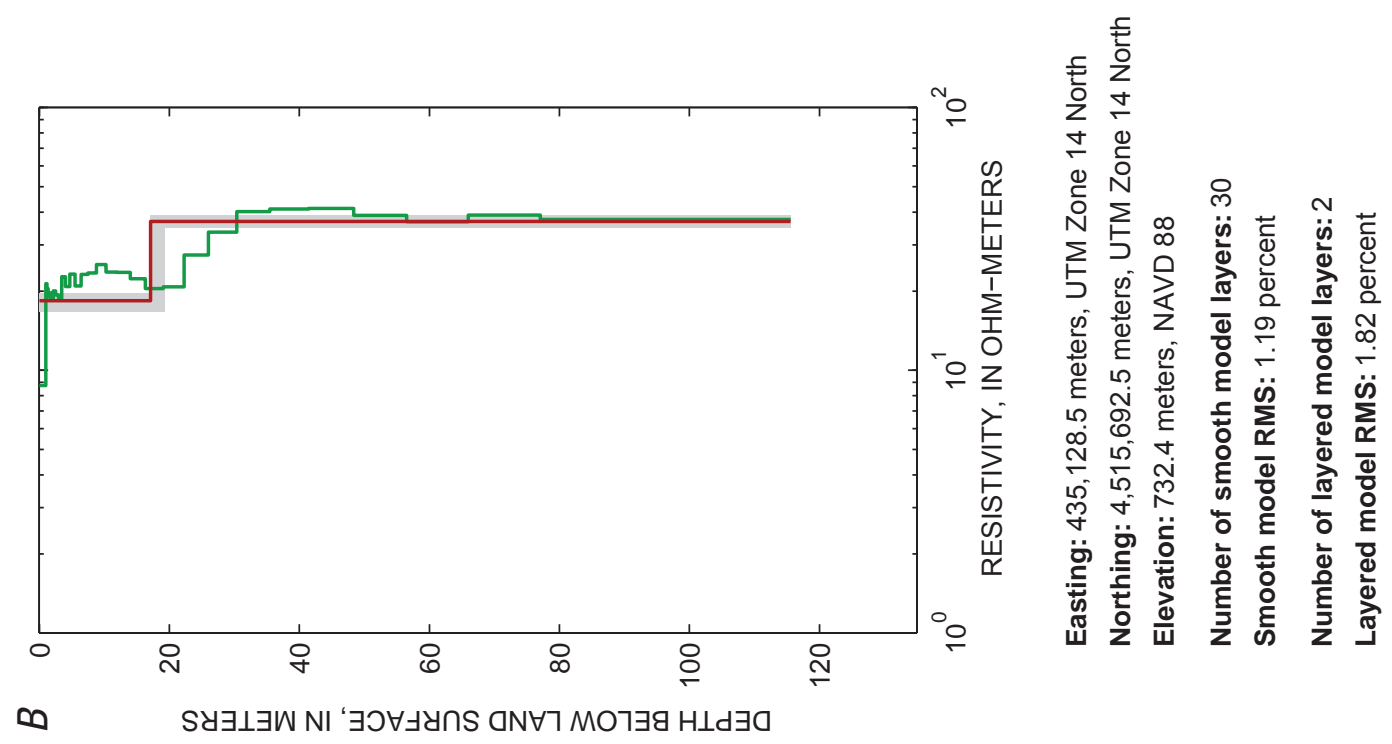

$\infty$
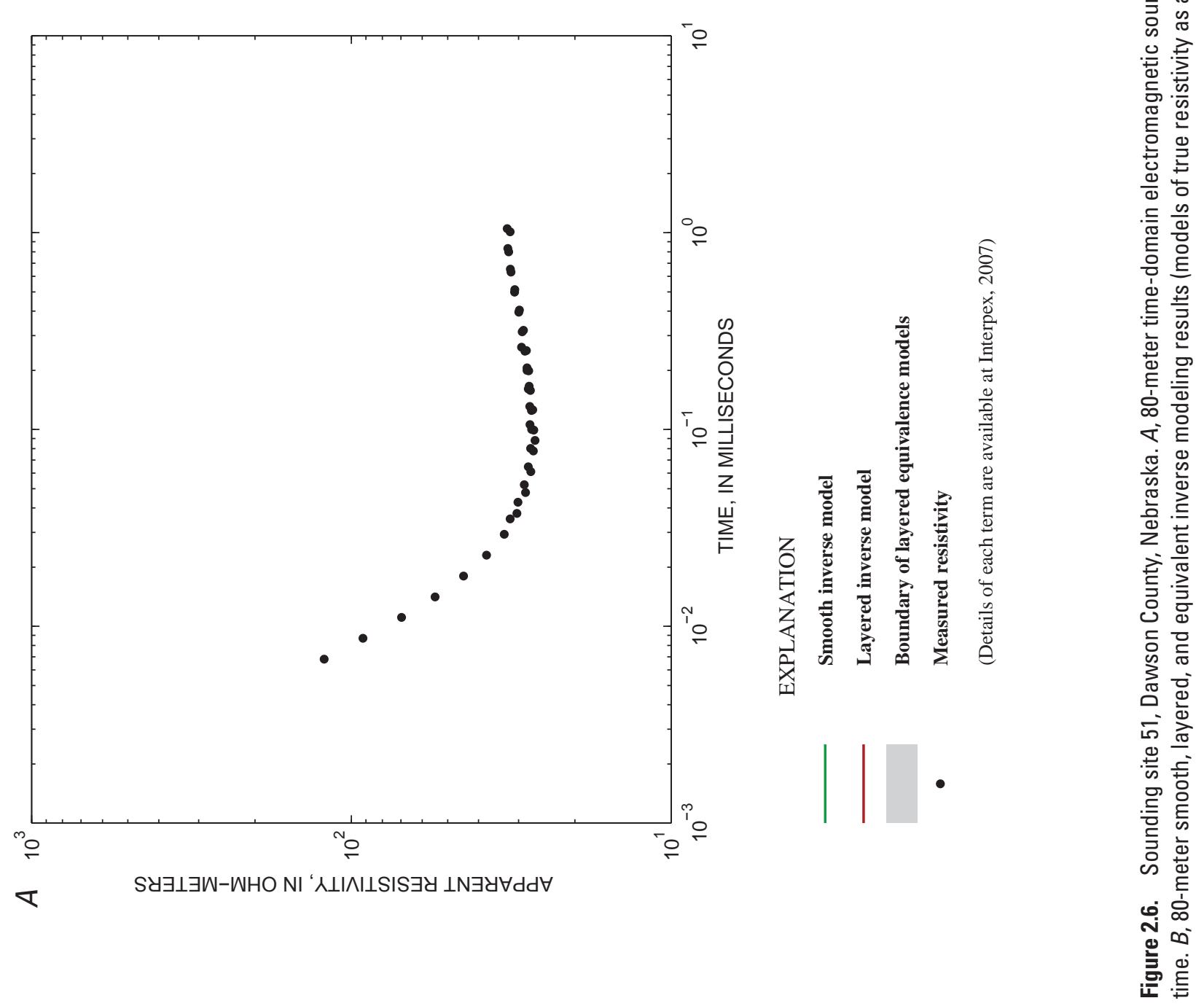

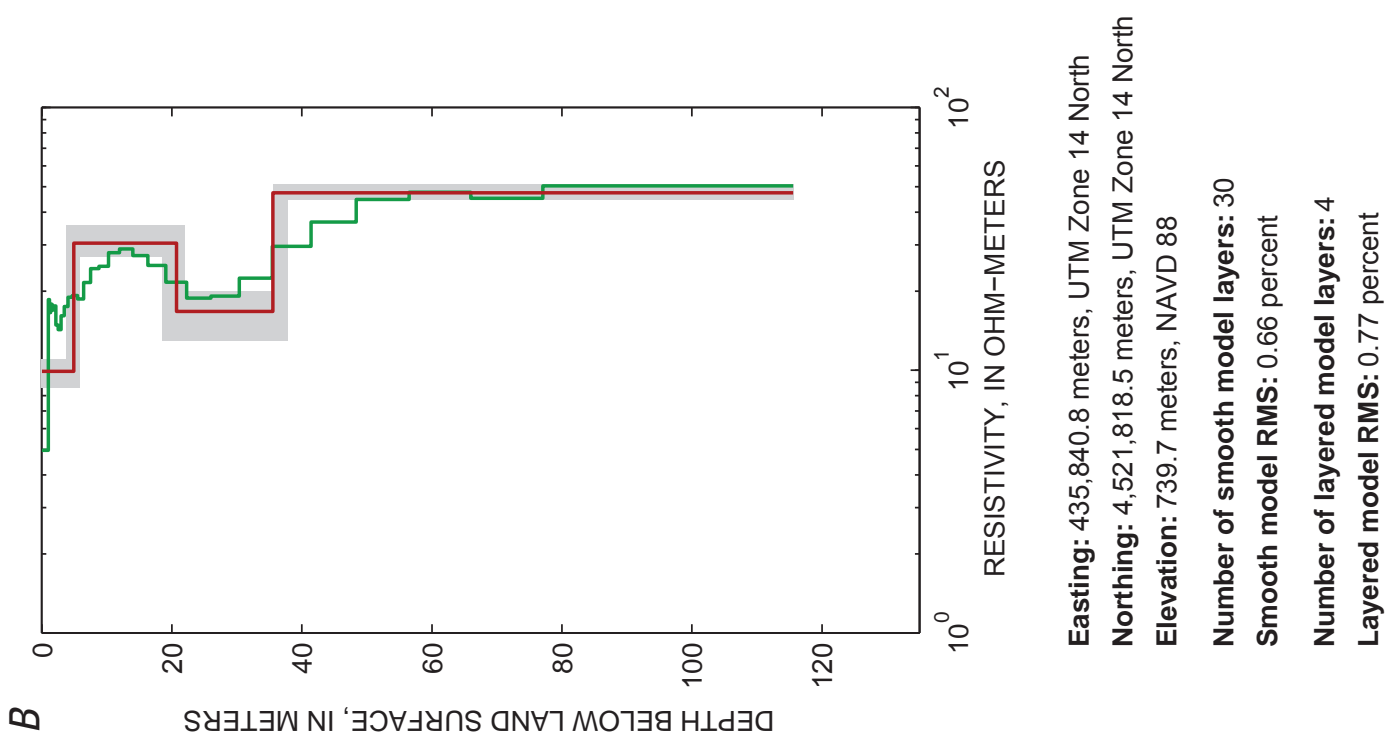

$\infty$
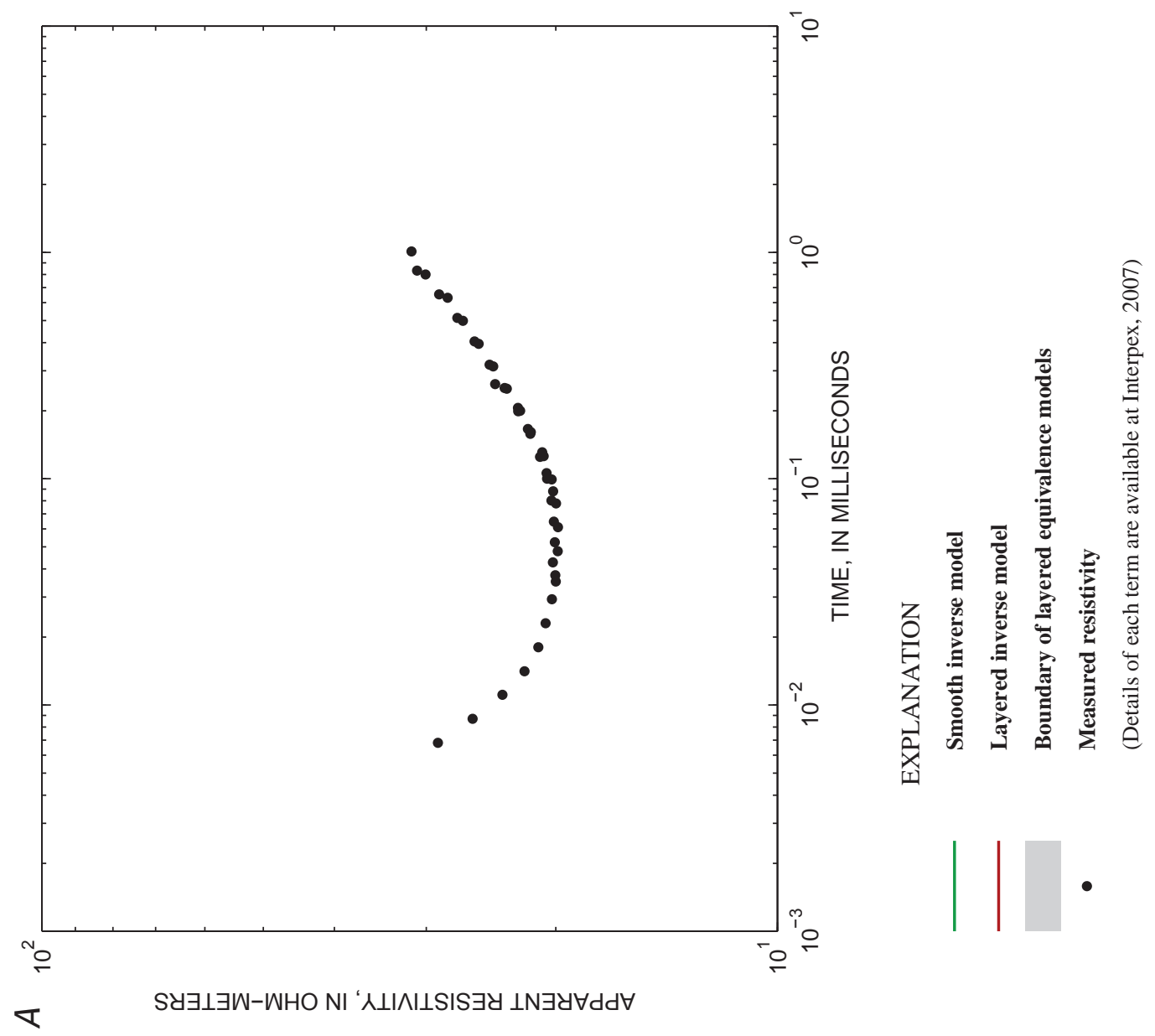

$\varangle$

SUIJW-WHONI ' $\lambda \perp I / I S I S \exists Y \perp N \exists Y \forall d d V$ 

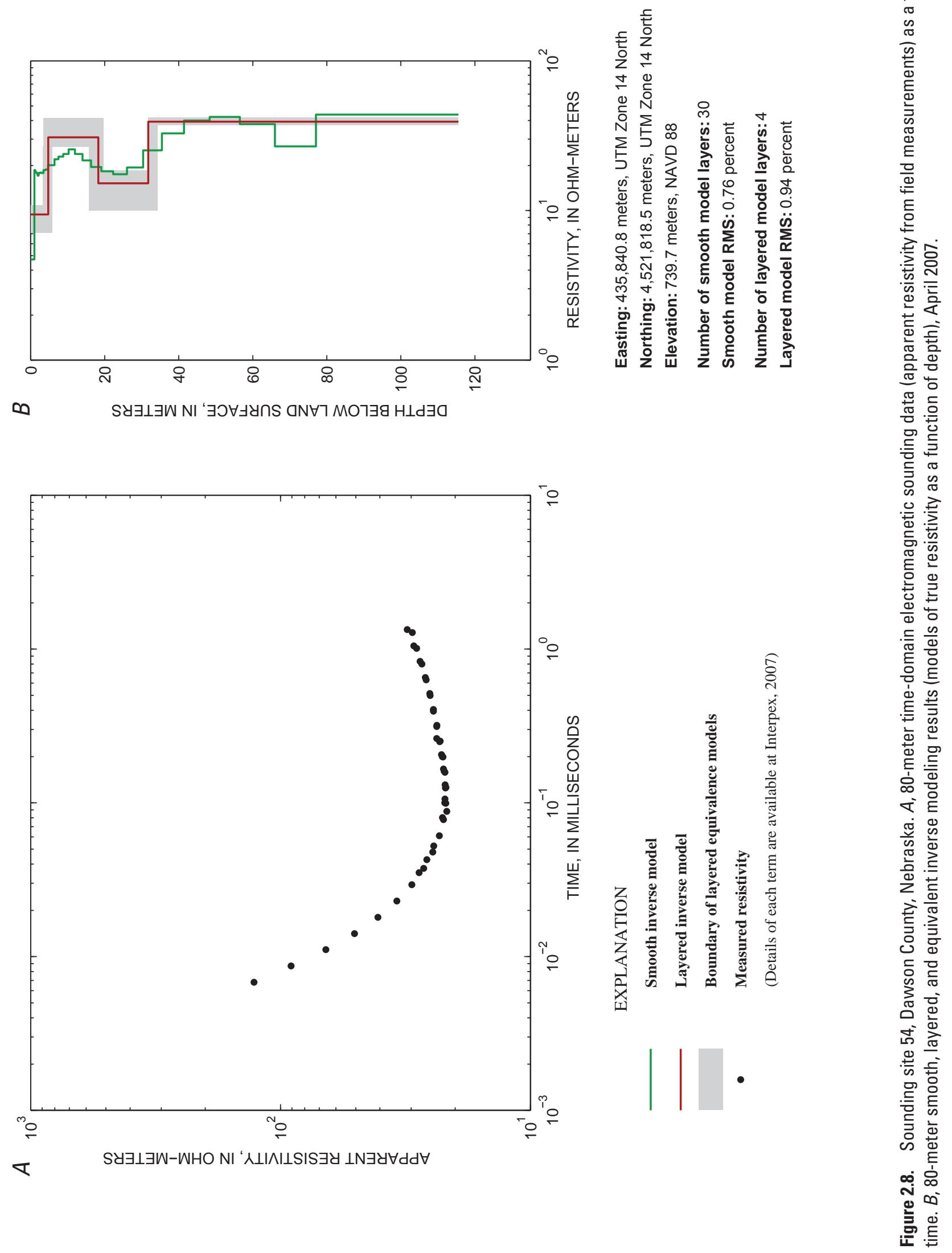

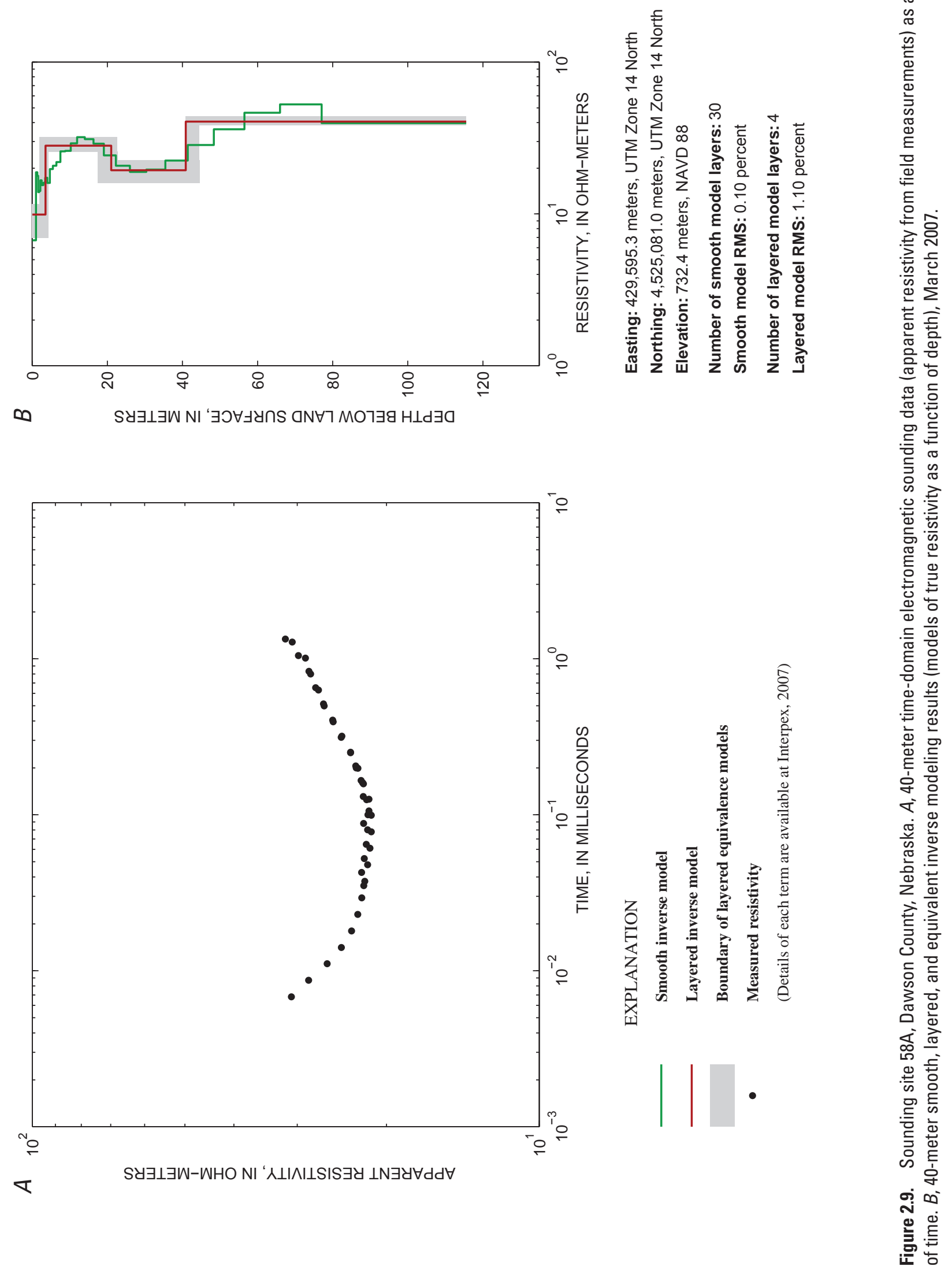


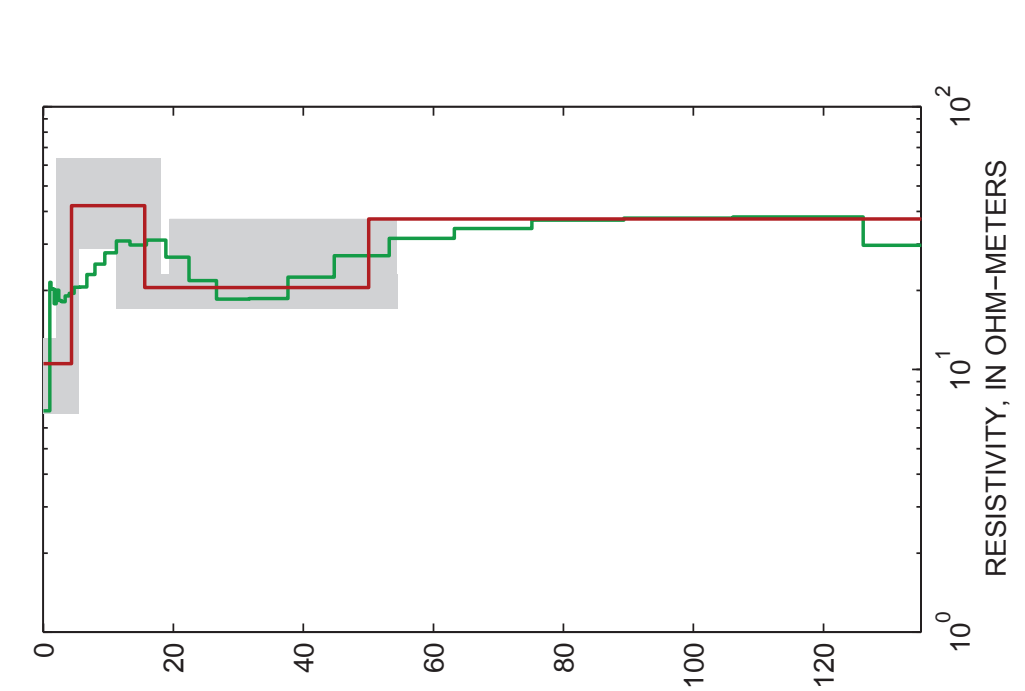

$\infty$
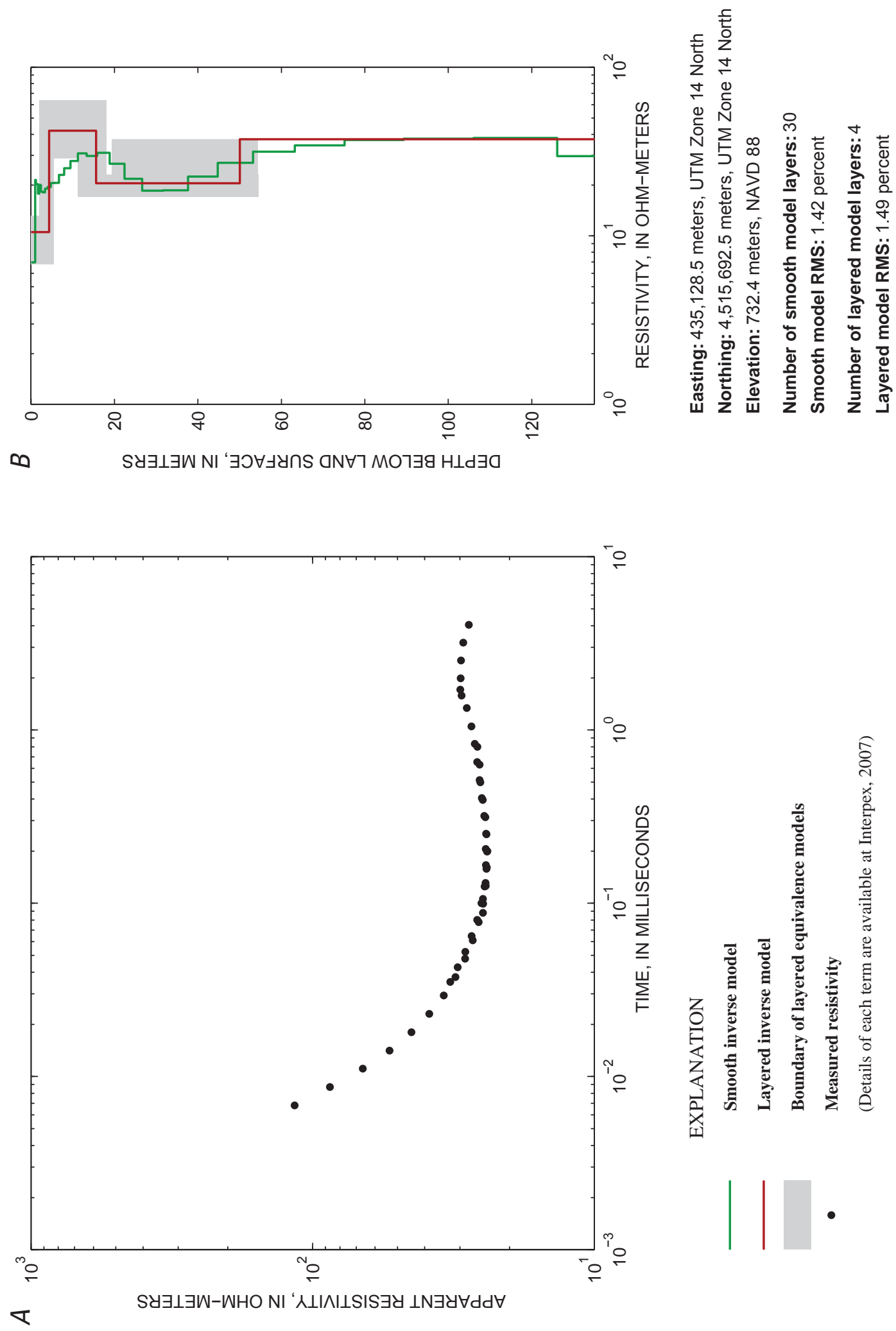

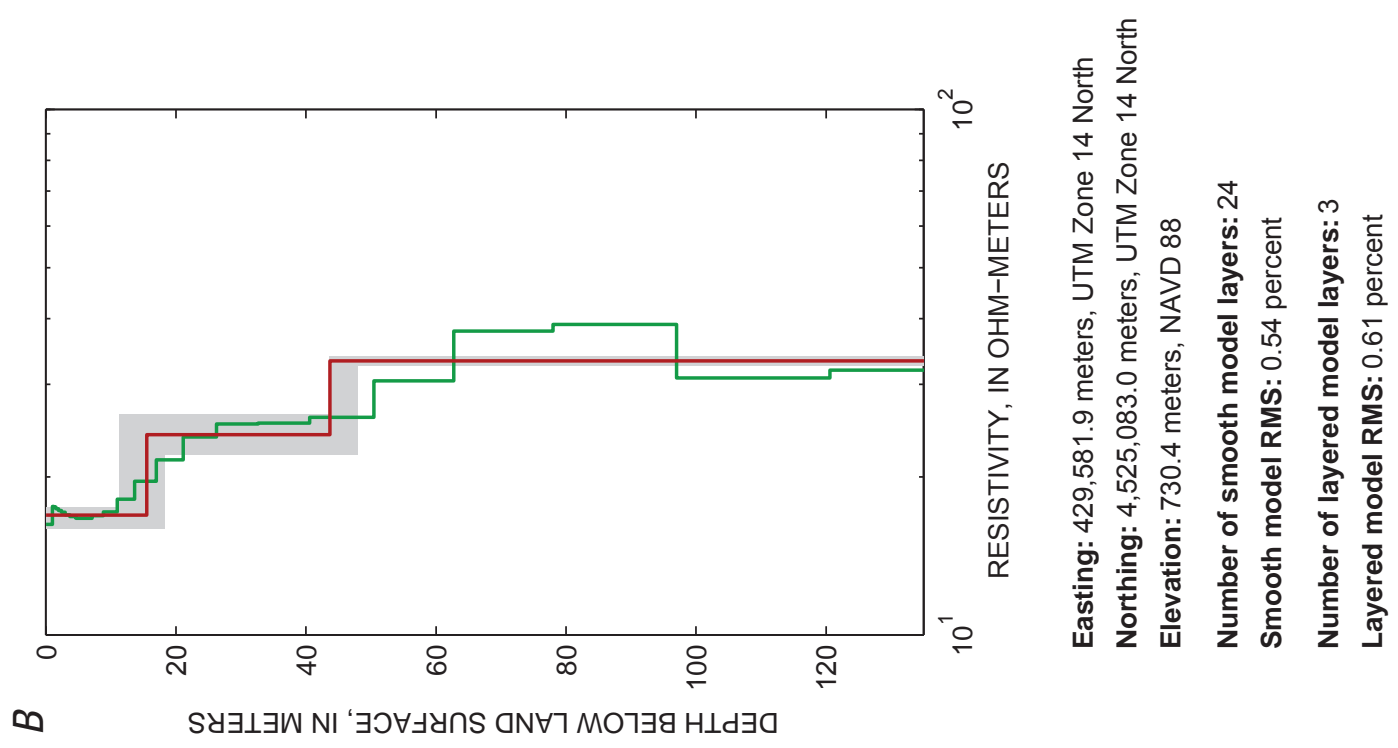

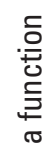
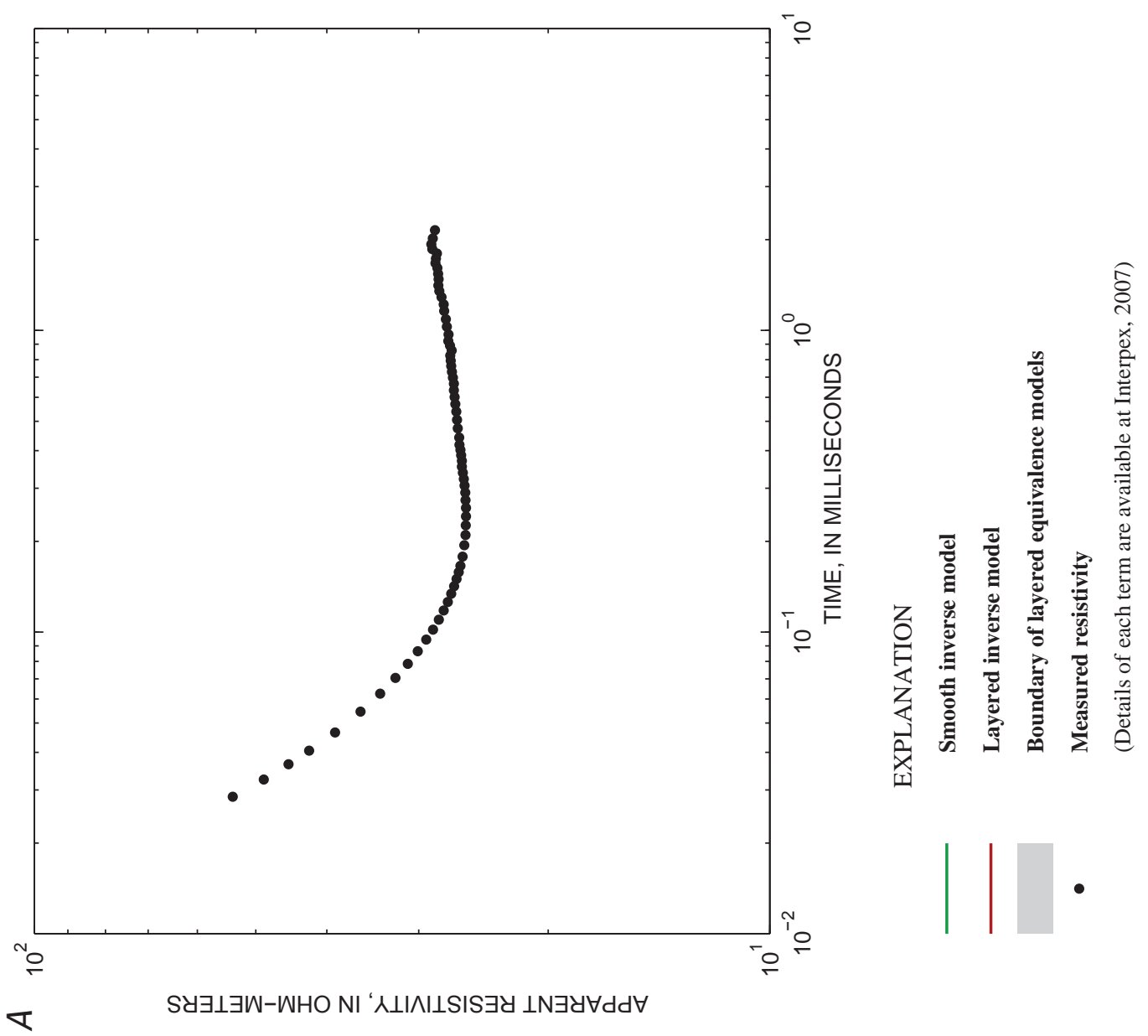

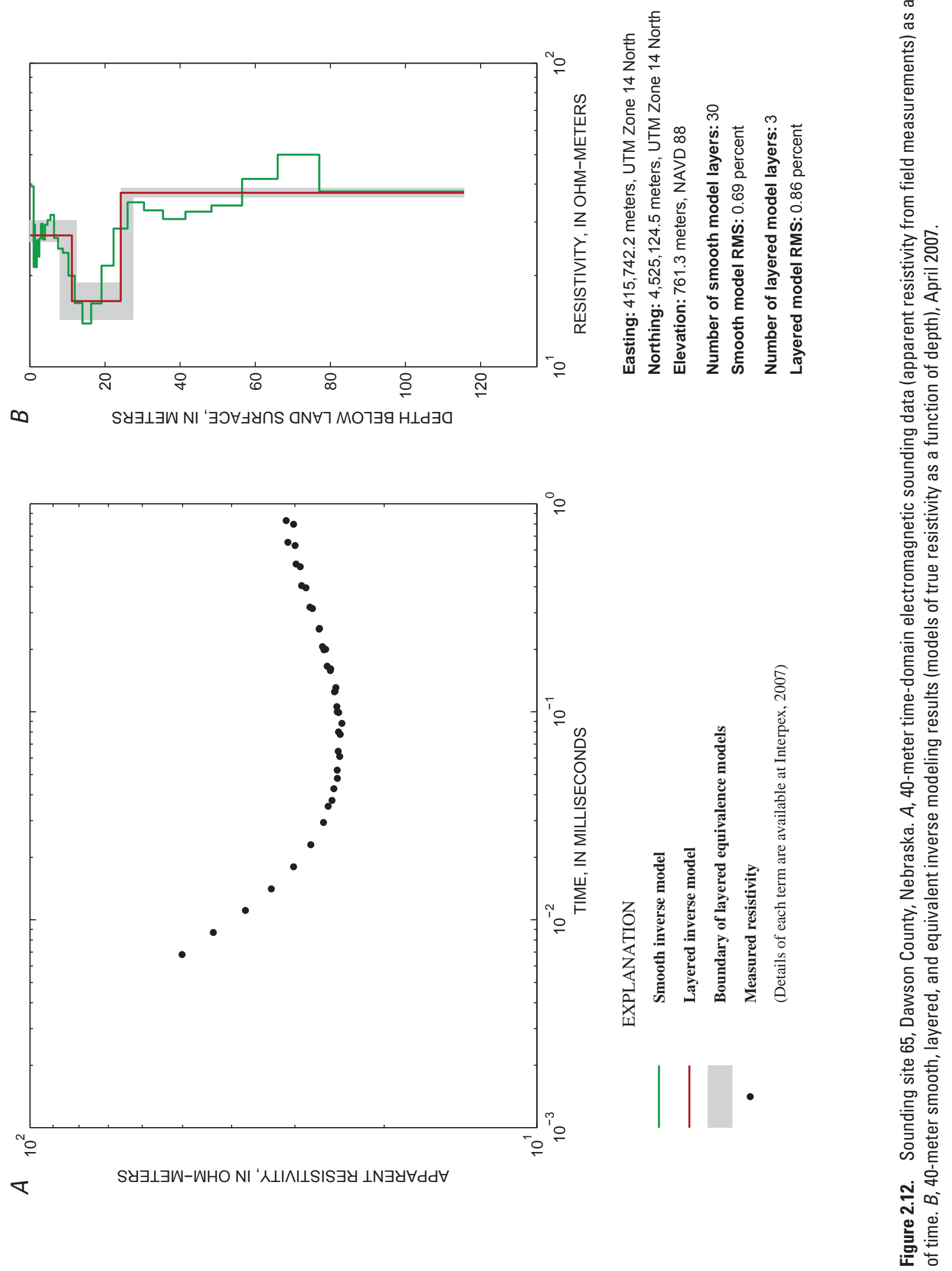

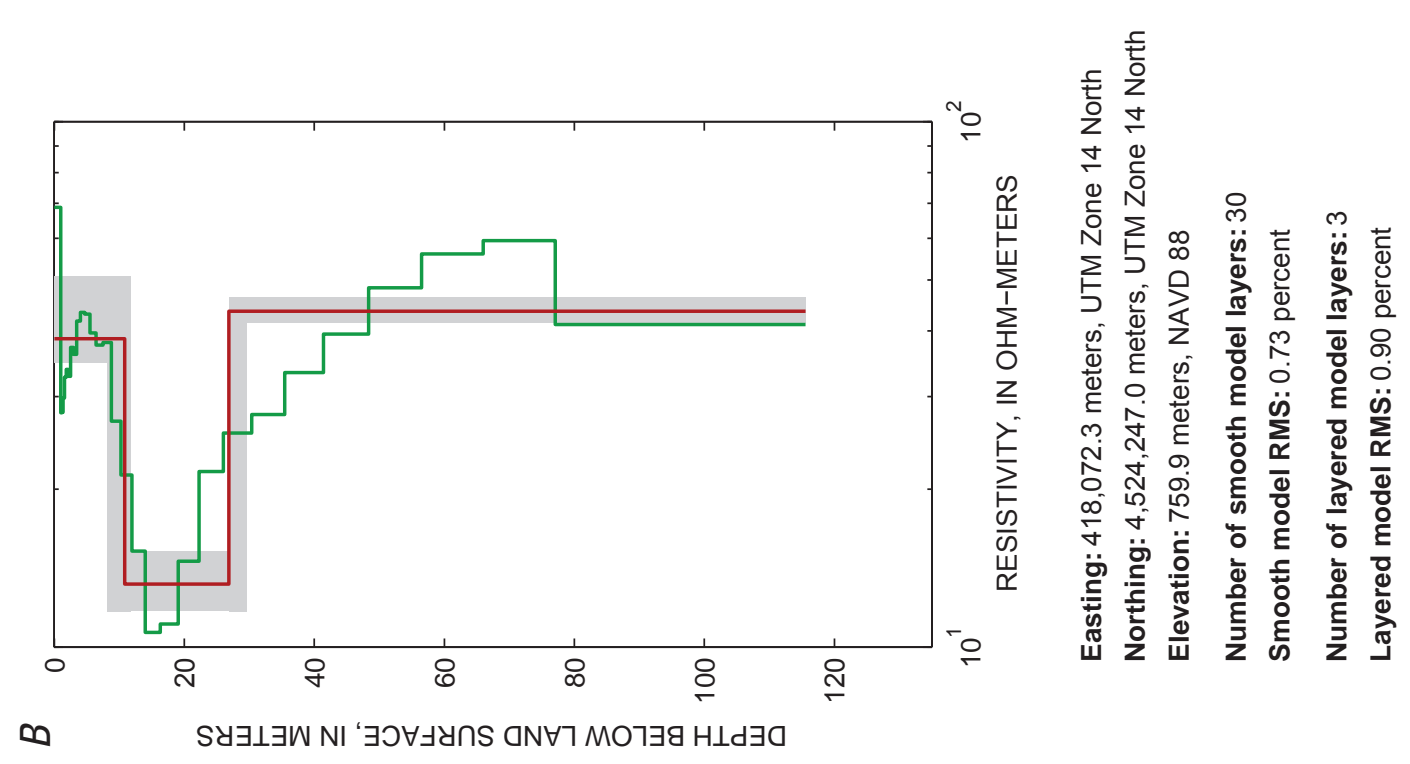

竞
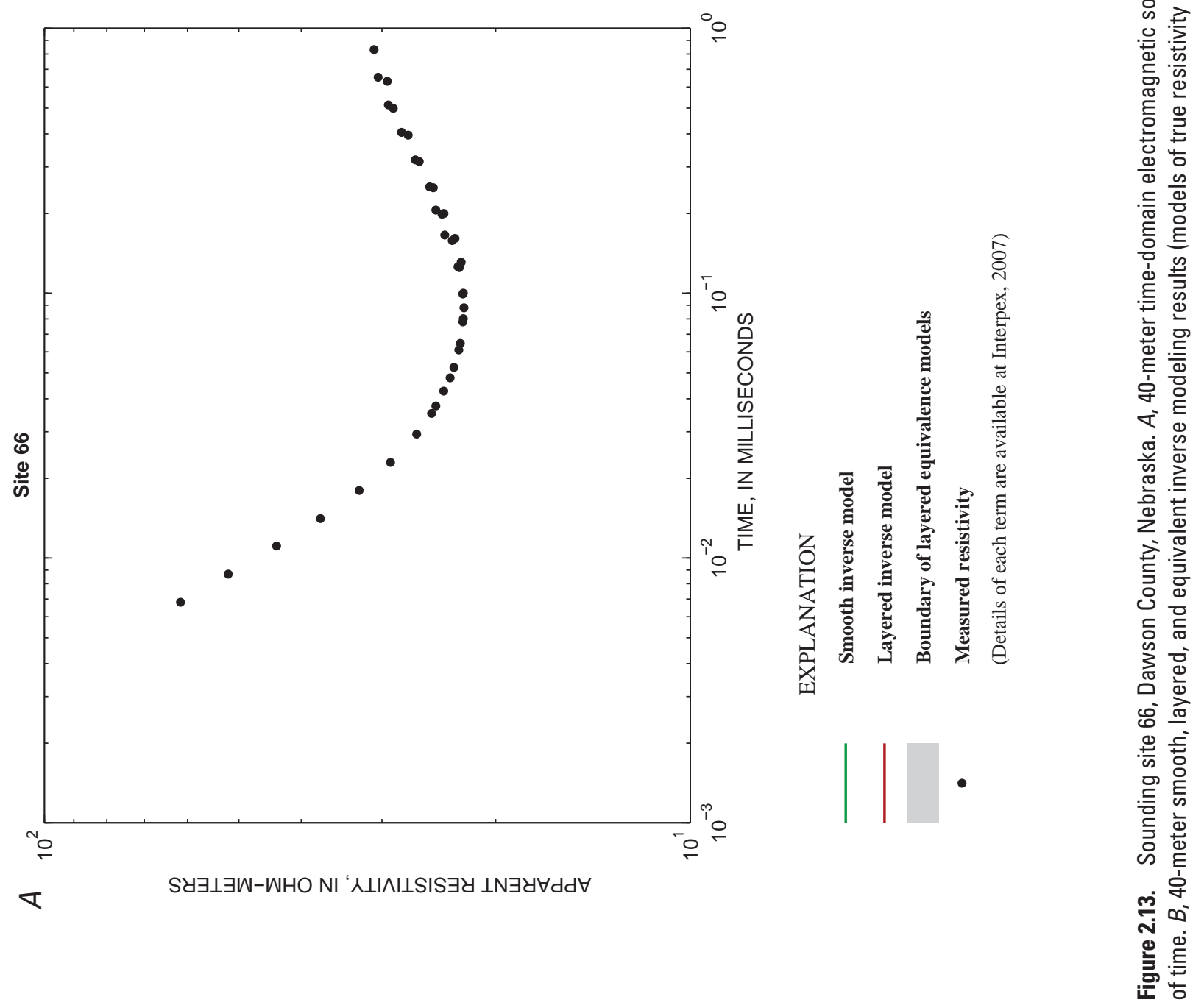

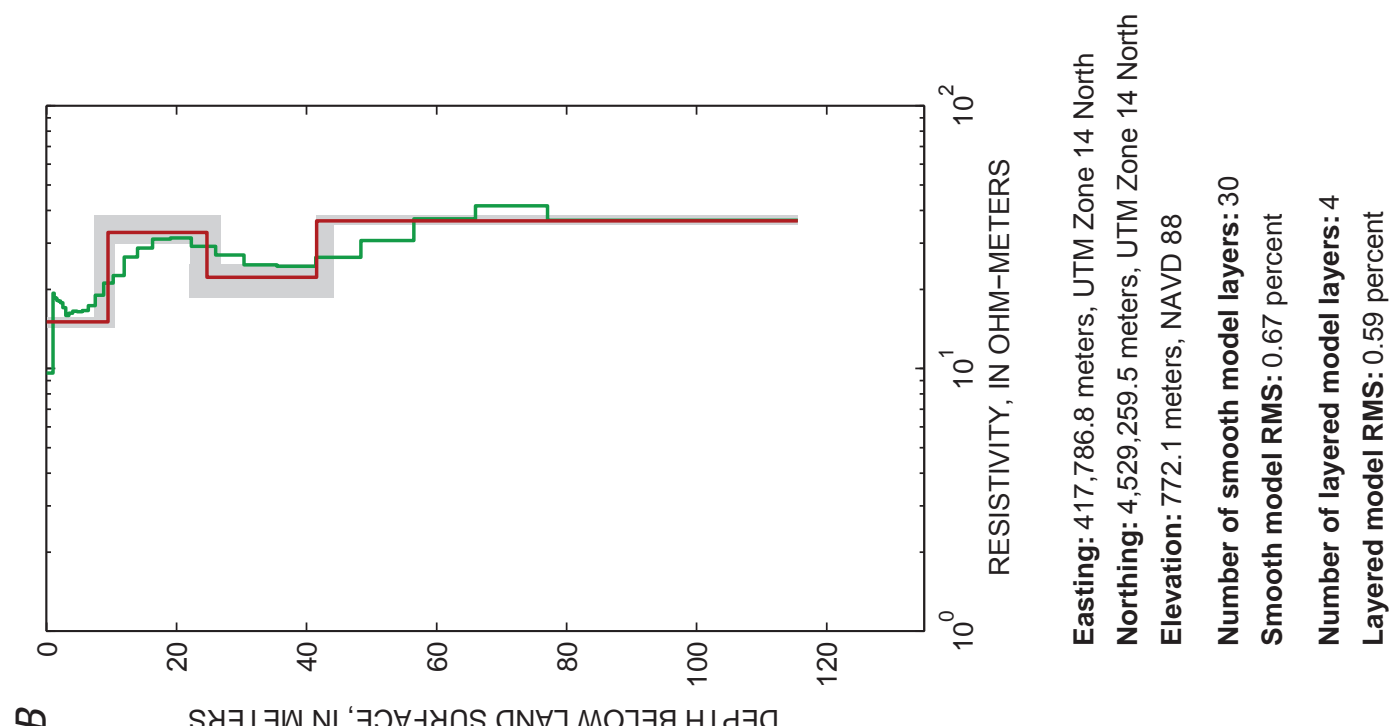

$\infty$

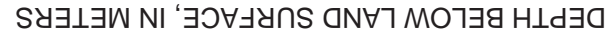

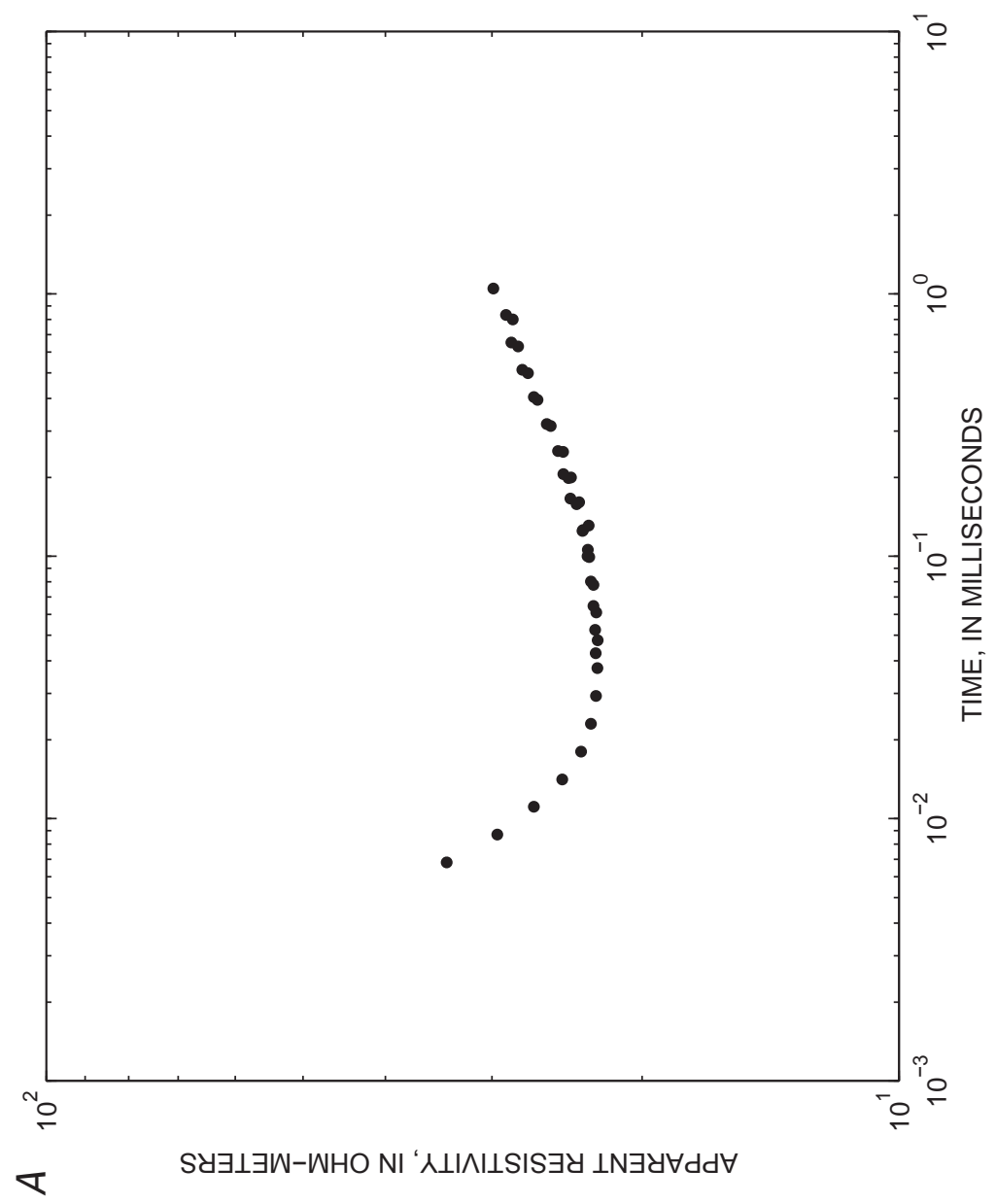



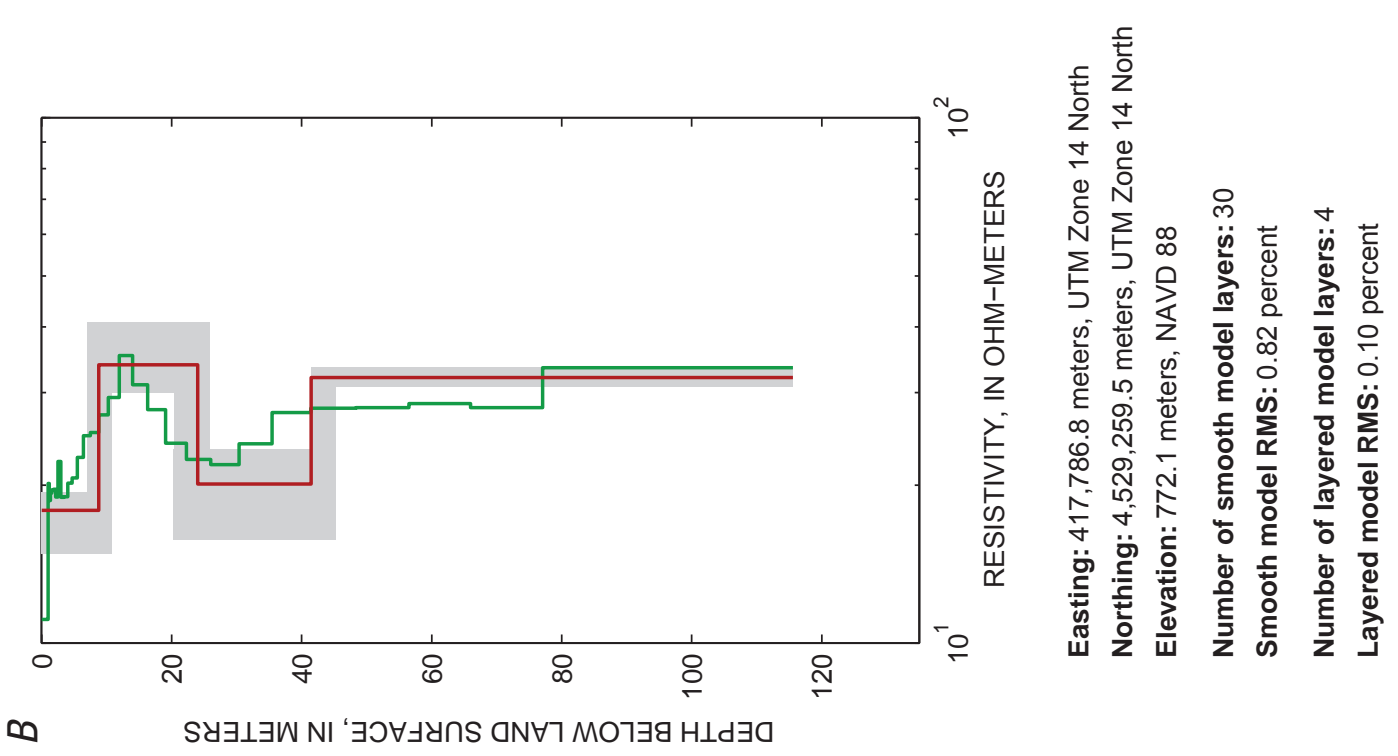

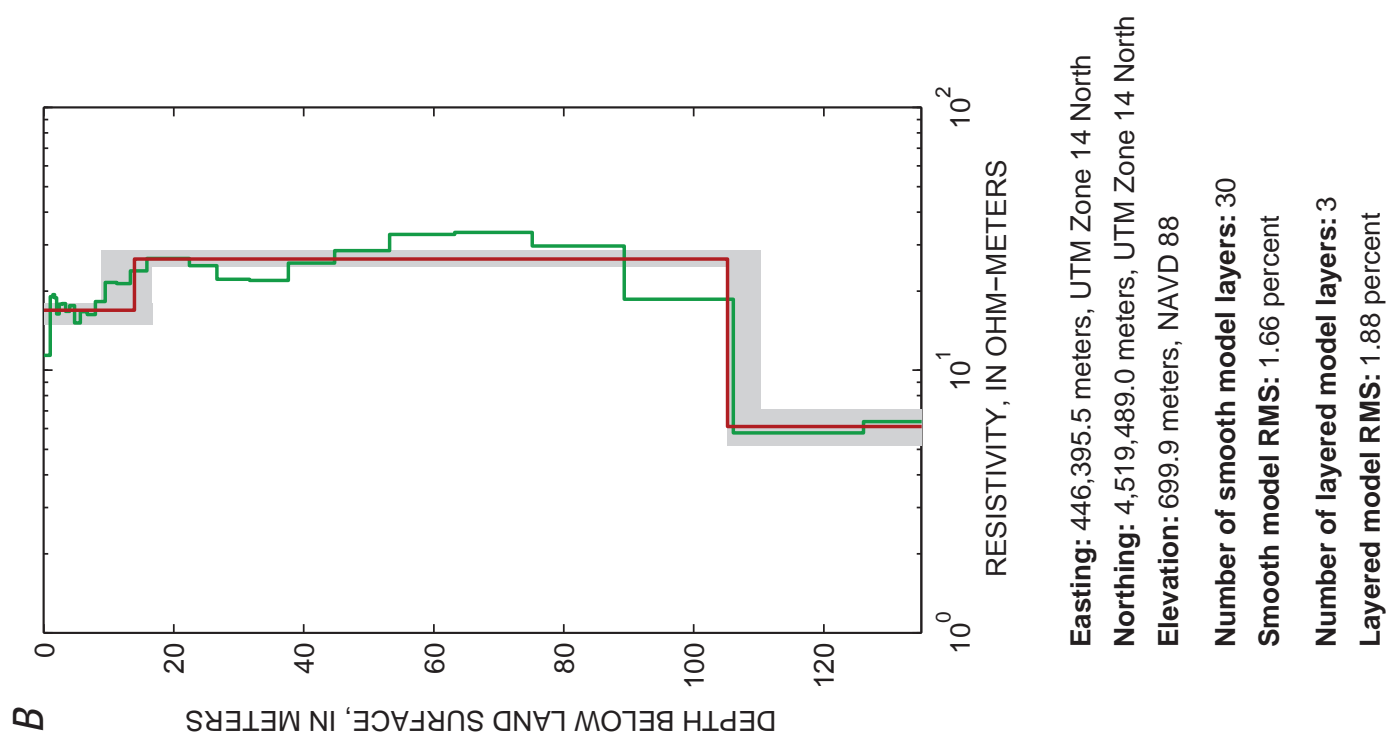

$\infty$

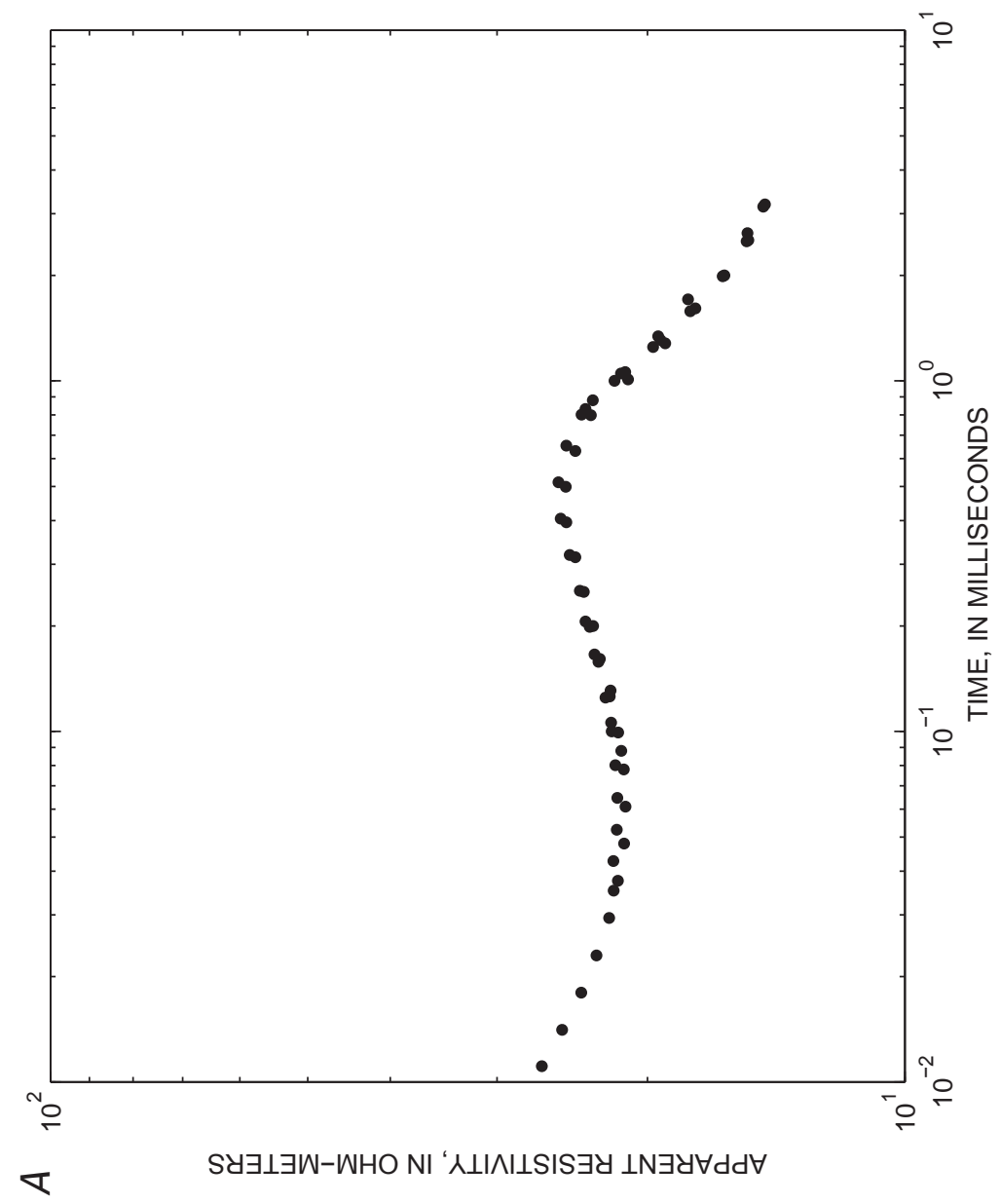



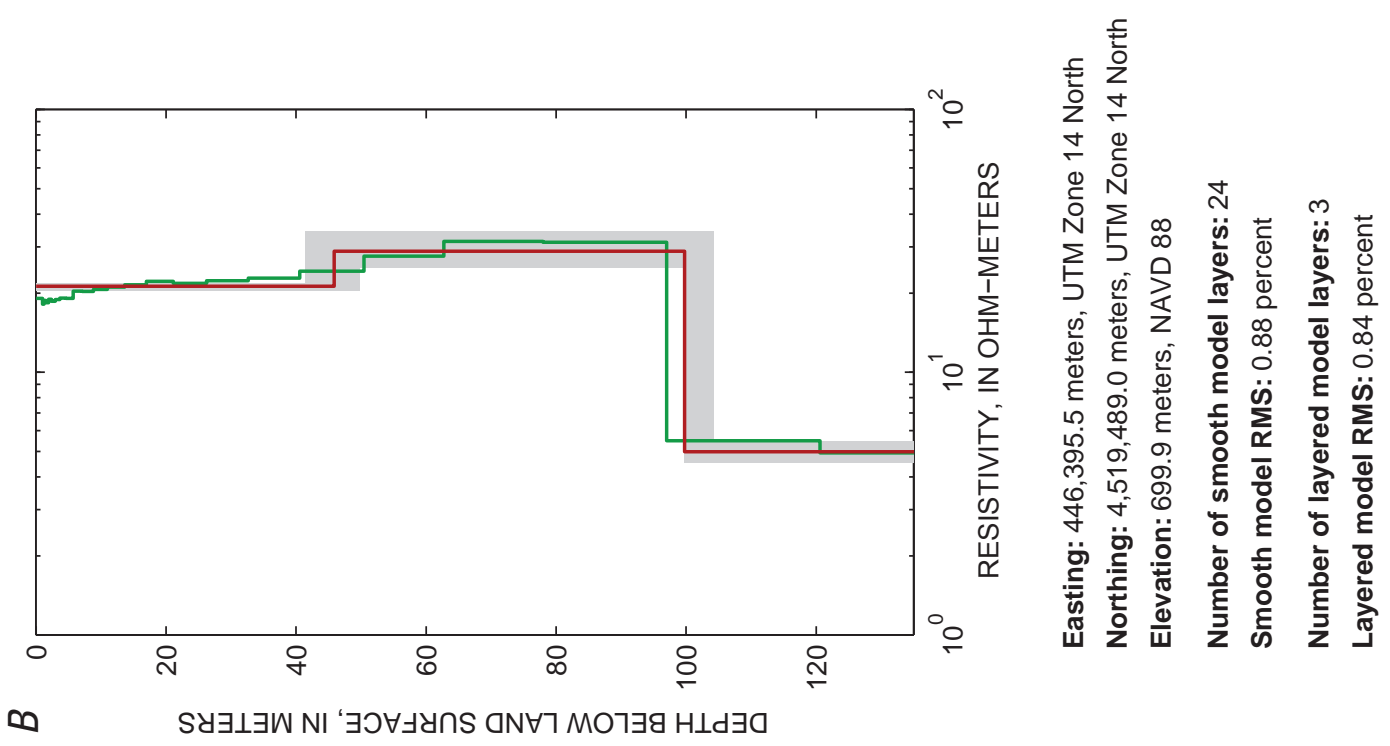

$\underbrace{\frac{0}{0}}_{0}$

$\infty$
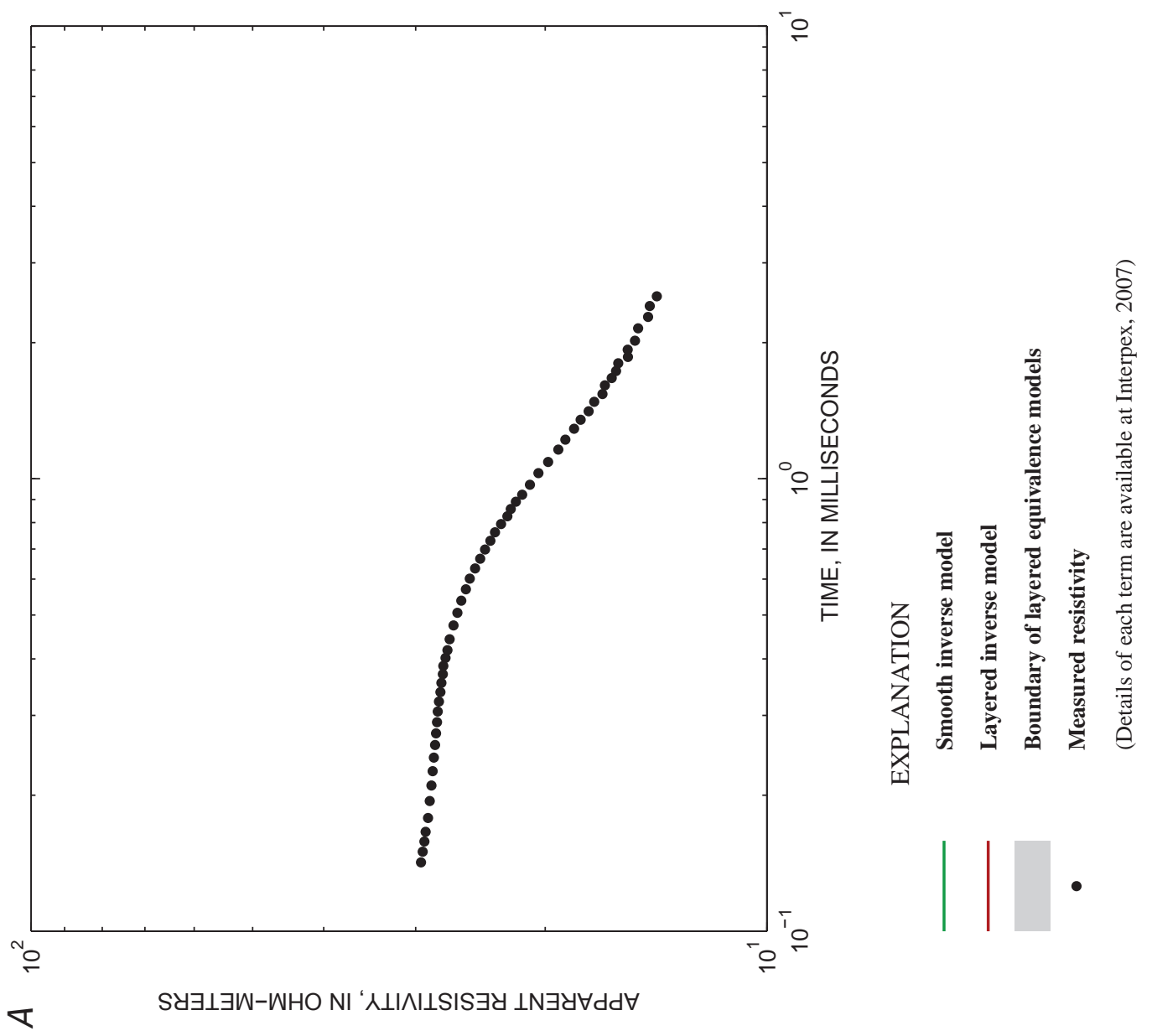

d

응

政

혼

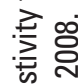

인

늠

흘 흥

뜬

要

잉

듬

空

을

.

ॠ

일

远

$\stackrel{\text { in }}{\triangle}$

高 $\frac{0}{0}$

흠 음

它

过

है.

灾

ष

बृं

采

흥

z

迹

言

동

次

造

近

竞

马

路

-

두

产 

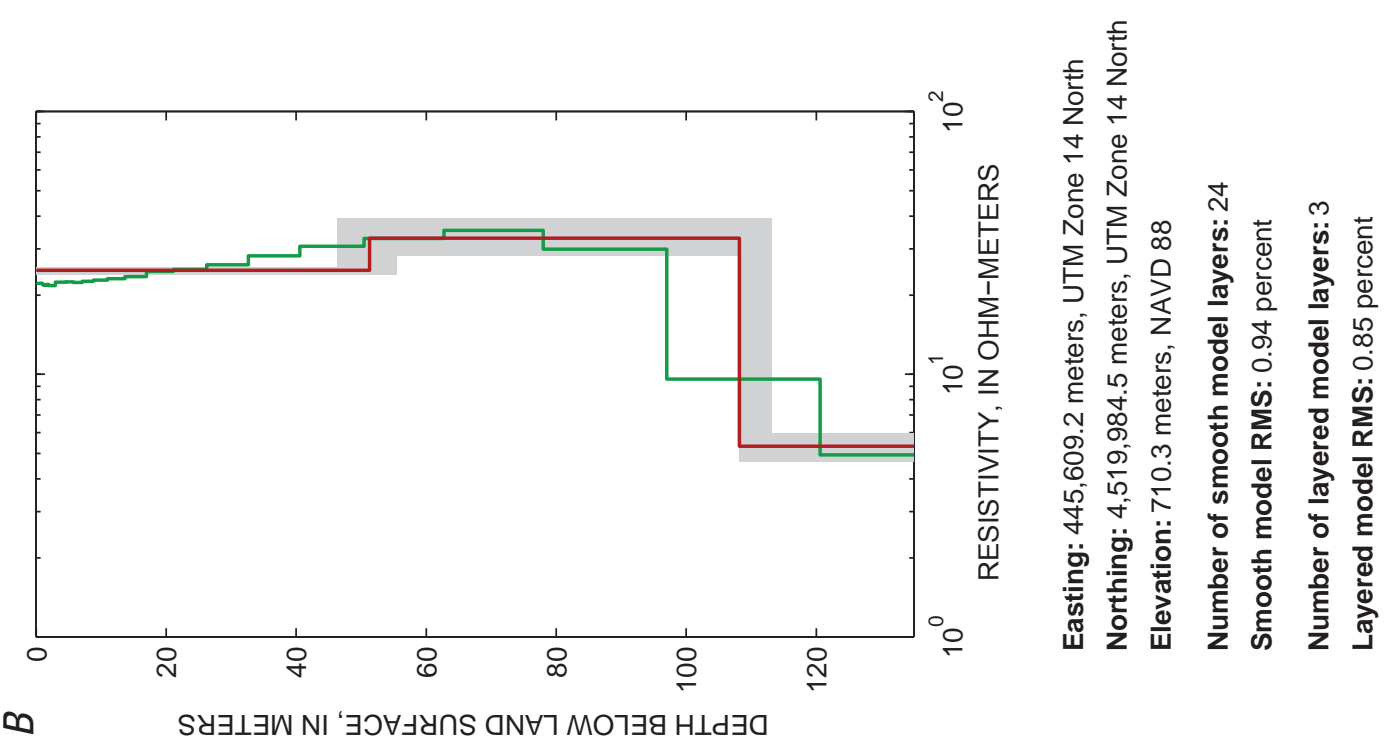

$\infty$
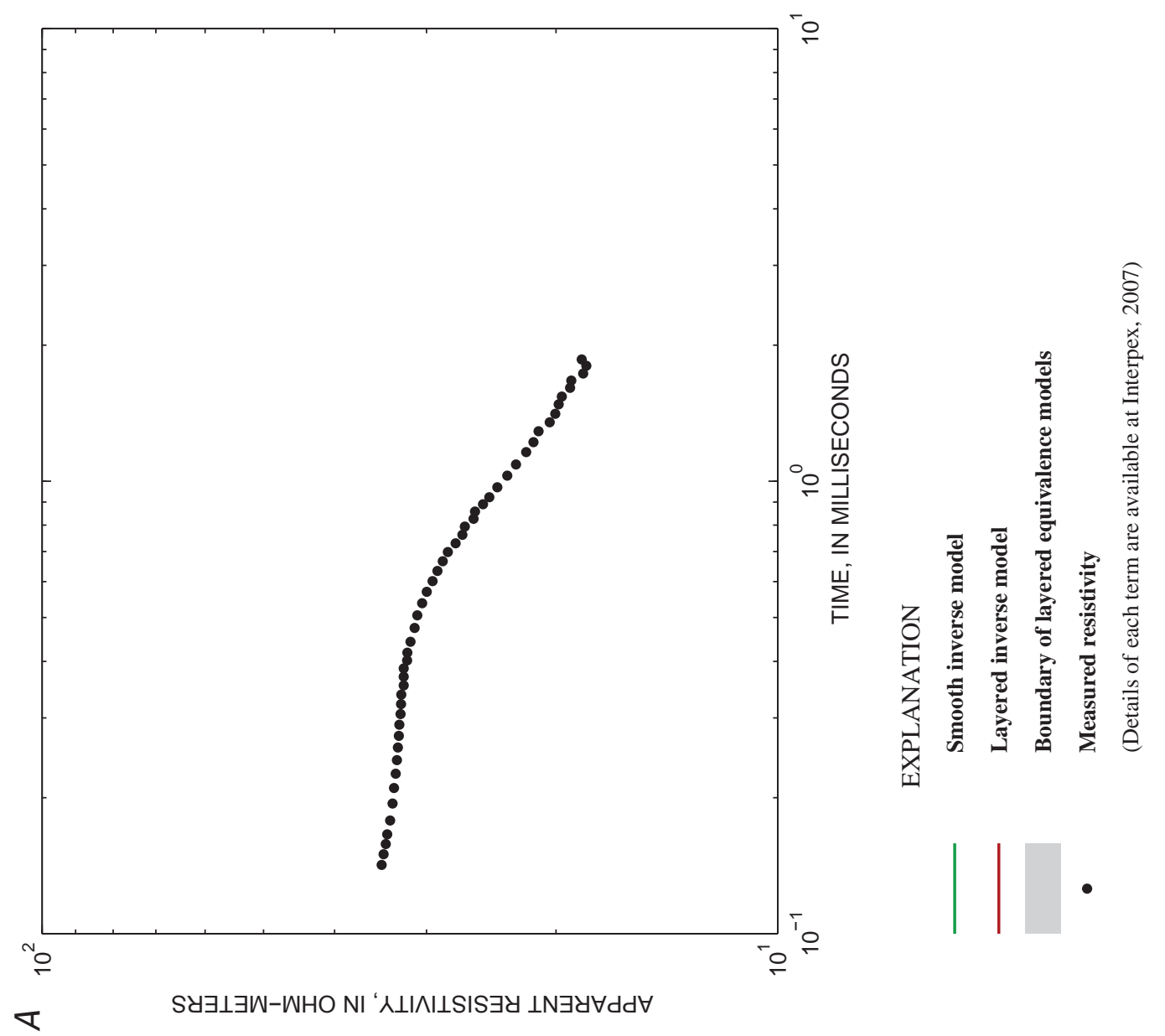

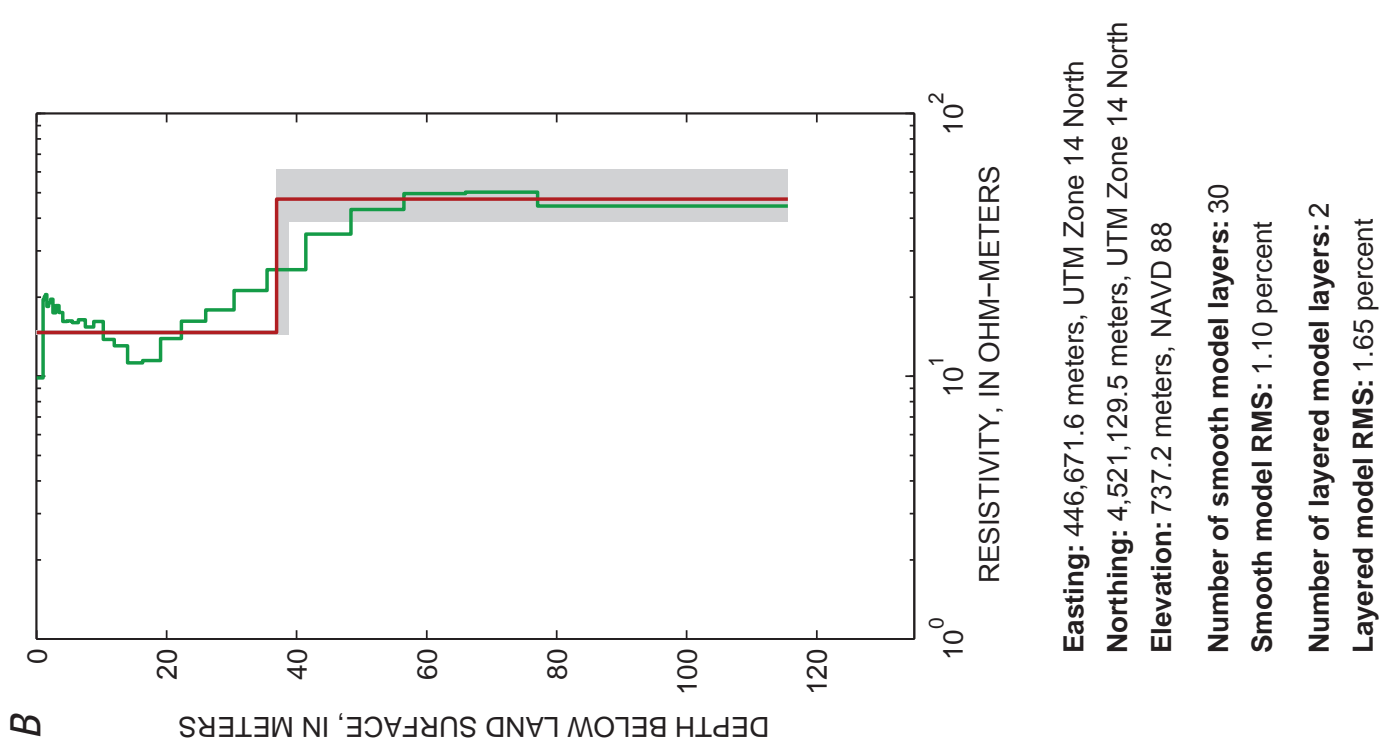

홍

$\infty$

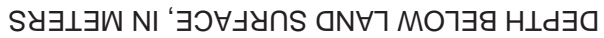
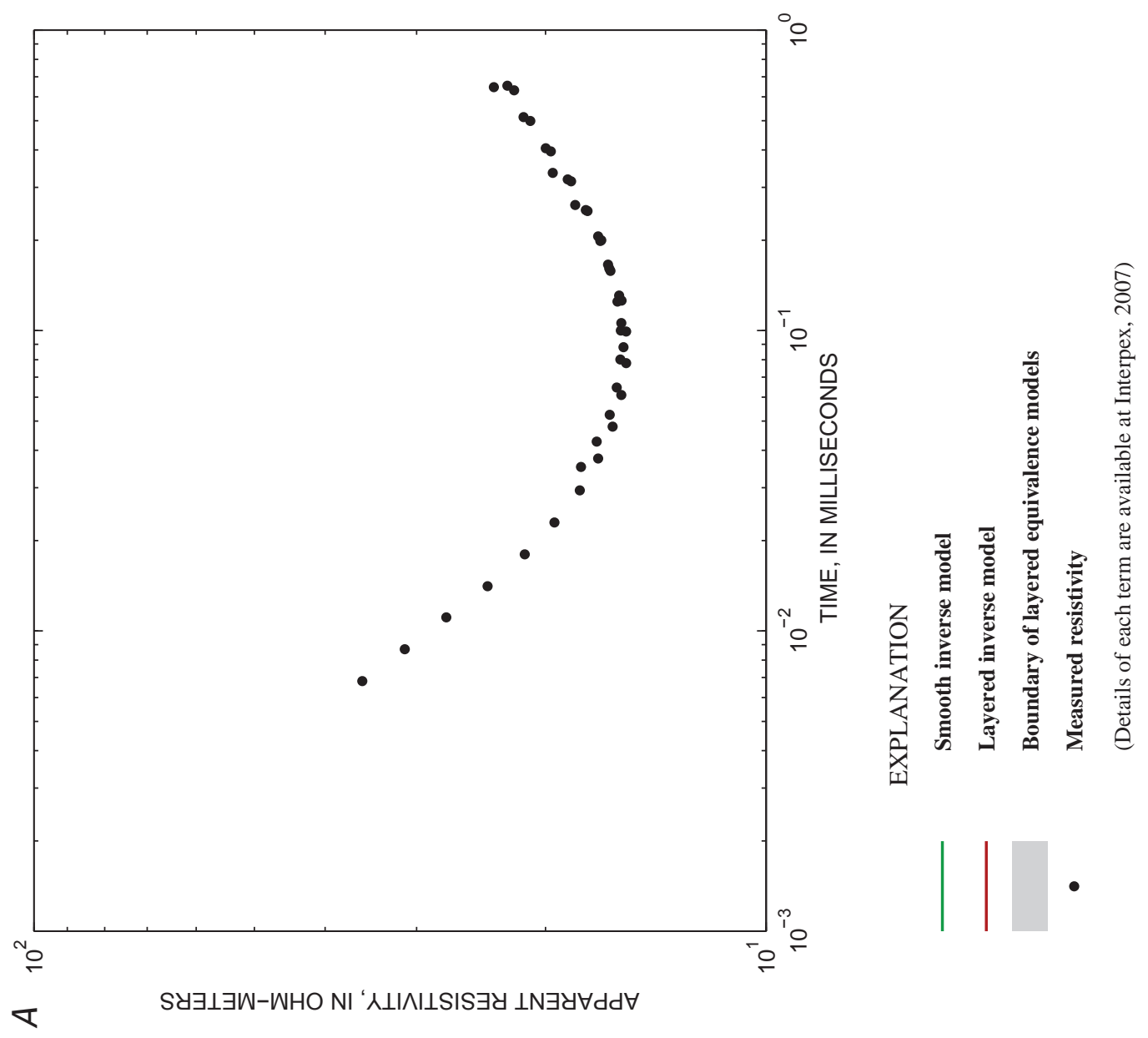

$\frac{\pi}{5}$

힐

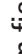

혼

效穴 

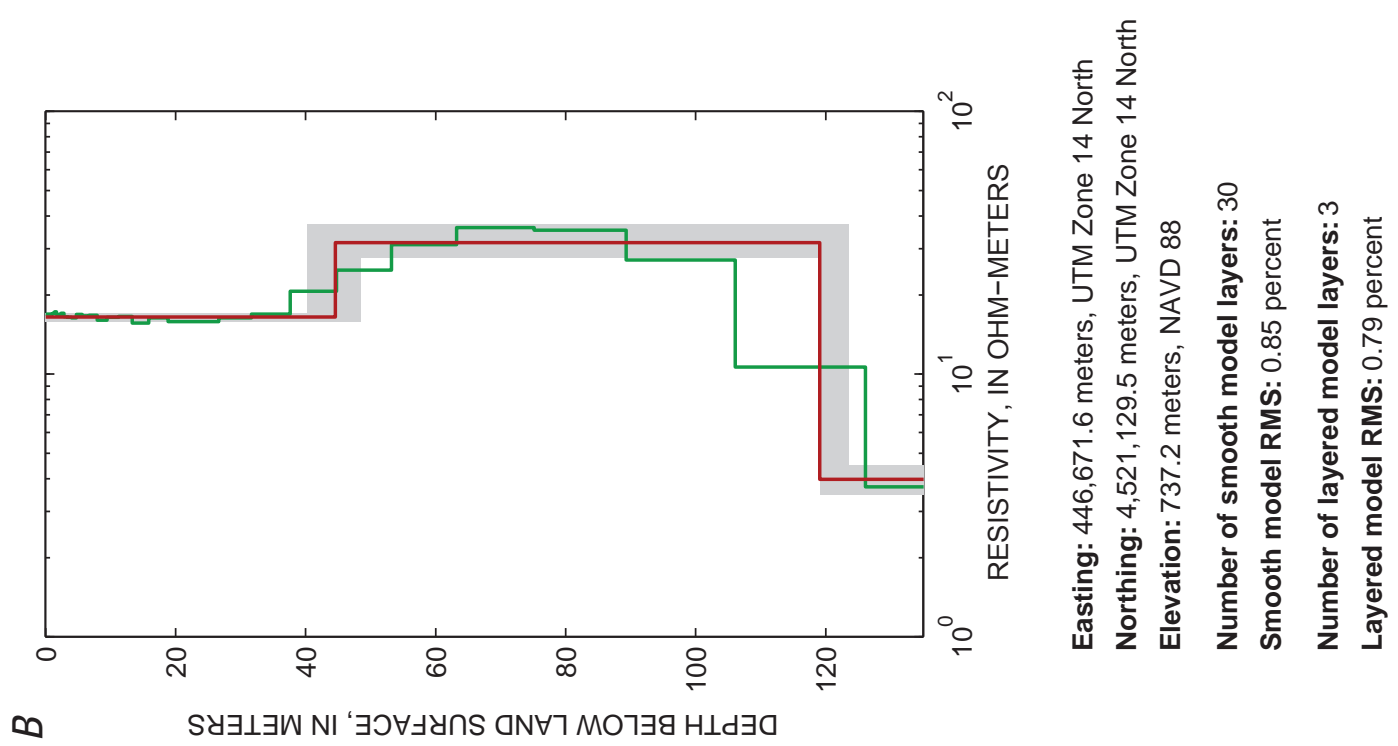

$\infty$

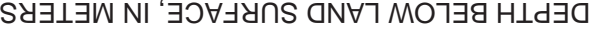

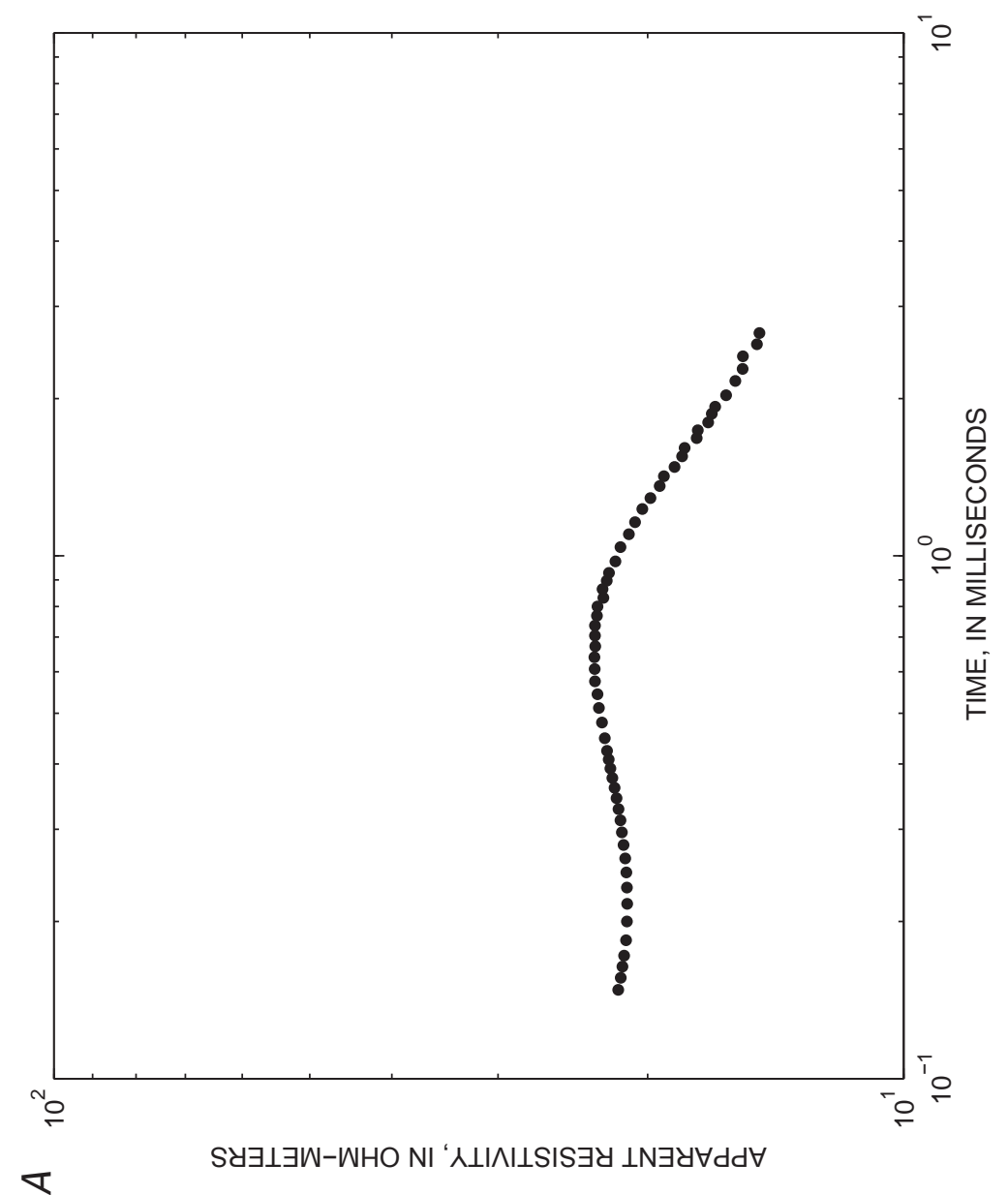



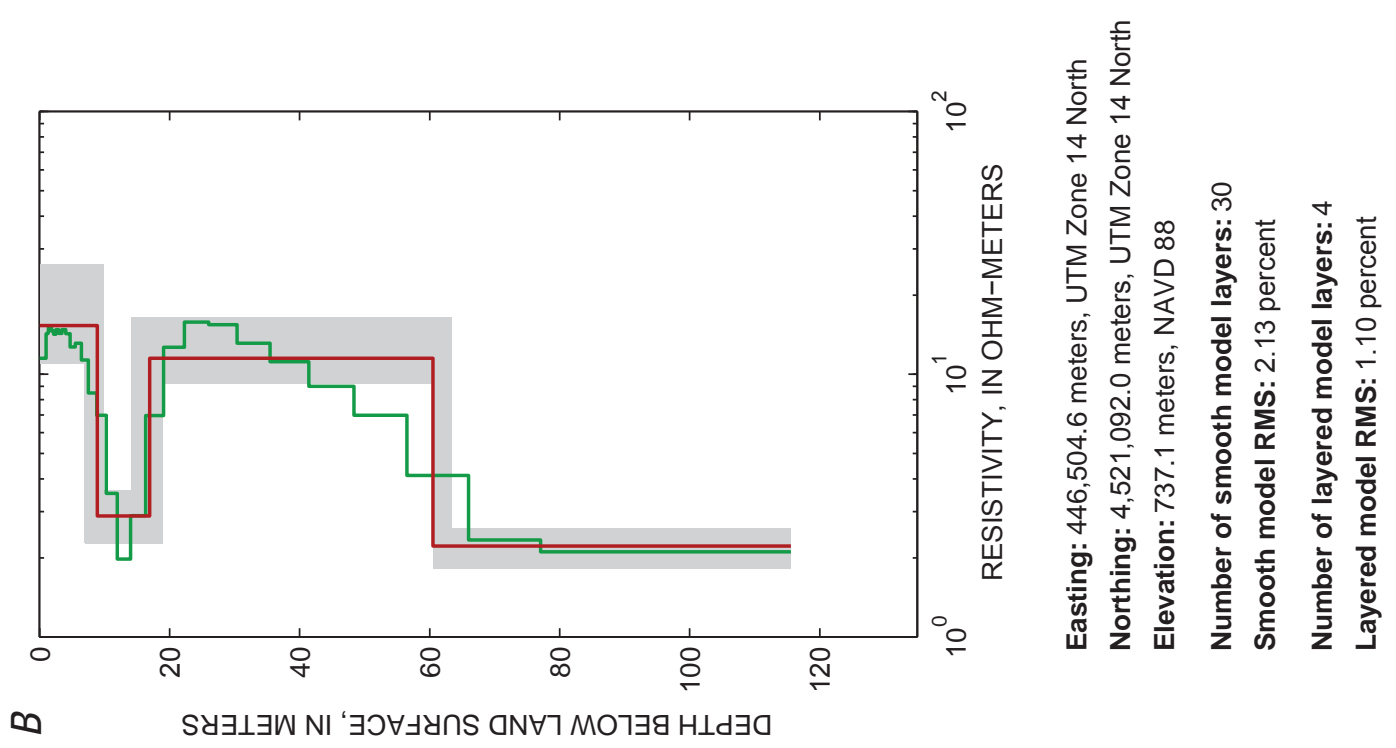

을
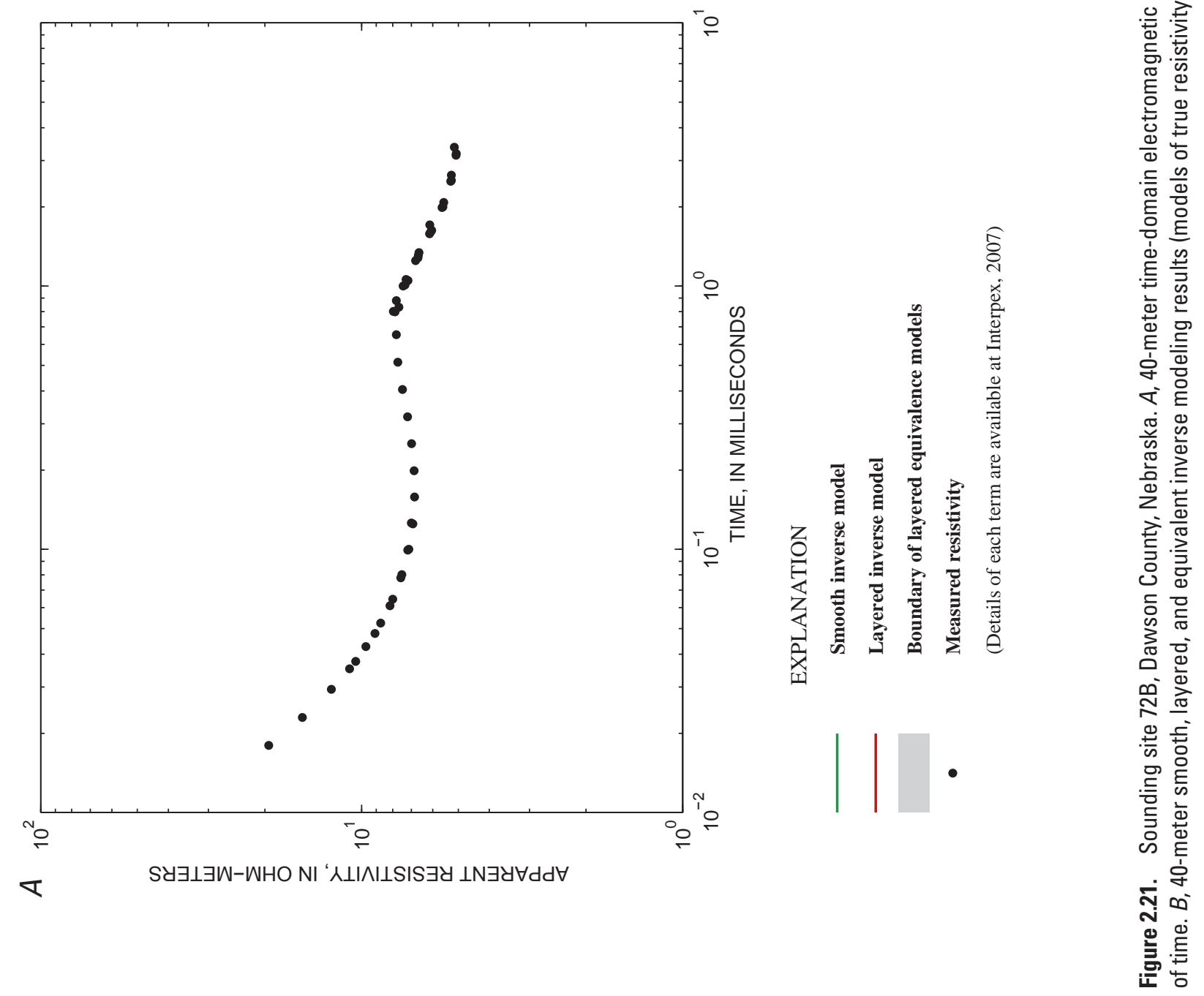

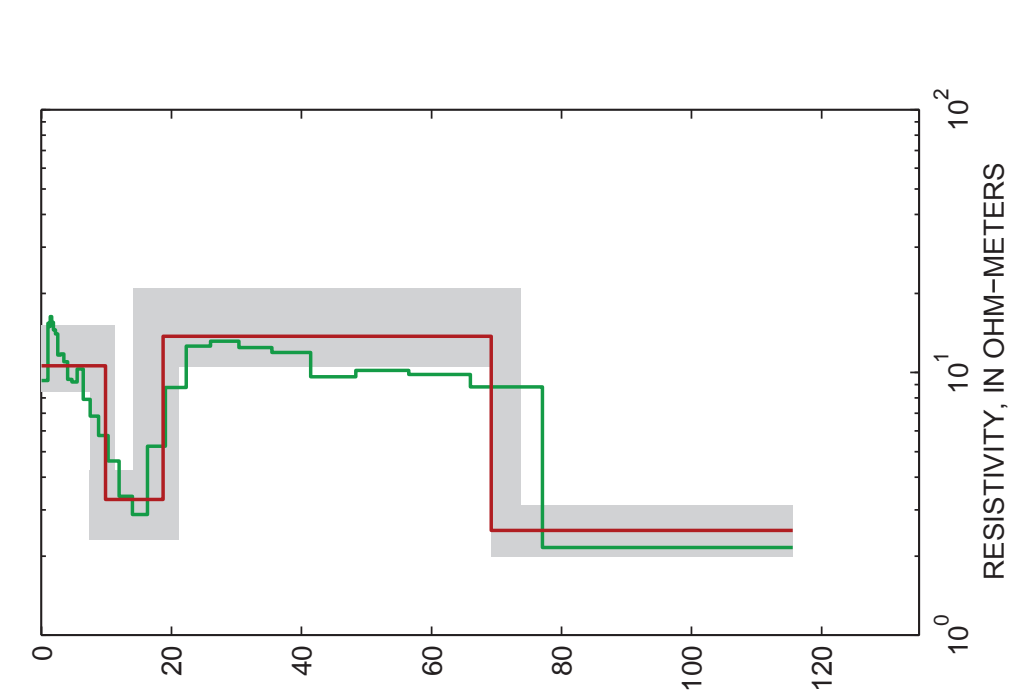

$\infty$

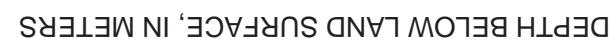
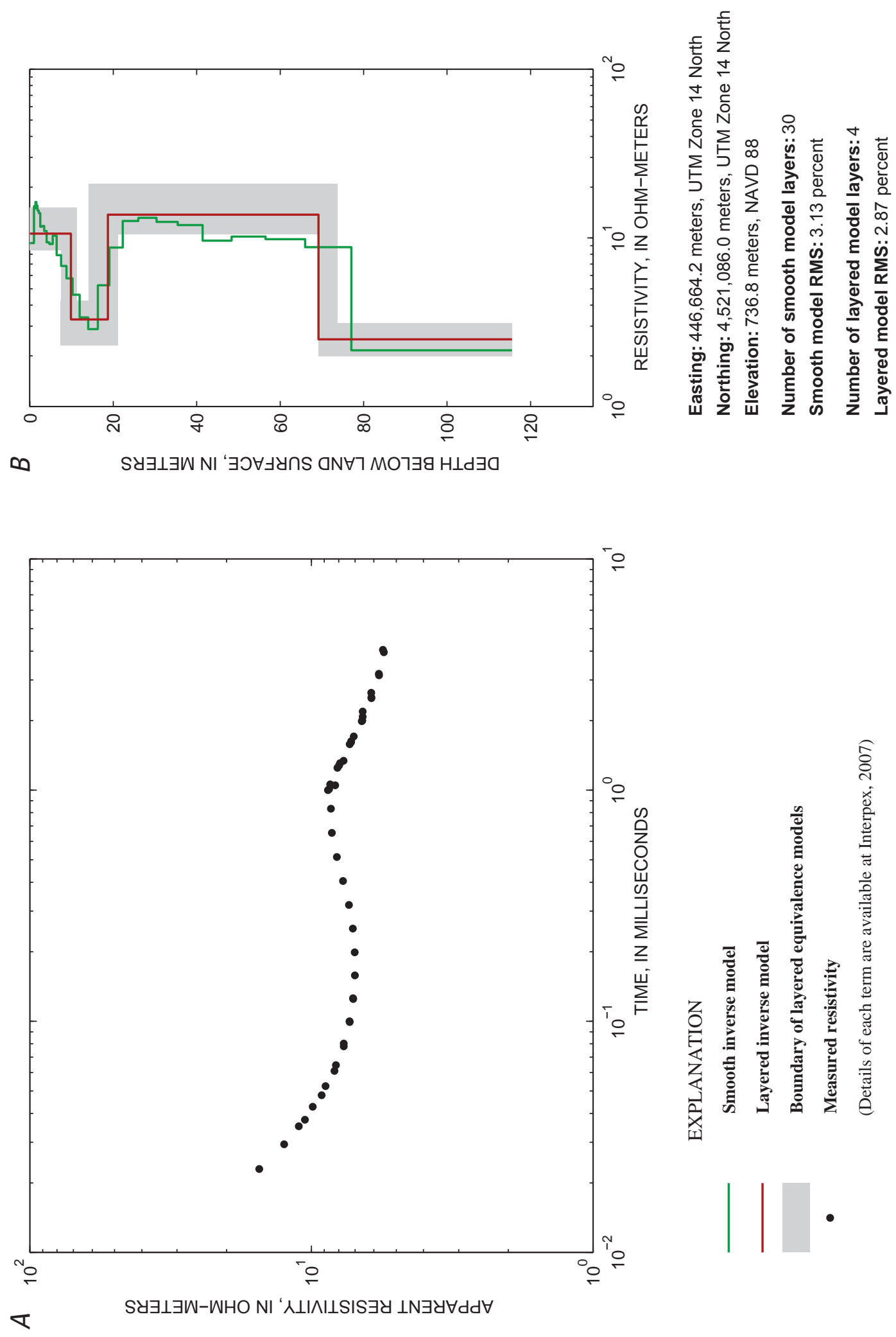

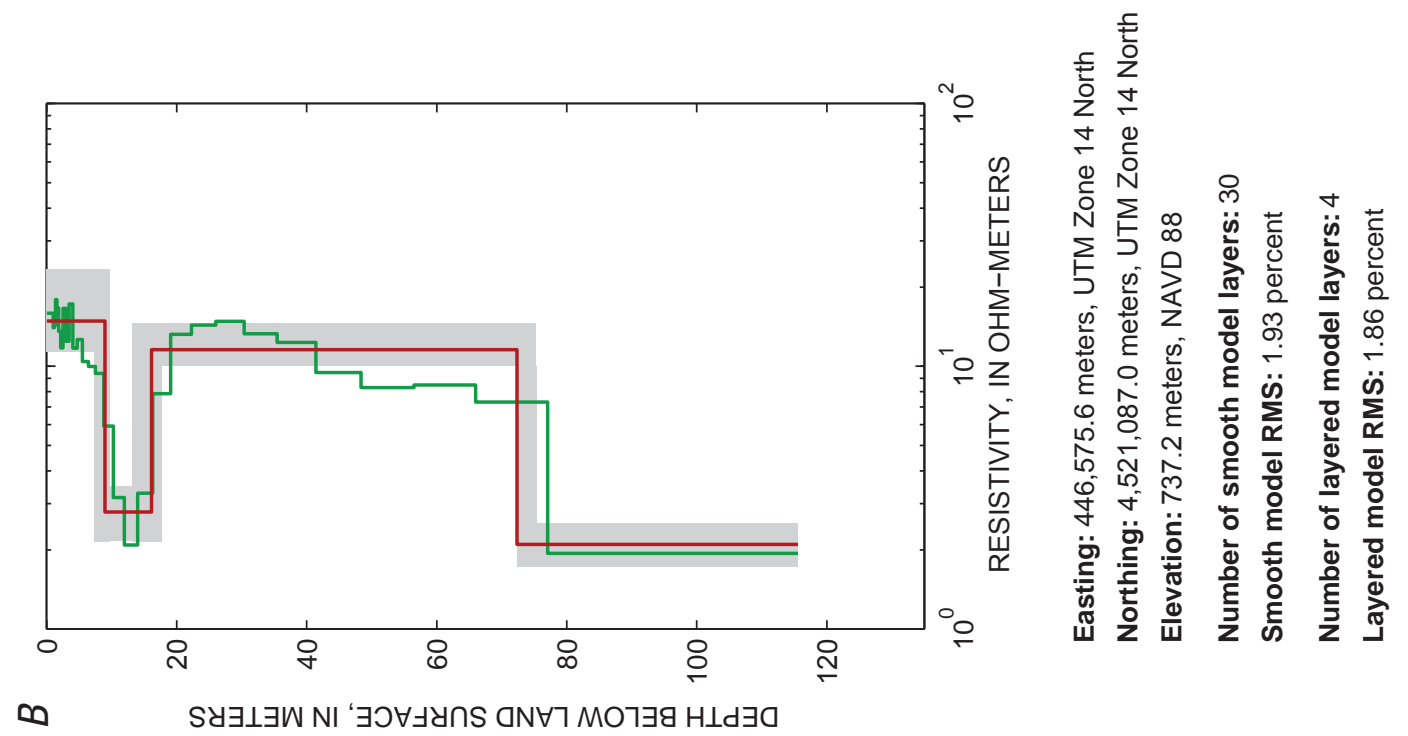

$\underbrace{\frac{0}{0}}_{0}$

$\infty$

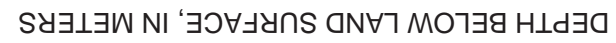
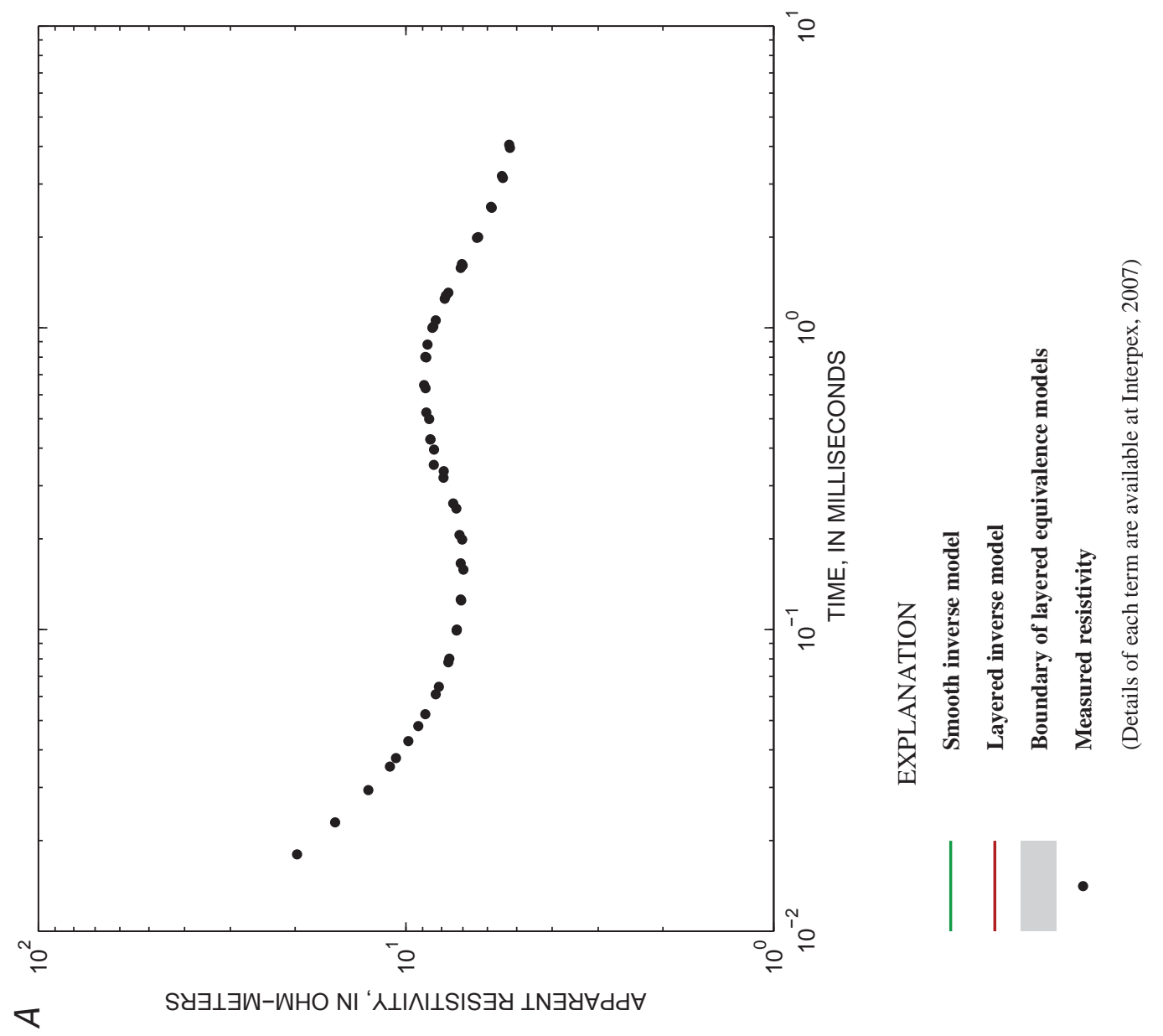

$\frac{\pi}{\pi}$ 

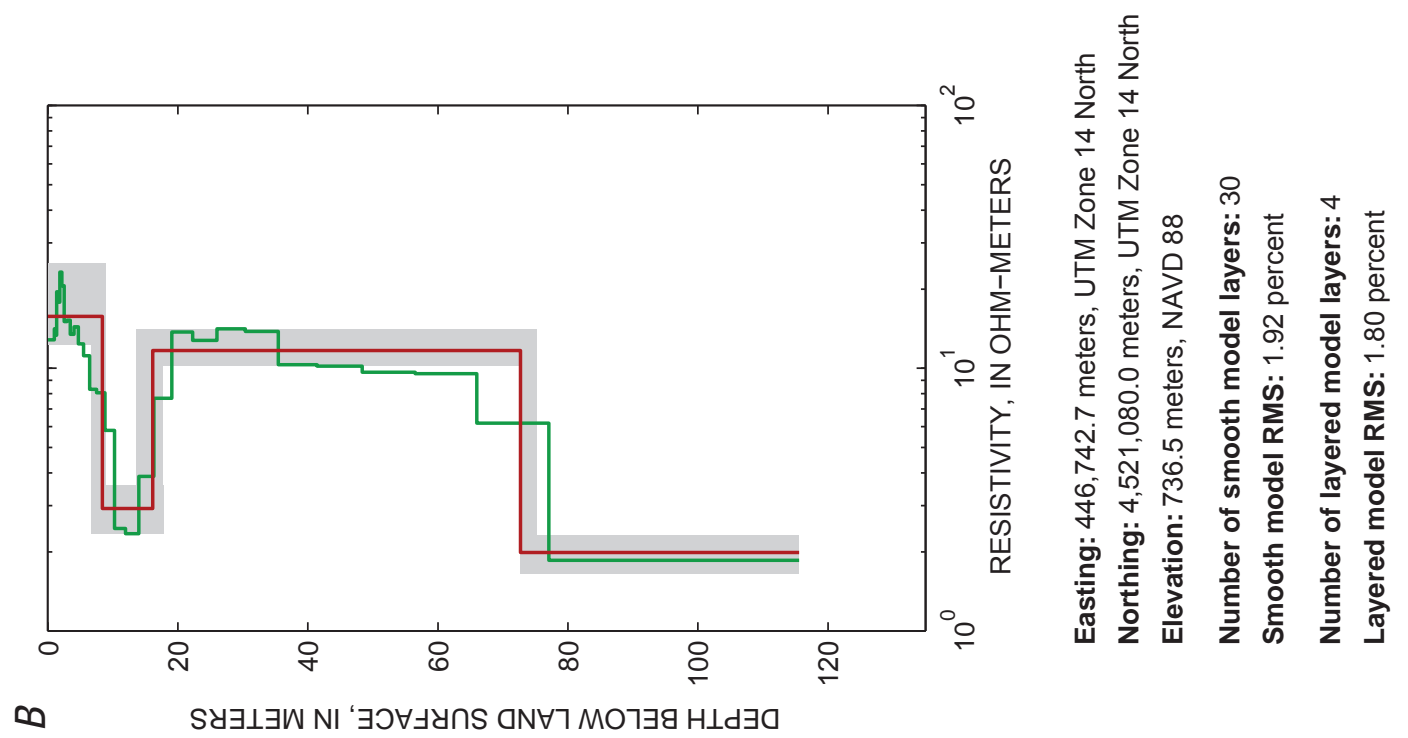

$\infty$
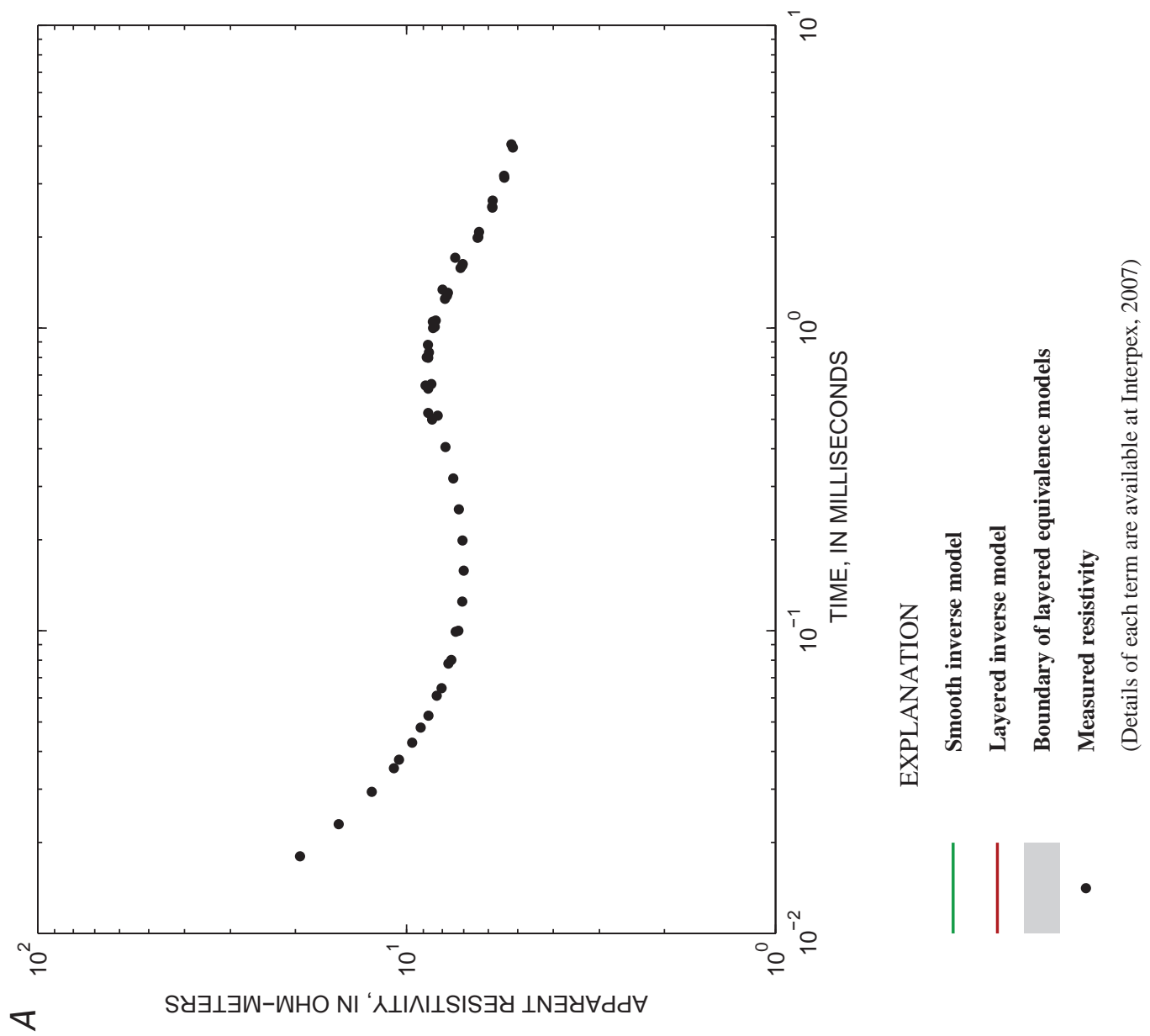

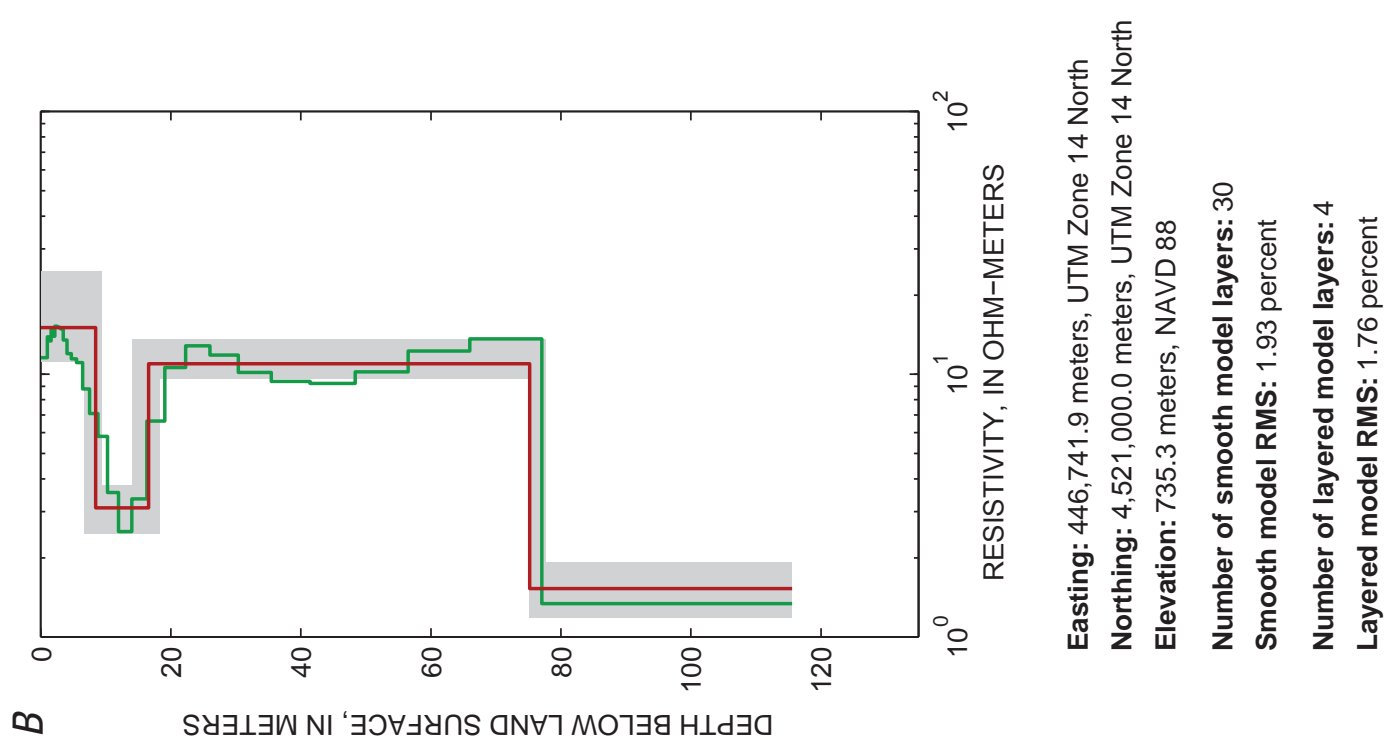

$\infty$
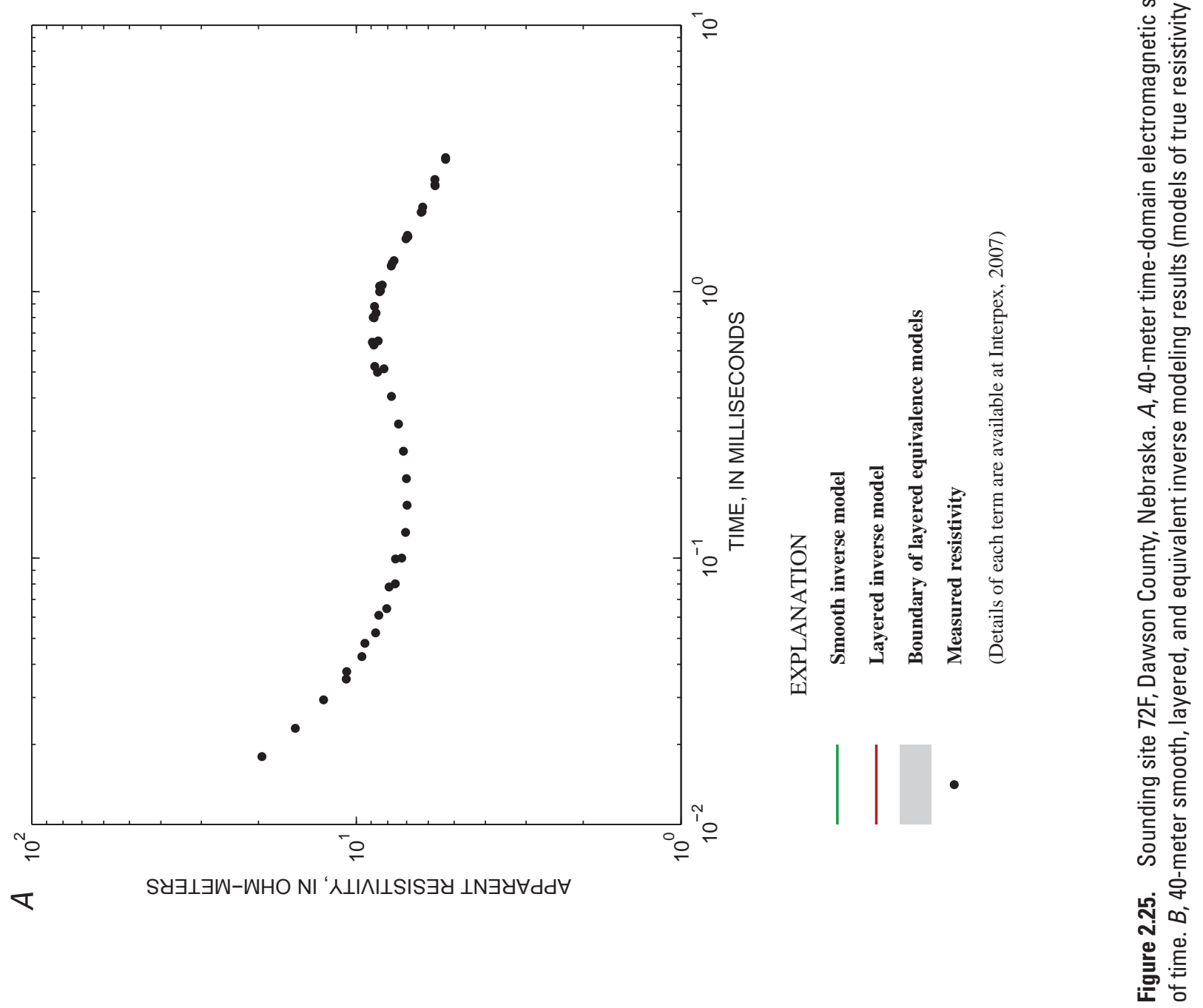


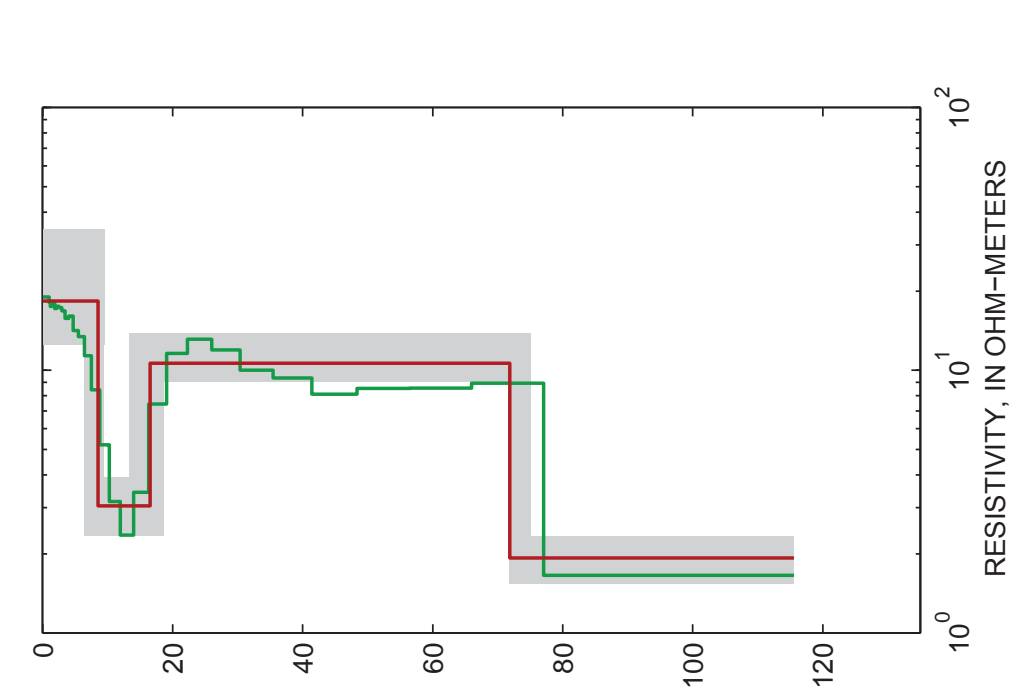

$\infty$
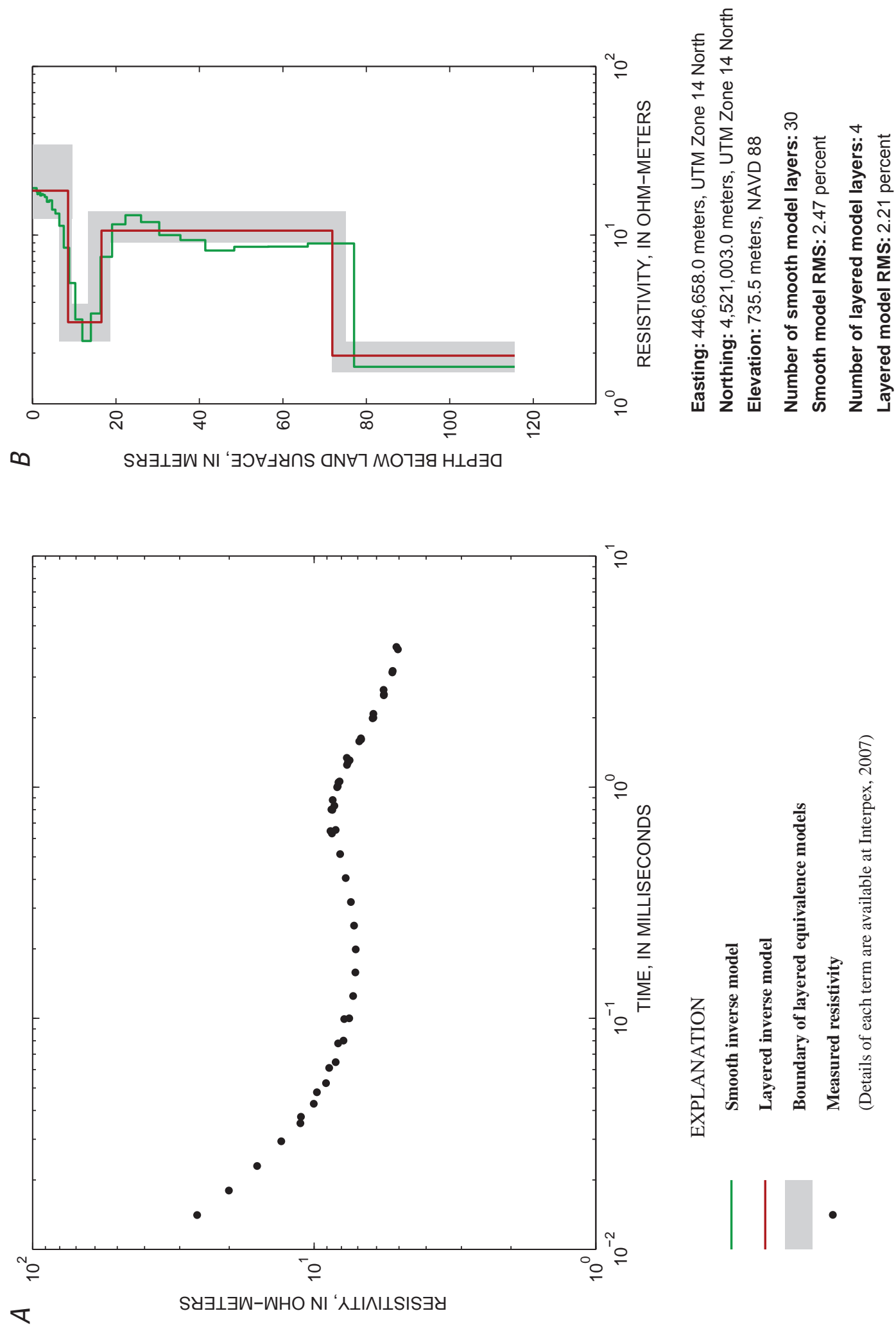
$\leftarrow$ SY $\exists \perp \exists W-W H O N I$ ' $\lambda \perp I N I \perp S I S \exists Y$ 

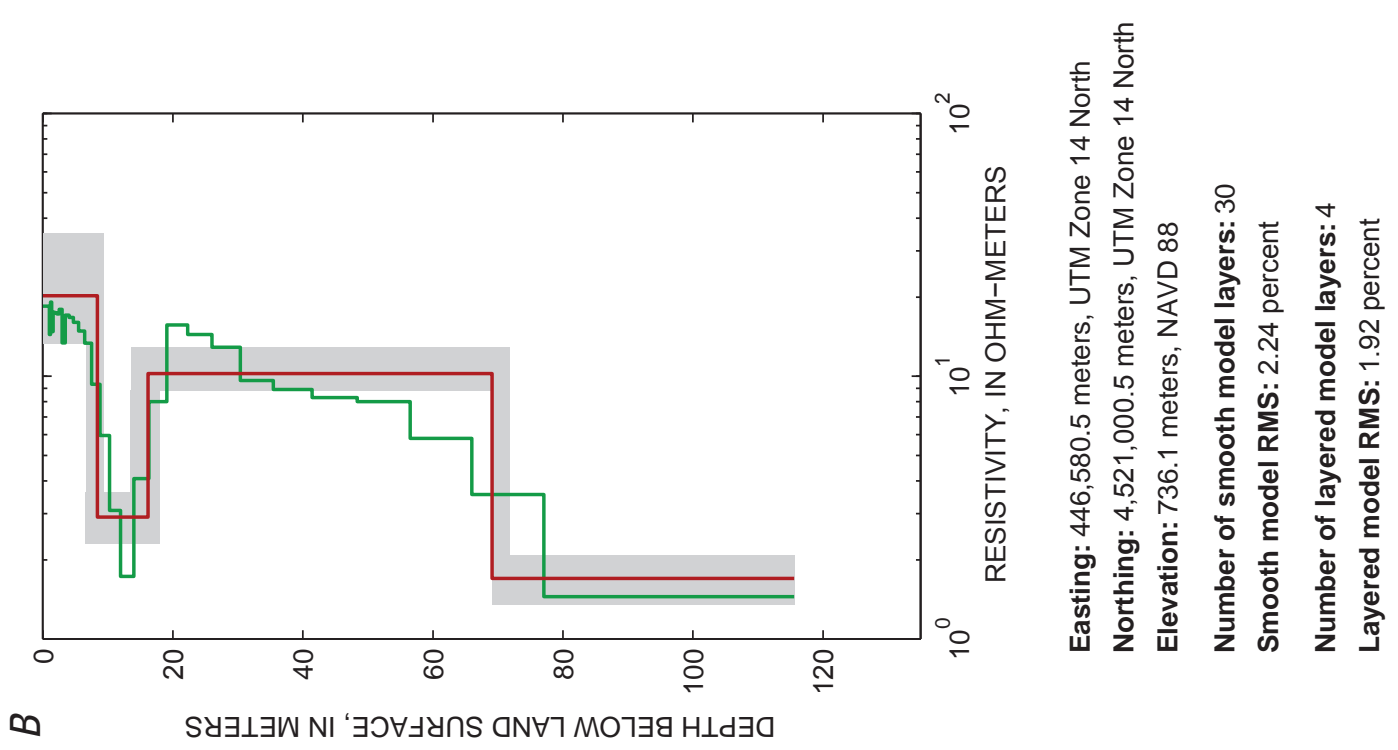

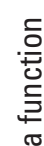
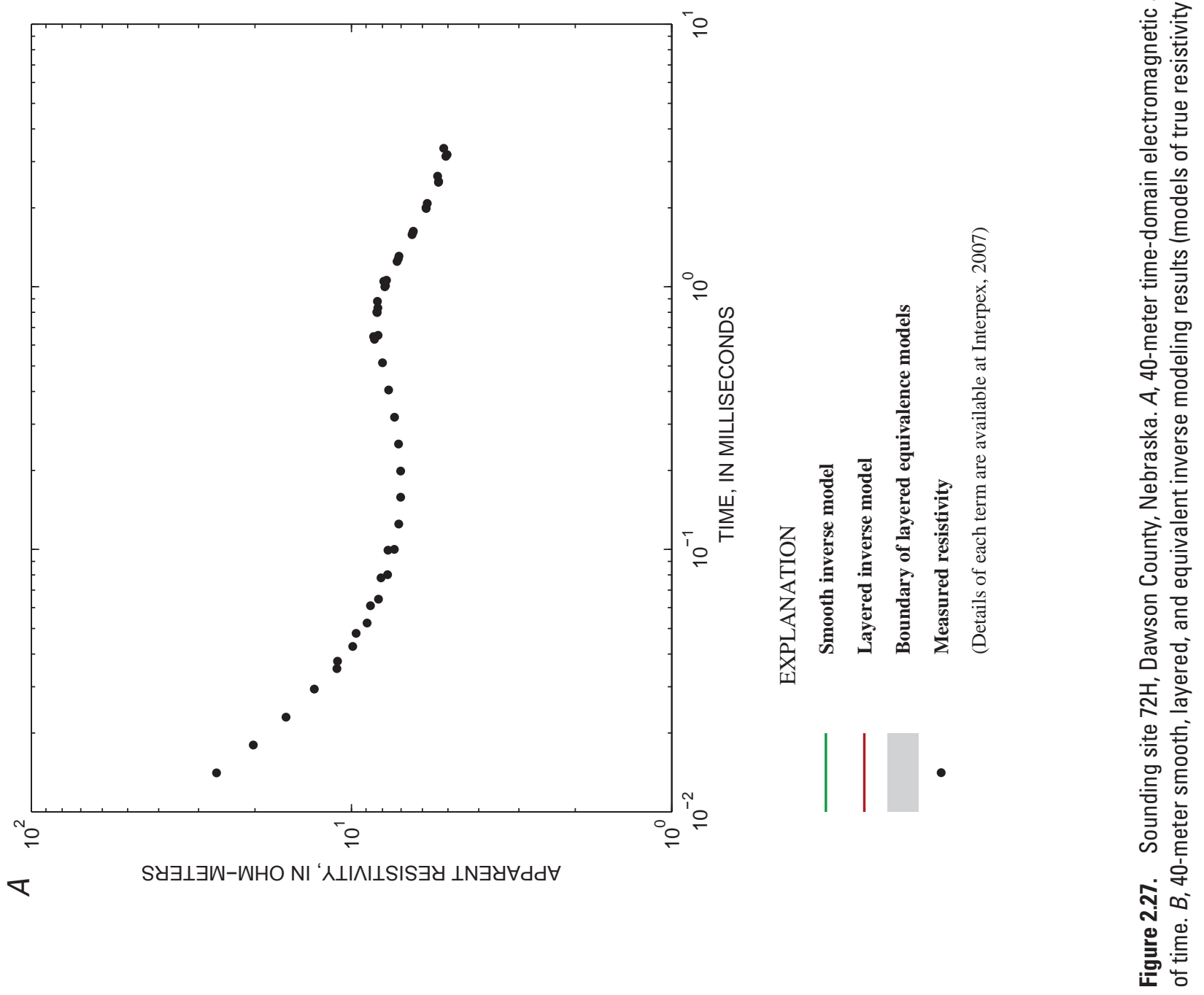

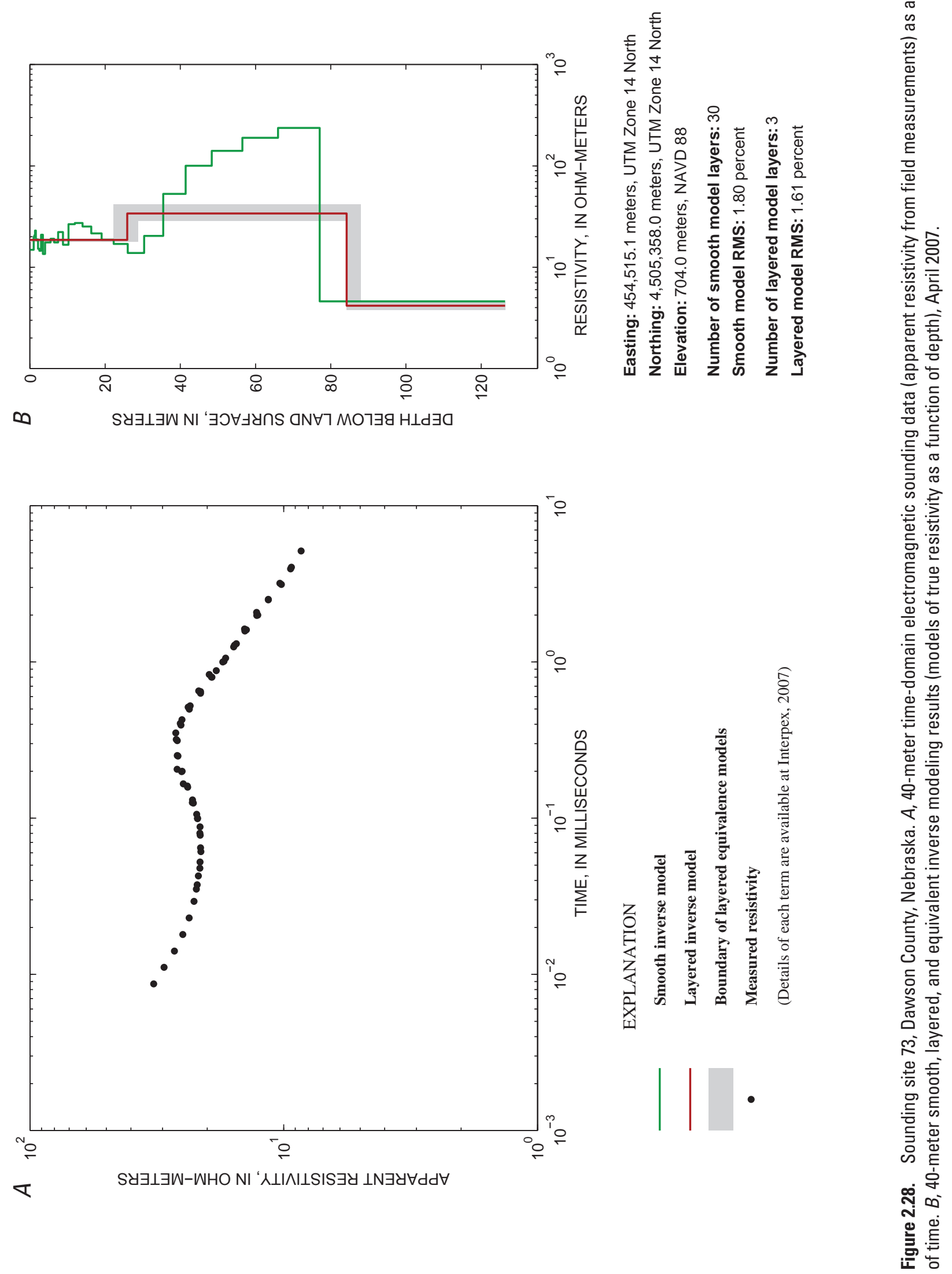

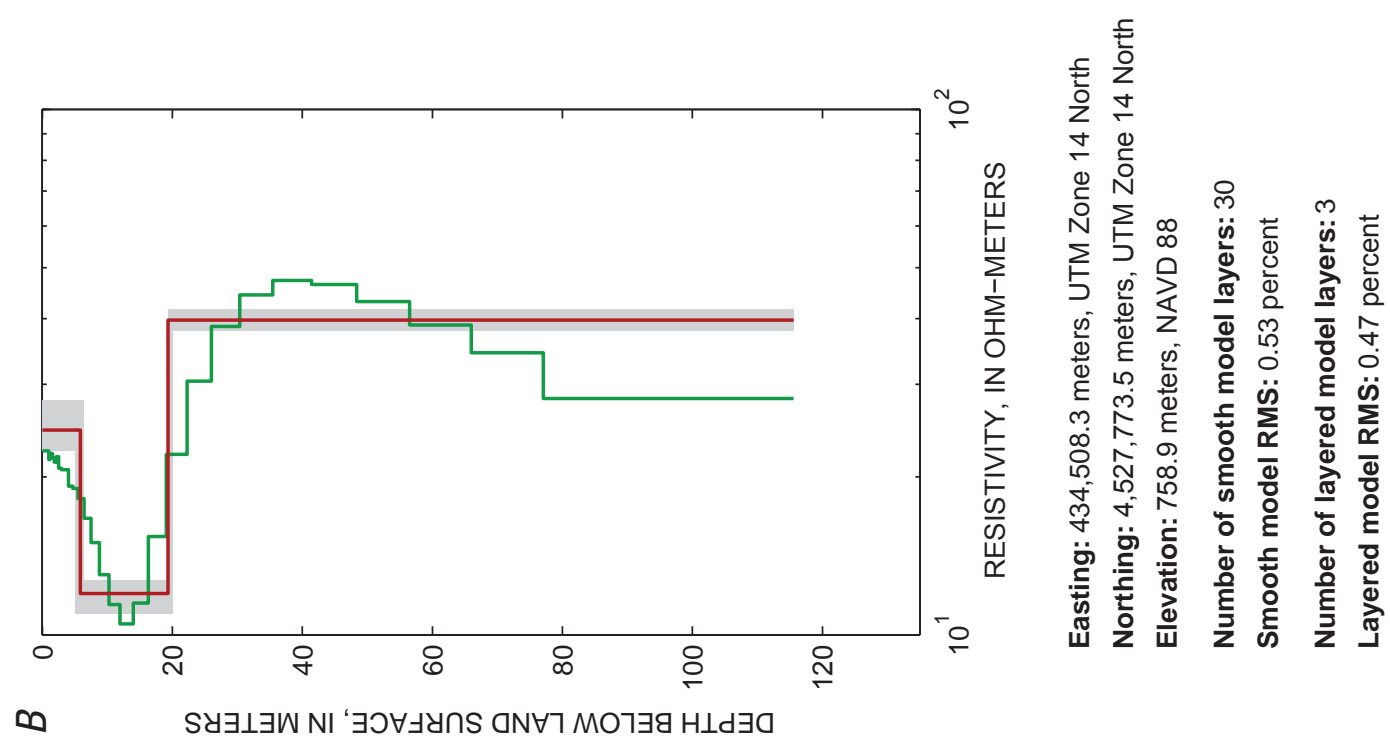

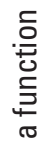

$\infty$
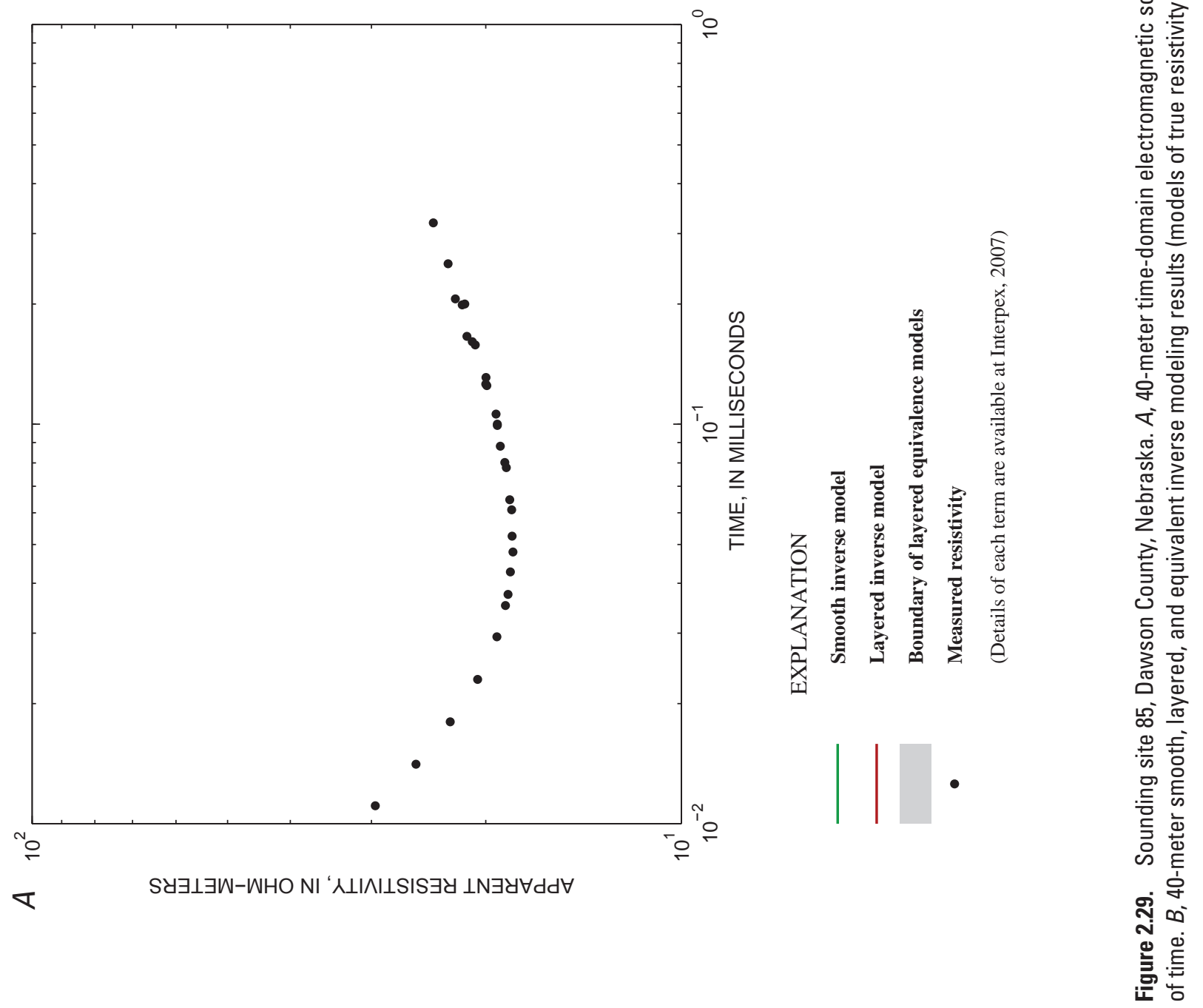

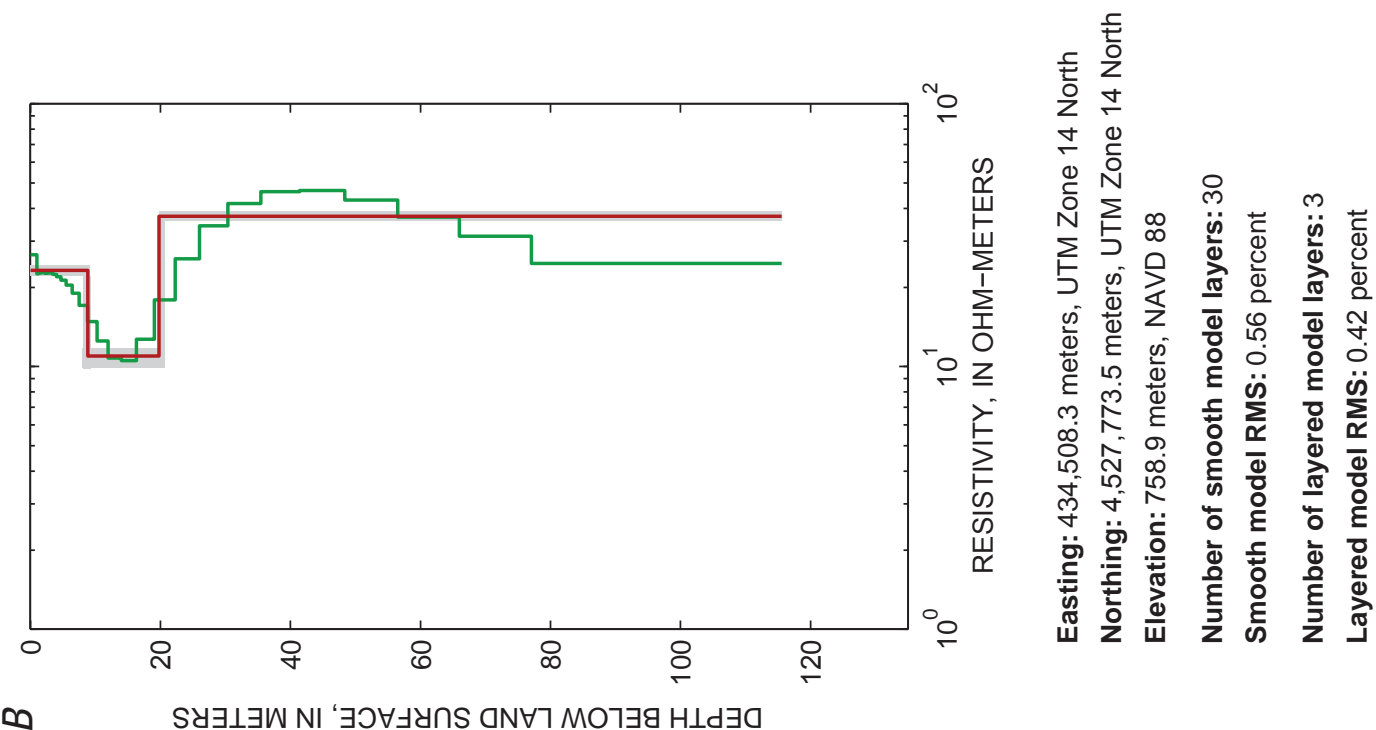

$\infty$

S
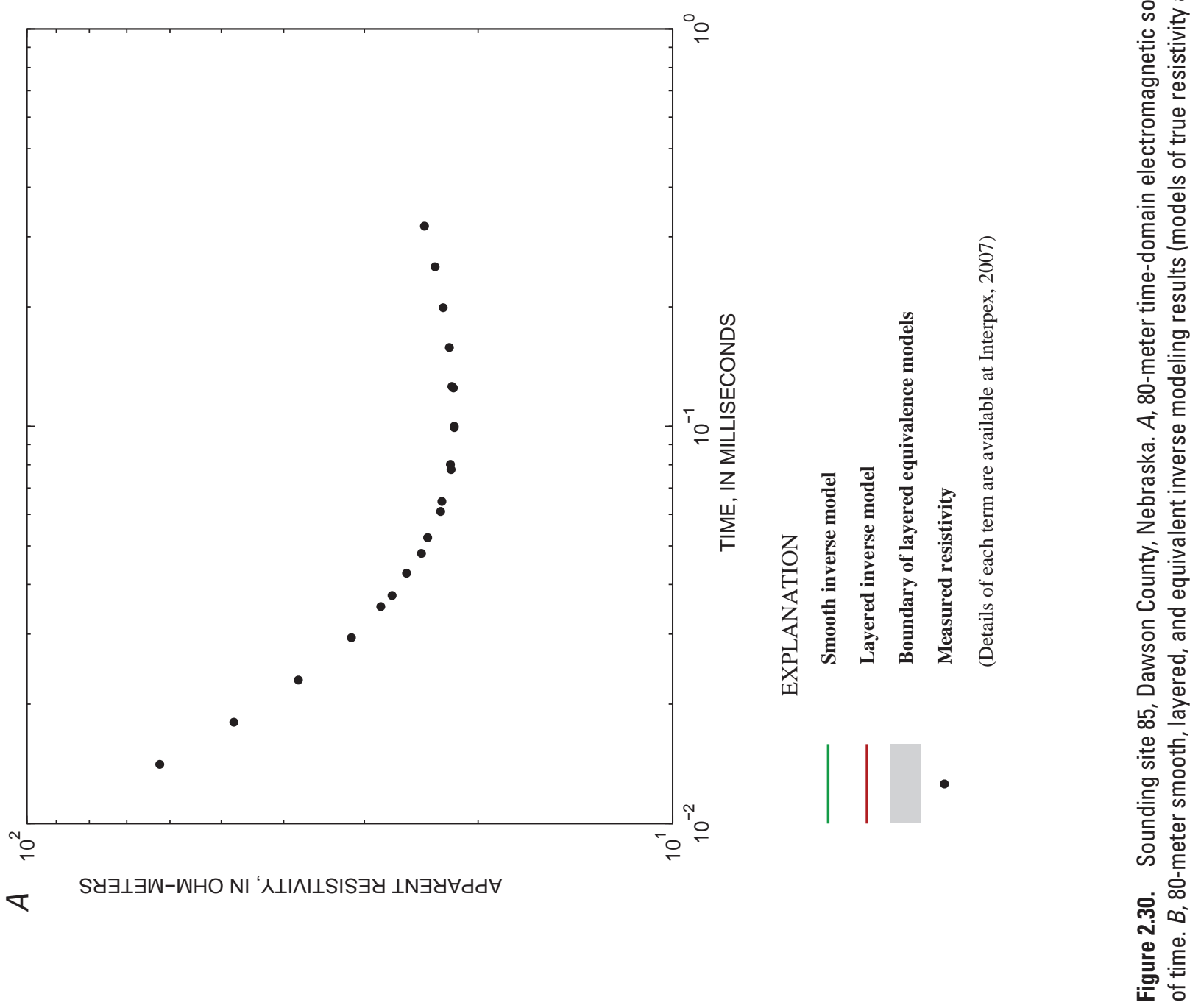


\section{Publishing support provided by Lafayette Publishing Service Center}

For more information concerning this publication, contact: Director, USGS Nebraska Water Science Center 5231 South 19 Street Lincoln, NE 68512

(402) 328-4100

Or visit the Nebraska Water Science Center Web site at: http://ne.water.usgs.gov 
造

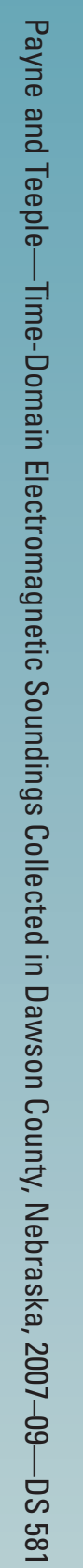

9 Printed on recycled paper 